Rhode Island College

Digital Commons @ RIC

Master's Theses, Dissertations, Graduate

Master's Theses, Dissertations, Graduate Research and Major Papers Overview

Research and Major Papers

4-13-2013

\title{
A Study of Cape Verdeanness In Postcolonial Cape Verdean Poetry
}

David Joseph Alpert

Rhode Island College

Follow this and additional works at: https://digitalcommons.ric.edu/etd

Part of the Linguistic Anthropology Commons, Other English Language and Literature Commons, Other Languages, Societies, and Cultures Commons, and the Race, Ethnicity and Post-Colonial Studies Commons

\section{Recommended Citation}

Alpert, David Joseph, "A Study of Cape Verdeanness In Postcolonial Cape Verdean Poetry" (2013).

Master's Theses, Dissertations, Graduate Research and Major Papers Overview. 64.

https://digitalcommons.ric.edu/etd/64

This Thesis is brought to you for free and open access by the Master's Theses, Dissertations, Graduate Research and Major Papers at Digital Commons @ RIC. It has been accepted for inclusion in Master's Theses, Dissertations, Graduate Research and Major Papers Overview by an authorized administrator of Digital Commons @ RIC. For more information, please contact digitalcommons@ric.edu. 

Beyond Sodadi and Morabeza:

A Study of Cape Verdeanness

In Postcolonial

Cape Verdean

Poetry

By

David Joseph Alpert

A Thesis Submitted in Partial Fulfillment

Of the Requirements for the Individualized Master of Arts

In

The Department of English

And The Program in Africana Studies

School of Graduate Studies

Rhode Island College

2012 


\section{Dedication}

I dedicate this Master's Thesis to its primary inspiration: Claúdia Elisa Veiga, who was born in Praia, Cape Verde, and who has lived in Massachusetts since 1981. Through the six years of our relationship, Claúdia Elisa Veiga has steadfastly embodied postcolonial Cape Verdeanness, and, in so doing, has compelled me to better understand what I have come to highly regard in her. Thank you, always, Claúdia Elisa Veiga, for your inspiration. 


\section{ABSTRACT}

Cape Verdeanness is another name for Cape Verdean cultural identity. Postcolonial Cape Verdeanness refers to Cape Verdeanness as it has expressed itself since July 5, 1975, the first day of Cape Verdean independence. Postcolonial Cape Verdeanness has previously been described at length in the social sciences scholarship. Postcolonial Cape Verdeanness has previously been implicitly rather than explicitly represented in descriptions of postcolonial Cape Verdean poetry in the scholarly literature.

This study is a first of its kind consideration of postcolonial Cape Verdeanness. It is also the first time Cape Verdeanness of any kind has been explicitly represented by means of a review of Cape Verdean cultural productions. The methods of this study include a review of the findings of the social sciences regarding postcolonial Cape Verdeanness, a review of the scholarly literature on postcolonial Cape Verdean poetry, and an analysis of a group of postcolonial Cape Verdean poems, including contributions from both the Cape Verdean Islands and the Cape Verdean diaspora.

The findings of this study are that postcolonial Cape Verdean poetry provides a significant lens into postcolonial Cape Verdeanness that both overlaps and complements the lens on Cape Verdeanness provided by the social sciences. Furthermore, postcolonial Cape Verdeanness demonstrates a rupture from colonial-era Cape Verdeanness. Because of this rupture, Cape Verdeanness has now expanded to reflect universal concerns in addition to specifically Cape Verdean ones. 


\section{Preface}

I am the person most surprised that my life has taken me, a Jewish man, originally from the New York metropolitan area, the locale of the greatest number of Jews living outside of the land of Israel, to this point of an in-depth study of postcolonial Cape Verdeanness, a study of a people wholly unknown to me as recently as 2005 . The fact that my life has brought me to this point invites legitimate curiosity as to how this came to be. I will begin to explain this personal 'migration' by describing historical and cultural similarities between the Jewish and Cape Verdean people. In the end, I will suggest that my interest in Cape Verdean culture and society most directly reflects my present appreciation and fondness for postcolonial Cape Verdeanness, which I shall describe as being about sodadi (longing), morabeza (warmth), and much, much more.

Jews are widely regarded as a historically diasporic people. They are said to originally have been made up of twelve tribes. More recently, Jews have been understood to be made up in terms of two major groupings, Ashkenazim (Jews of recent European descent) and Sephardim (Jews of recent Spanish, Portuguese and Arabian descent).

Before the founding of the State of Israel, in 1948, Jewish cultural identity survived a nearly two thousand year absence of a homeland. Yet the Jewish people paid a dear price for this absence of a homeland, in their experience of virulent anti-Semitism, Pogroms, and the genocide of European Jewry commonly known both as the Holocaust and the Shoah. Jewish cultural identity was not static over those nearly two thousand years without a homeland, and it has been fluid, as well, since 1948. At the present time, 
there are approximately twice as many Jews living in the Jewish diaspora as there are living in the Jewish homeland.

For more than twenty-five years, now, I have lived in the Boston, Massachusetts metropolitan area (which, when broadly conceived, includes Providence, RI, and Brockton, Taunton, New Bedford, and Onset, MA), the locale of the greatest number of Cape Verdeans living outside of Cape Verde. Cape Verdeans, like Jews, are widely regarded as a historically diasporic people. Cape Verde, which only gained its independence in 1975, is an archipelago of nine inhabited islands (with Santo Antão, Sao Vicente, Sao Nicolau, Sal, and Boa Vista making up the inhabited Barlavento/Windward group of islands, and Brava, Fogo, Santiago and Maio making up the inhabited Sotavento/Leeward group of islands), along with one uninhabited island (Santa Luzia, which is Windward). At the present time, there are approximately twice as many Cape Verdeans living in the Cape Verdean diaspora as there are residing in Cape Verde.

It has been stated by a number of Cape Verdean scholars that many, if not most, of the original Portuguese settlers in Cape Verde were New Christians, that is, they were recent forced converts from Judaism. Cape Verde has spent the bulk of its existence without independence. In fact, its colonization lasted approximately five hundred years. Due to its neglect by its primary colonizer, Portugal, prior to independence in 1975, Cape Verde suffered repeated episodes of drought, famine, death, and emigration.

During its colonial period and since its independence, Cape Verdean cultural identity has remained fluid. Cape Verdeans are viewed as being made up of two primary cultural groups. One group of Cape Verdeans is made up of those who were born in the 
archipelago of Cape Verde and the other group is made up of those who were born in the Cape Verdean diaspora.

Not only was there an early on Jewish-Cape Verdean connection by way of the New Christians that were many of Cape Verde's first Portuguese settlers. There are also an unusual number of parallels between Jewish history and culture and Cape Verdean history and culture. These parallels include cultural identities for both peoples that have historically been unusually transnational in nature, respective histories rife with tremendous suffering that has only abated since gaining independent statehood in the twentieth century, respective diasporic populations which for a very long time have maintained their greatest presence in the Northeastern United States (the New York metropolitan area for Jews, and the Boston, Massachusetts metropolitan area, for Cape Verdeans), and the fact that there are two relatively distinguishable cultural identity groups within each of these cultures.

Yet these and other surprising similarities between the Jewish and Cape Verdean cultures are truly insufficient to account for the fact that I have embarked on an extraordinary personally meaningful Cape Verdean journey that has included sodadi, morabeza, and much, much more during these past six years. My journey into the world of Cape Verdeanness began when I encountered a Kriola, a Cape Verdean woman, Claúdia Elisa, who, like me, was a member of the audience at a public talk on "The Zen of Listening," held at Newton-Wellesley Hospital on September 16, 2006.

That chance meeting (if there is such a thing as chance) provided me with a first experience of Cape Verdeanness. Through regular encounters with Claúdia Elisa, her 
family, and Cape Verdean reality (by that, I mean to include listening to truly numerous compact discs of Cape Verdean music, attendance at a wide variety of Cape Verdean festivals, educational programs, and community events, numerous significant studies of Cape Verdean society and culture, and attending many live Cape Verdean music events, especially including my first experience of Cesária Évora, Cape Verde’s most well-known 'export', performing at the Berklee Performance Center, in Boston, Massachusetts, in 2007), over the past six years, I have come to appreciate Cape Verde as if it were my third homeland (after the United States and Israel, in that order).

Additionally, I have come to identify with the Cape Verdean people as if they were my own people (perhaps before Israel and the United States, as it were, in reverse of the order of my sense of homelands). There is something about the sodadi and morabeza and the much, much more that is postcolonial Cape Verdeanness that accounts for the fact of my fondness for the Cape Verdean people.

Perhaps that something is the depth of willingness to feel blue that allows, and perhaps demands, Cape Verdeans to remain warmly open to others to an especially rare degree. Nevertheless, for six years, while encountering and experiencing the nuances of postcolonial Cape Verdeanness, I have both basked in the morabeza and wallowed in the sodadi which are the colonial legacies of the postcolonial Cape Verdean world. I believe that I have been deeply and positively transformed by both of these relatively unconscious parallel processes of immersion into the sodadi and morabeza which occupy a significant portion of postcolonial Cape Verdeanness. My primary motivation for undertaking this study has been my great fondness for postcolonial Cape Verdeanness as 
I have come to personally appreciate it. 


\section{Table of Contents}

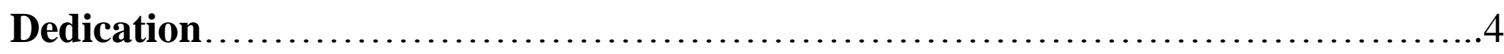

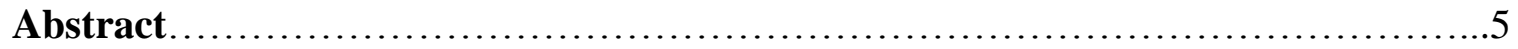

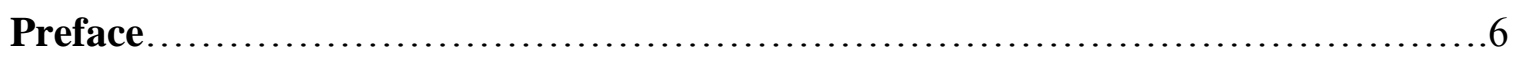

Introduction: An Overview of Cape Verdeanness in Postcolonial Cape Verdean

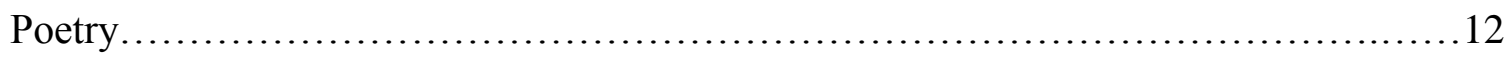

Chapter One: Three Foundational Dialogues Pertaining to Cultural Identity.............23

Chapter Two: A Comparison of Cape Verdean \& Martinican Cultural Identity.........44

Chapter Three: Social-Scientific Perspectives on Cape Verdean Identity..............67

Chapter Four: Cape Verdeanness in Postcolonial Cape Verdean Poetry: The

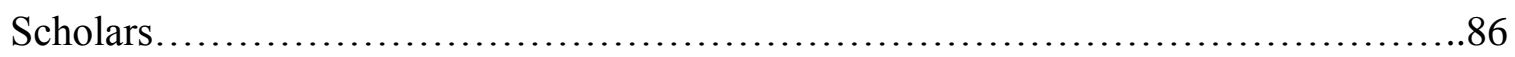

Chapter Five: Cape Verdeanness in Postcolonial Non-Diasporic Cape Verdean

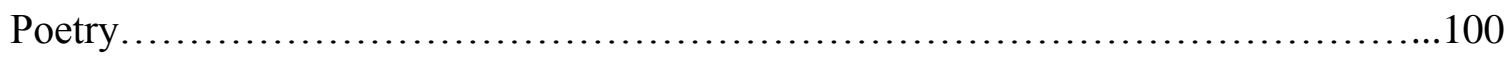

Chapter Six: Cape Verdeanness in Postcolonial Diasporic Cape Verdean Poetry......136

Chapter Seven: Cape Verdeanness in Postcolonial Cape Verdean Poetry............. 168

Chapter Eight: Beyond Sodadi and Morabeza in Postcolonial Cape Verdeanness......172

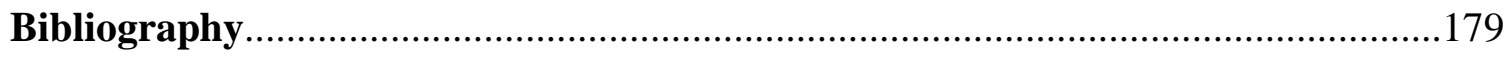

Appendix A: Beyond Sodadi and Morabeza: a poem by David J. Alpert.............185

Appendix B: Eleven Postcolonial Cape Verdean Poems..........................186

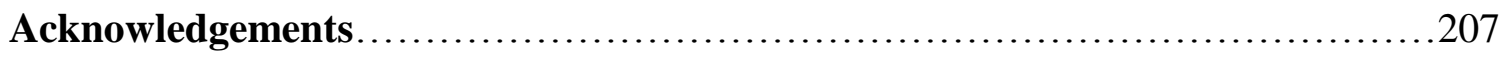

David Joseph Alpert: A Brief Biography..................................208 


\section{Introduction:}

\section{An Overview of Cape Verdeanness in Postcolonial Cape Verdean Poetry}

Pedro Góis, the author of the chapter "Cape Verdeanness as a Complex Social Construct: Analysis of Ethnicity through Complexity Theory," in Identity Processes and Dynamics in Multi-Ethnic Europe, espouses a theory of social constructivism regarding Cape Verdean culture. The theory of social constructivism holds that cultural identity is so fluid it is therefore indefinable. If, in contradistinction to Góis' idea of social constructivism, one can postulate essential elements to postcolonial Cape Verdeanness, two of those elements appear to be long-standing Cape Verdean attributes from the colonial era: sodadi and morabeza. Sodadi is generally translated as a longing for what is absent, which may be a homeland, family, friends, and/or, especially, a beloved.

Morabeza is generally translated as gently penetrating, sincere, interpersonal warmth. This study aims to describe postcolonial Cape Verdeanness, including but extending beyond sodadi and morabeza.

This project's specific study of postcolonial Cape Verdeanness is taking place within a context of a surprisingly large body of English-language scholarly work on Cape Verdeanness. The extent of that scholarship hints at the fact that Cape Verdean cultural identity differs significantly from traditional expectations of cultural identity. This may be, at least, in part, because, as Góis noted, Cape Verdean cultural identity has been historically transnational in nature.

The body of work on Cape Verdeanness has primarily been approached through 
the methodology of the social sciences. This study, on the other hand, represents a first of its kind English-language focus on postcolonial Cape Verdean poetry as a means for gleaning elements of postcolonial Cape Verdeanness. This study of Cape Verdeanness is being based on a review and analysis of Cape Verdean cultural productions, specifically, postcolonial Cape Verdean poetry, which has been written in English, translated into English, or reviewed in English.

This specific study on postcolonial Cape Verdeanness is limited by several factors. For one, there has so far been, during the postcolonial era, just a relatively small amount of Cape Verdean poetry which has been initially published in or translated into the English language. Secondly, for the postcolonial Cape Verdean poetry in translation, poetic translation, itself, requires a great deal of a translator for it to be faithful to its source culture's nuances and subliminal rhythms. Finally, as well, there has only thus far been rudimentary English-language study on postcolonial Cape Verdean poetry.

This study focuses on postcolonial Cape Verdeanness rather than colonial-era Cape Verdeanness. The reason for that is my significant appreciation for the following postulated elements of postcolonial Cape Verdeanness: fondness for Cape Verde (which includes a desire for its ecological well-being), a love for Kriolu (the Cape Verdean language), transnational Cape Verdean identity, and, something far from uniquely Cape Verdean, an extraordinary interest in phenomenological awareness. This study aims to make central use of a review and analysis of postcolonial Cape Verdean poetry so that the elements of postcolonial Cape Verdeanness may become better elaborated and well understood. 
This study's primary aim is to provide a better understanding of postcolonial Cape Verdeanness, beyond just sodadi and morabeza, especially as that may be located in postcolonial Cape Verdean poetry. The primary means by which I will work towards this aim is through a careful analysis of postcolonial Cape Verdean poetry within the context of previous scholarship on that subject. Specifically, I will describe postcolonial Cape Verdeanness by way of locating its signs in a wide range of eleven postcolonial Cape Verdean poems.

To support this study's aim of utilizing postcolonial Cape Verdean poetry to better describe postcolonial Cape Verdeanness, I will review a group of social scientific studies of cultural identity and, specifically, Cape Verdean identity. The review of these social scientific studies shall act as a means to compare their findings regarding postcolonial Cape Verdeanness with my consideration of the scholarly literature on postcolonial Cape Verdean poetry and with my original analysis of eleven postcolonial Cape Verdean poems. I will elaborate a construct of Cape Verdeanness that is informed by, yet not bound by, previous general work on the subject of cultural identity.

Furthermore, while this work shall give a great deal of consideration to the seminal ideas of national identity espoused by Benedict Anderson, in his Imagined Communities, I will also contest that work, as necessary. For example, consistent with the perspective of Góis, Cape Verdeanness will be shown to extend sometimes by reasons of law and always by the human imagination beyond national borders, in contradistinction to Anderson's postulate of national boundaries. Cape Verdeanness will be identified as, in fact, a phenomenon that traverses the entirety of the Cape Verdean diaspora. 
Earlier, when discussing sodadi and morabeza, I hinted at the fact that Cape Verdean cultural identity is a contested construct. According to Góis, Cape Verdean cultural identity is always in dynamic flux, and, crucially, since it is constantly being re-created, it is impossible to describe. For Góis, all one can legitimately do is somewhat superficially distinguish native-born Cape Verdeans from those of a diasporic origin.

Yet I suggest, while acknowledging, along with Góis, how difficult cultural identity is to measure and specify, that Góis has under-estimated the representational role of artistic productions. When properly considered, while a given cultural work may only point to particular attributes of a people, a collection of creative works within a particular genre and period may serve as a window to the variable, fluid, but nonetheless discernible elements that compose a culture's consciousness at any point in a people's history. Therefore, it is an assumption of this study that impressions of a particular culture's identity at any given time may be gleaned from careful consideration of that culture's literary productions, and, specifically, the culture's poetry.

One significant matter about cultural identity demands something more of this study and that is to consider how the label of a particular cultural identity group gets affixed to any particular individual or their creative work. I must here address the question of which persons or what cultural productions may be considered to be Cape Verdean, in particular. For example, while Jarita Adia Davis' doctoral dissertation, As Minhas Mornas, is predominantly, if not completely, centered on Cape Verdean themes, and while she self-identifies as having a Cape Verdean grandparent, when I spoke with her in 2010 she did not self-identify as Cape Verdean but, instead, as African-American. 
It might seem, or even be, somewhat neo-colonial of this author to consider the Davis doctoral dissertation a Cape Verdean cultural production over and against the assertion made by Davis about her own cultural identity. Yet, I believe that the extensive evidence of Cape Verdeanness in As Minhas Mornas should allow that work by Davis to be fairly viewed as a diasporic Cape Verdean cultural production. In fact, Lindsey Campbell-Badger's on-line text, A Selective and Annotated Bibliography of English and French Language Sources on Cape Verdean Literature, has assigned Davis' doctoral dissertation to the Cape Verdean literary tradition.

Most published Cape Verdean poetry has been written in Portuguese. Nonetheless, a significant amount of published Cape Verdean poetry, and this is especially true of postcolonial Cape Verdean poetry, has been written in various forms of Kriolu, the Cape Verdean language, which has only recently been officially standardized by the Government of Cape Verde. Only a very small amount of Cape Verdean poetry has either been originally written and published in English, or been published in English translation. It is true that there has been somewhat less published English-language postcolonial Cape Verdean poetry than there has been of its colonial-era counterpart. That fact may be reasonably accounted for by understanding that Cape Verde had a colonial period lasting approximately five hundred years, whereas it has only maintained its independence from Portugal, thus far, for thirty-seven years.

One might consider if those Cape Verdeans who write poetry in Kriolu are differentially interested in their works' magnitude of impact than those who write their poetry in Portuguese, given the fact that Portuguese is understood by more than 300 
million people on Earth whereas Kriolu is understood by less than two million persons. It is not the purpose of this study to decide that matter nor to identify the particular reasons why relatively little Cape Verdean poetry has been published in the English language. Yet I am suggesting here that this dearth of Cape Verdean poetry in English translation may reflect the degree to which Cape Verde still remains hidden from the consciousness of English-speaking peoples in a terribly disproportionate manner to the nation's historic international importance. In consideration of the corpus of Cape Verdean poetry penned in Portuguese and Kriolu, and my faith in the extraordinary quality of that body of work, if this study in any way encourages more Cape Verdean poetry to be published in the English language, that would be an extremely welcome outcome.

Following my review of a book chapter by David Brookshaw, "Cape Verde," from The Post-Colonial Literature of Lusophone Africa, which offers an articulation of the distinct thematic periods in colonial-era Cape Verdean poetry, I will consider the social scientific work on cultural identity and Cape Verdean cultural identity, and provide thorough attention to the English-language scholarship on postcolonial Cape Verdean poetry. Then, this study shall undertake consideration of a broad spectrum of postcolonial Cape Verdean poetry, through eleven poems which will be carefully analyzed for their representations of Cape Verdeanness. I have chosen to mine English-language postcolonial Cape Verdean poetry from its three richest sources: the 2003 doctoral dissertation As Minhas Mornas, by Jarita Adia Davis; Changing Africa: The First Literary Generation of Independent Cape Verde, from 1992, by Gerald M. Moser; and Across the Atlantic: An Anthology of Cape Verdean Literature, from 1988, edited by 
Maria M. Ellen. Specifically, the review of postcolonial Cape Verdean poetry will include the consideration of both non-diasporic and diasporic representations of Cape Verdeanness. The poets to be studied include Alberto Ferreira Gomes (a.k.a. 'Binga'), Corsino Fortes, José Luís Hopffer C. Almada (a.k.a. 'Zé di Sant’y Agu'), Tomé Varela Da Silva, Tacalhe, João Rodrigues, David Hopffer Almada, Jarita Adia Davis, and Adelina C. Da Silva.

I believe it to be extremely important to give adequate attention in this study to the voice of Ngũgĩ wa Thiong'o's classic text, Decolonising the Mind: The Politics of Language in African Literature, as it pertains to the matter of the languages in which postcolonial Cape Verdean poetry has been written. It is that text's perspective that a truly African cultural production demands of a work that it be written in an African language. Ngũgĩ wa Thiong'o perceives the use of European colonial languages by writers such as Chinua Achebe (author of the classic English-language novel about colonialism's impact on African village life, Things Fall Apart) as a necessary transitional but temporary phenomenon of Afro-European literary production.

In consideration of Ngũgĩ wa Thiong'o's text, Cape Verde is in a special category. Prior to its colonization by the Portuguese, the archipelago of Cape Verde had short-term visitors but no known permanent residents (and therefore no native language). Cape Verde was the colonial site where numerous Europeans, primarily Portuguese, along with West Africans (most, if not all, of whom arrived as slaves during the slave-trading period in the colonial-era), amongst others, populated nine islands with speakers of a new vernacular-Kriolu. Kriolu fits nicely into Ngũgĩ wa Thiong'o's embrace of new African 
languages that have naturally arisen through cross-cultural contact. Yet, as George Lang suggests, in "Literary Crioulo since Independence in São Tomé, Guinea-Bissau and Cape Verde," it may be inappropriately essentialist to privilege African-language literary production as the true source of African reality. To wit, it may be important to consider what language an African writer dreams in when considering what language he or she should write in.

An additional assertion I am making herein is that since Cape Verde achieved its independence, in 1975, the nature of Cape Verdeanness has undergone its greatest historical rupture, its most profound transformation. This assertion is based on the ineluctable significance of the ending of an era of relentless colonial oppression. According to Brookshaw's chapter "Cape Verde," before Cape Verdean independence Cape Verdean poetry passed through several distinct stages. While those transitions generally demonstrated reasonably expectable changes, the postcolonial rupture in Cape Verdean culture has brought us surprising discontinuities (especially in its more universal phenomenological elements). According to Carmen Lucia Tindó Secco’s “Postcolonial Poetry in Cape Verde, Angola, and Mozambique: Some Contemporary Considerations," one of a small group of works by postcolonial Cape Verdean scholars writing in English (or whose work has been translated into English), in postcolonial Cape Verdean poetry, one sees that women's previously silenced poetic voices have become audible, that women's lived realities are now communicated, that traditional images like the sea gain new meanings, and disappointments of postcolonial Cape Verdean life are being recognized and confronted. Such content in postcolonial Cape Verdean poetry constitutes 
a rupture when set against colonial-era Cape Verdean poetry.

I am here defining postcolonial Cape Verdean poetry as any Cape Verdean poetry both written and published since July 5, 1975, the date of Cape Verde's independence from Portugal. I consider Cape Verdean independence to be the most salient event in this nation's history. This study may well suggest that postcolonial Cape Verdeanness has more in common with cultural identity in other diasporic independent former third world nations than it has with present-day third world nations, or than it has with a present-day subsidiary of a first-world nation, Martinique (a possession of France), whose culture has been carefully described by postcolonial scholars such as Aimé Césaire, Frantz Fanon, and Edouard Glissant. Furthermore, this study may lend support to other researchers who use other means for considering, assessing, and describing various manifestations of postcolonial Cape Verdeanness. It may also be valuable to those researchers examining the specific nature of postcolonial rupture in Cape Verde and elsewhere on Earth.

Significantly, rather than merely indicating a point on a time-line, the term 'postcolonial', as I use it here, suggests a well-known method of literary criticism that has been developing since the latter part of the twentieth century. As seen in the work of such postcolonial scholars as Aimé Césaire (in his Discourse on Colonialism), Frantz Fanon (in his Black Skin, White Masks), and Edouard Glissant (in his Caribbean Discourse: Selected Essays), postcolonial literary criticism examines cultural productions through a lens that is especially focused on the consequences and aftermath of a people's historically lived experience of colonial relations. It also considers the intrusion of neocolonial elements into post-independence national life. This study of Cape 
Verdeanness in postcolonial Cape Verdean poetry is being undertaken primarily through such a postcolonial theoretical perspective. It does so based on the belief that a postcolonial theoretical perspective is significantly more inclusive than that possible through any other identifiable lens of literary criticism.

\section{A Very Brief History of Cape Verdean Poetry}

According to Brookshaw, the colonial era's first stage of poetry was its classic stage, which might be considered its stage of denial, when the poetry then produced by Cape Verde's elites might now be seen to have been fairly indistinguishable on the matter of Cape Verdeanness in its content and form from other Portuguese poetry of its period (180). But in the late nineteenth century and the early twentieth century, Cape Verdean poetry's themes shifted to reflect much more the experience of life in Cape Verde. That life, though depicted at first with enormous passivity, was suffused with drought, famine, death, and emigration, the latter typically represented by the sea.

Later on, in the third quarter of the twentieth century, Cape Verdean poetry's themes shifted to actively contest the source of the oppressive conditions of life in Cape Verde, rather than merely being lamentations. The idea of Cape Verdeans maintaining fidelity by struggling to evade emigration, despite it being all but compelled by Cape Verdean living conditions, became prominent. This culminated in the combative Cape Verdean poetry written during the movement for Cape Verdean independence. Since Cape Verde achieved its independence, in 1975, drought, famine, and the related loss of life have abated both as lived realities and as cultural representations, whereas emigration 
has remained a constant theme in Cape Verdean life and culture. 


\title{
Chapter One: Three Foundational Dialogues Pertaining to Cultural Identity
}

\author{
$\underline{\text { Introduction }}$
}

Before reviewing the scholarly literature on Cape Verdean poetry and analyzing a representative sample of that postcolonial Cape Verdean poetry which exists in the English language, it is important to look at some foundational understandings regarding culture, cultural identity, nationalism and national culture, postcolonial cultural identity, and postcolonial Cape Verdean cultural identity. A culture represents any group set in a particular time wherein there is some shared reality that influences its members' actions so that a set of significant behaviors within that culture are relatively distinct from such sets within other cultures, while also being predictable and comprehensible to that culture's respective group members. This construct of culture is not essentialist, in that it does not presume ineluctable constancy over time nor does it assume that the specific culture-related activities of all members of any particular group will be alike in all ways.

Cultural identity represents all of the qualities that encompass a particular culture, such as language, ethnic identification, perceived history, values, food, clothing, arts, lifestyles, gender constructs, and gender relations. An individual may be seen to possess significant aspects of a particular cultural identity to the degree that their reality encompasses such distinct qualities of a given culture. Many persons can be seen to possess significant aspects of multiple cultures. These may be multiple cultures one has been born into or may represent additional cultures which one has adopted. For a variety 
of reasons, an individual may decide not to outwardly identify with a particular culture despite the possession of many of its distinctive aspects.

\section{Benedict Anderson and the Meaning of Nationalism for Cultural Identity}

Looking at Benedict Anderson's Imagined Communities, which is a seminal work on nationalism and cultural identity, helps one understand the significance of Cape Verdean identity for a transnational culture such as Cape Verde. For most of us, today, according to Anderson, national identity is the strongest element of our cultural identity. Anderson's text's title implies, and his text explicates, how nationalism ineluctably requires our imaginative faculties. A diasporic Cape Verdean's imagination, along with the Cape Verdean nation's Second Constitution, which politically links the diasporic Cape Verdean to the Cape Verde Islands, allows him or her to feel connected to the nation of Cape Verde.

The reader can see the roots of transnational Cape Verdean identity in how Anderson understands national identity. He defines nation as "an imagined political community-and imagined as both inherently limited and sovereign" (6). He notes how "the nation is always conceived as a deep horizontal comradeship" (7). Anderson juxtaposes the ironic “'political' power of nationalisms vs. their philosophical poverty and even incoherence" (5). Anderson is frightened of the power nations hold over the imagination. Anderson also takes offense with nationalism because it is artificially 
constructed and because it foments unnatural antagonisms between persons without the same national identity.

Like any postcolonial nation, Cape Verde is a product of the forces of world history. Anderson situates the development of nationalism in the context of human history. He especially seizes on its capacity to address core existential concerns of humankind (especially regarding life's meaning and purpose) which he suggests had been previously addressed by religions, sacred languages, or royal dynasties, and sometimes by two or more of those in combination. Being part of a nation, then, gives one's life a significant degree of meaning and purpose which it might well otherwise lack.

Anderson postulates that the loss of religious and linguistic exceptionality, along with the demise of royal dynasties, disturbed an existential order which he imagines was fairly satisfactorily embraced by pre-nationalistic humankind. He notes how the considerable positive attention that dying for one's country elicits today positions the state as God. Noticing simultaneous trends in Europe, Anderson points out that "in Western Europe the eighteenth century marks not only the dawn of the age of nationalism but the dusk of religious modes of thought" (11). I am not sure what data Anderson has in support of that claim, and wonder, perhaps, if he overestimates both religions' decline at the time and nationalism's genesis. Yet it is true that Cape Verdean nationalism grew following European nationalism.

Anderson recognizes the "magic of nationalism" in its capacity to turn "chance into destiny" (12). Significantly, like the water within which fish swim, Anderson points out that we humans take nationalism too easily for granted at this time (12). I would counter 
that the building blocks of nationalism have always been present in the form of human tribal identification, and that humans evolved within the context of tribal being. While it took some time for Cape Verdeans to think of themselves as Cape Verdeans, I imagine that this transition would have transpired at some perhaps later point even were nationalisms not as markedly developing in Europe. After a while, a particular physical space binds people who share it.

Surprisingly, however, Anderson attributes the development of nationalism even more to the development and diffusion of print-capitalism than he does to its existential utility. The reader learns from Anderson how "after 1640...publishing was ceasing to be an international enterprise" (18-19). In contradistinction to the hegemony of multi-national corporations in areas such as energy and finance in the economic world of today, publishing, in part because of the 'Babel' effect, has resisted such a concentration of wealth. The reader is informed regarding the relative recentness of newspapers and novels (24-25). Anderson informs us how the German philosopher, Hegel, perceived the morning paper to be a replacement for the ritual of morning prayers (35). Anderson informs us that newspapers create "that remarkable confidence of community in anonymity which is the hallmark of modern nations" (36). It would seem that for Cape Verdeans, since Cape Verde has no daily paper, that Cape Verdean roots music serves a similar purpose.

According to Anderson, "print-capitalism...made it possible for rapidly growing numbers of people to think about themselves and to relate themselves to others, in profoundly new ways" (36). No doubt the newspaper enabled more such opportunities for 
the literate populations. Given the history of the role of theatre for democracy in Ancient Greece, however, I question whether this 'self thinking about self' and this 'relating of self to other' was completely new in kind for literate and illiterate humans, both, or whether it was merely new in its particular manner of being instigated and in the scope and speed of its reach. Nevertheless, Anderson makes it evident that book publishing became a prototypical capitalistic enterprise and that because of print-capitalism languages have likely become more fixed, less fluid, (44). Anderson amply demonstrates the revolutionarily "vernacularizing" impact of print-capitalism (39).

Anderson demonstrates how Luther's challenge to Catholicism became a 'best-seller', and how Martin Luther became the first known author to have cache within the publishing industry (39). Anderson suggests that there was a "coalition between Protestantism and print-capitalism, exploiting cheap popular editions" to expand readership (40). While Anderson suggests that print-capitalism enabled the literate person of the time to imagine the unknown other, I would suggest that those persons of means and leisure adequate to enable their education for literacy at the time likely came to imagine the unknown other in an inevitable fashion, and that it was the increase in the population of those with means and leisure adequate to enable their education for literacy, as much as or more than print-capitalism, that expanded the degree to which the unknown other thereby became imagined (42-43).

Anderson describes a process by which "print-languages laid the bases for national consciousness" (44). For Anderson, one aspect of this is that "print-capitalism created languages-of-power" that enabled particular dialects that were closer to a print-language 
to dominate (45). Another aspect of this process for Anderson is that because of the new relative fixity of languages, an "image of antiquity so central to the subjective idea of nation" could be implicated for relatively recent language systems (44). Anderson claims further that readers will come to identify with other consumers of their print language (44).

Whereas much reading was previously in Latin, now reading was taking place in numerous, equally legitimate, written languages. Yet I would point out that Anderson may privilege reading as opposed to oral communication in the vernacular language as the foundational basis for national consciousness. I say this in consideration of the fact that Kriolu has been the vernacular language on Cape Verde since the inception of the Cape Verdean colony in the late fifteenth century by the Portuguese, and until the twentieth century the majority of Cape Verdeans could not read or write in Portuguese or any other language. Furthermore, Kriolu has never been the dominant written language either before or after Cape Verdean independence.

Anderson presents a classification of a Creole person at odds with the customary definition of that term, as I believe it to be presently understood, at least as that term relates to Cape Verde. I define a Creole person as a person born in the Common Era (A.D.) of mixed African descent, that is, as someone not of solely African descent. For Anderson, a Creole is a "person of...pure European descent but born in the Americas (and, by later extension, anywhere outside Europe)" (47). The term "Creole" appears throughout Anderson's text, and must be understood in reading his text as he has specifically defined it. 
I have introduced Anderson's construct of the term 'Creole' so that the reader may understand what Anderson means when he appreciates the power of a shared predicament for Creoles (57). He notes how Creoles (all of whom were considered to be of full European descent) were assigned subordinate status with regards to native Europeans in the various European colonial settings (58). Anderson points out the long tentacles of racism that made it "only too easy...to make the convenient, vulgar deduction that creoles, born in a savage hemisphere, were by nature different from, and inferior to, the metropolitans [those born in Europe]" (60). Portugal, perhaps because of its late medieval history of Arab influence, and also because of its Luso-tropicalism in the early twentieth century, which was a Portuguese perspective that accentuated the positive about colonial relations based on a supposed Portuguese empathy for intercultural relations, may have thereby had less racism or, at least, less overt racism than Anderson's perspective might imply.

Anderson explores the distinction between embracing "a sort of mental miscegenation" for Indian Hindus becoming English through their education and the limits of such an embrace (91). Despite British willingness to conceive that an Indian Hindu could be trained to behave as a proper British elite might, the British could never allow the Indian Hindu to gain parity with his British peer. Anderson recognizes how these Indian-looking but British-acting men were "such strangers in their native land [yet] were still condemned [to a] permanent subordination to the English" (93). For Anderson, racism mutes the power of nationalism. Yet while this may be so in the former British colonies, racism is significantly more absent, and where it is present it is much less overt, 
in Cape Verde than it is in those former British colonies. Cape Verde considers itself to be a Creole nation, not in Anderson's sense of Europeans born in Africa but rather in the sense that most Cape Verdeans identify as being of mixed European and African heritage.

Anderson notes that from 1922 on, "the legitimate international norm was the nation-state" (113). Anderson demonstrates how the world has taken the situating of nations as a positive development without any considerable deliberation on the matter. While Anderson suggests that the new nations established after the Second World War represent distinctly different entities than those nations that arose sooner, he nevertheless assures us that these nations reflect an “isomorphism between each nationalism's territorial stretch and that of the previous imperial administrative unit" (114). The story of Cape Verde appears to counter Anderson's perspective.

Cape Verde was established in 1975 after the Second World War. First of all, despite the fact that Cape Verde and Guinea-Bissau had been under separate rule during the colonial period, Amilcar Cabral, the revolutionary father of Cape Verdean independence, chose to strategically link the independence movements of those two peoples who were then to become one nation (though it is true that at the end of the freedom struggle the two colonies had separated their independence movements). Secondly, in its present, second, national Constitution, Cape Verde grants its expatriates the opportunity to vote for diasporic representation in the Cape Verdean Assembly (diasporans are assigned as many as six seats out of a potential total of seventy-two seats), and their vote tally for the Cape Verdean presidency shall count towards up to twenty percent of the amassed vote tally in such elections. Both the Cape Verdean 
revolutionary linkage with Guinea-Bissau and the enfranchisement of the Cape Verdean diaspora are inconsistent with Anderson's premise of such isomorphism. Cape Verde is clearly an example of a transnational nation-state, something Anderson apparently never fathomed.

Anderson recognizes that radio and television facilitate the imagining of community at least as well as the written word (135). I am curious if the Internet, today, fulfills the role of imagining a borderless transnational world, and, thereby, the transcendence of separate nationalisms. While Anderson clearly laments nationalism, noting with dismay that he despaired when two socialist national entities were engaged in war in Southeast Asia, he nevertheless does appreciate how nationalism enables positive feelings of kinship and a sense of home (143). Anderson calls this unifying force of a nation's members “unisonance” (145). Anderson associates this especially with a nation's "poetry and songs" (145). This is consonant with my view of the unifying force held by Cape Verdean roots music within the transnational Cape Verdean community.

\section{Aimé Césaire and the Meaning of Colonialism for Cultural Identity}

Prior to its independence, Cape Verde endured five hundred years of colonialism. The effects of this colonialism, even today, thirty-seven years after Cape Verdean independence, should not be casually dismissed. The experience of colonial relations in just a singular instance strikes hard on the psyche. The blow of five hundred years of such relations is profound. It surely requires more than thirty-seven years for its 
resolution, especially when one considers neo-colonial penetration, that is, postcolonial intrusion, by the former colonizer.

Few thinkers have carefully considered the dynamics of colonialism and the effect of those dynamics on cultural identity as capably as the Martinican, Aimé Césaire, has. Césaire's Discourse on Colonialism could well be considered a declaration of war against colonialism, and may have been a significant inspiration to Amilcar Cabral, the 'father' of Cape Verde, and to other anti-colonial freedom fighters. In Discourse, Césaire provides the reader with a profound appreciation of the perversions of human relations that arise from colonialism. Césaire labels Europe as “a decadent civilization” (31). Turning upside down the claim that people outside of the West might best be viewed as savages, Césaire utilizes his breadth of knowledge of world history and European scholarship to suggest the extreme history of savagery of bourgeois Europeans.

Césaire notes that "the decisive actors [in colonization] are...appetite and force" (33). Césaire recognizes the positive potential in bringing "different societies in contact with each other" (33). He understands how "a civilization that withdraws into itself atrophies" (33). Yet the essential incompatibility of civilization and colonization is identified by Césaire, for whom "there is an infinite distance" between them (34). For Césaire, not "a single human value" can arise from colonialism (34). Césaire is thoroughly anti-colonial.

Césaire exposes how the colonizer grows progressively more dehumanized in the process of colonizing the colonized. For Césaire, "poison has been distilled into the veins 
of Europe and slowly but surely, the continent proceeds toward savagery" (36). Césaire further suggests that Europeans created the fertile ground in which Nazism took root, that "before they were its victims, they were its accomplices...because, until then, it had been applied only to non-European people" (36). Césaire confronts the European person with a claim that "without his being aware of it, he has a Hitler inside him, that Hitler inhabits him, that Hitler is his demon" (36). For Césaire, "at the end of capitalism...there is Hitler".

For Césaire, "a civilization which justifies colonization-and therefore force-is already a sick civilization, a civilization which is morally diseased" (39). For Césaire, the process of man seeing his fellow man as a beast leads to the degradation of such a viewer, "The colonizer, who...gets in the habit of seeing the other man as an animal,...tends objectively to transform himself into an animal" (41). Between the colonizer and the colonized, Césaire sees "no human contact, but relations of domination and submission" (42). Césaire laments the deleterious consequences of colonization, "societies drained of their essence...extraordinary possibilities wiped out" (43). Césaire imagines what might otherwise have been had it not been for colonialism.

Césaire admires the old societies that were exterminated by the actions of colonialism. He does not seek to return to what has been, but laments how "they were communal societies, never societies of the many for the few" (44). Challenging European arguments regarding the complicity of African leadership in the colonial enterprise, Césaire argues that Europe "has actually tended to prolong artificially the survival of 
local pasts in their most pernicious aspects" (45). For Césaire, "colonialist Europe has grafted modern abuse onto ancient injustice, hateful racism onto old inequality" (45).

According to Césaire, "it is not the head of a civilization that begins to rot first. It is the heart” (48). Césaire “defend (s)...old Negro civilizations; they were courteous civilizations" (51). Césaire values humility and community. He contests the West's "obsession with monopolizing all glory for their own race” (56). Césaire paints a stark picture of the colonizer.

Césaire demonstrates a deep commitment to the erasure of both witting and unwitting deficits of human compassion. Césaire sees such deficits "when smug self-satisfaction rots the eyes, when a secret contempt for others withers the heart, when racism, admitted or not, dries up sympathy" (71). In the end, for Césaire, no work of man is greater than "one spark of human sympathy" (72). For Césaire, sincere care is the highest good.

Césaire saves his most severe criticism for the United States. He believes that "the barbarism of Western Europe has reached an incredibly high level, being only surpassed--far surpassed, it is true--by the barbarism of the United States" (47). Césaire perceives American domination as "the only domination from which one never recovers. I mean from which one never recovers unscarred" (77). As Césaire was writing Discourse, he viewed that moment in time as Europe's "last chance [to avert]...the pall of mortal darkness" (78). For Césaire, it is clear that there are degrees of barbarism. One can only imagine how the experience of five hundred years of barbaric colonialism impacted the Cape Verdean psyche, complicated as the Cape Verde psyche may be seen 
to be by the fact that most Cape Verdeans have lineages that include both the colonizer and the colonized.

\section{Frantz Fanon, Aimé Césaire, and Stuart Hall:}

\section{Confronting Otherness and Cultural Identity}

Most diasporic Cape Verdeans have experienced being seen as the 'other'. For example, Cape Verdean-Americans have seen themselves lumped together by non-Cape Verdeans as African-Americans, Latinos, or Caribbean. Such diasporic Cape Verdeans have had to contest their being seen as the 'other'. Frantz Fanon, Aimé Césaire and Stuart Hall have spoken about the phenomenology of being seen as 'other', and their analyses have applicability to Cape Verdean diasporic experience.

In Frantz Fanon's “The Fact of Blackness” (in Black Skin, White Masks), Aimé Césaire's Notebook of a Return to My Native Land, and Stuart Hall's “ Cultural Identity and Diaspora," one is provided with deep understandings of the phenomenological experience of blackness, especially as it relates to being seen as 'other'. Fanon begins by describing how a person viewed as black understands the way he is talked to and about uniquely by one who is not black. It is he, but not the white man, who hears "Look, a Negro" (109). The experience of being seen as 'other' is shared by most non-white-skinned persons who have been in contact with white-skinned persons. Diasporic Cape Verdeans have experienced this to different degrees due to the fact that they range from being light skinned to being dark-skinned, with every possible shade in between. 
Fanon found for himself that "the movements, the attitudes, the glances of the other fixed [him] there in the sense which a chemical solution is fixed by a die" (109). For Fanon, "the black man has no ontological resistance in the eyes of the white man" (110). He is under the involuntary control of "a racial epidermal schema" (112). The black man is rendered non-human by the white man, and, significantly, has no apparent way to alter this rendering.

Fanon came to realize that he "existed triply: I occupied space. I moved toward the other... and the evanescent other...disappeared" (112). The white man refused to see the black man as a person, and in so doing stopped being human. All Fanon had wanted "was to be a man among all other men" (112). Each of us would want this. Fanon "resolved...to assert (himself) as a BLACK MAN" (115).

Fanon realizes that he is "given no chance. I am overdetermined from without. I am the slave... of my own appearance" (116). Fanon feels helpless. Then, Fanon decides to "strive for anonymity, for invisibility" (116). Perhaps he can find peace in being ignored by the white man. But in expecting his black 'brothers' to accept him, to Fanon's "horror, they too reject" him (116).

Fanon further notes Alan Burns' 1948 text on "color prejudice" in explaining what is transpiring in such dynamics (118). Appreciating a shared reality of the oppressed, Fanon suggests that "an anti-Semite is inevitably anti-Negro" (122). In the 'othering' of one class of persons, one is establishing oneself as a one who generically practices 'othering'.

Fanon tells us that "no agreement was possible on the level of reason [so he threw 
himself]...back towards unreason" (123). Logic has proved itself useless in the task of dealing with this 'othering'. This leads Fanon to perceive that "here we have the Negro rehabilitated...ruling the world with his intuition...raining his poetic power on the world" (127). In contradistinction to the black man, Fanon perceives that "the soul of the white man was corrupted" (129). While the black man can transcend the white man's oppression of him, the white racist man is seen as being ineluctably incapable of self-transcendence.

Countering Sartre's exposition of blackness in Black Orpheus, Fanon suggests that Sartre's conception of blackness engenders for blacks the same alienation which he found in Sartre's Being and Nothingness (138). Fanon refuses "to accept that amputation. I feel in myself a soul as immense as the world" (140). In the end, Fanon weeps over the divide between "Nothingness and Infinity", between his reality and that of the alienated masses (140). Fanon wants very much to cross that divide.

Aimé Césaire's long poem, Notebook of a Return to My Native Land, shares his student's (Frantz Fanon's) interest in phenomenology, the lived human experience. Césaire's Notebook may be viewed as a poetic representation of the themes which he later fleshed out in his Discourse on Colonialism. Césaire demonstrates in Notebook that a poem can well describe a given cultural reality and can, furthermore, contest that reality. The perhaps inevitable experience for the reader of Notebook is a sense of dislocation and disorientation. This dislocation and disorientation represents Césaire's intention to communicate the status of Caribbean islanders, especially Martinicans, with regards to their disconnected relationships to their lands and to themselves. This 
dislocation and disorientation may, at least in part, parallel the experience of diasporic Cape Verdeans who left Cape Verde before Cape Verdean independence or who were born to parents who left Cape Verde prior to Cape Verdean independence.

In Césaire's Notebook, the reader sees a population "alienated from its own flora and fauna" (73). One sees "these roads with no memory" (93). One sees "the nigger every day more debased, more cowardly, more sterile, less deep...more estranged from himself...less immediate with himself' (125). Most chillingly, the reader experiences "this squabbling crowd so strangely swayed from its own cry as the town is swayed from its own movement and meaning, without concern, swayed from its only true cry" (75). This population is "taking part in nothing which expresses, asserts, frees itself" (75). Here is a clear and profound exposition of Martinican, West Indian, and Caribbean alienation.

Repeatedly, in fact more than a dozen times throughout Césaire's Notebook, one encounters the phrase "at the brink of dawn" (75). This phrase's repetition, as a quasi-mantra for the text, suggests a poignant juxtaposition of the forces of darkness and light. Césaire sees both the darkness of the current Martinican, West Indian, Caribbean reality by way of "the brink" as well as the immediate potential for profound positive transformation by way of "the dawn" (75). The numerous repetitions of that phrase, "brink of dawn," suggest that Martinican reality has reached a moment of truth (75). Martinique shall either be reborn to soar like the mythical Phoenix or it shall disappear like dust absorbed by the waters surrounding it.

Césaire's Notebook is replete with explicit and implicit elemental references to earth, air, fire, and water. For example, it speaks of fire in "the repressed fire of the 
morne, like a sob gagged on the verge of bloodthirsty outburst" (75). In Notebook, the magic of the earth is suggested in "the unpredictable fermentations of rotting species" (77). Another earthy representation in Notebook is the townspeople at Christmas, which has a Carnival-like atmosphere. There we see "not only the mouths are singing, but the hands, but the feet, but the buttocks and the genitals, and the whole creature liquefying into sound, voice and rhythm" (81). The air is implied in Césaire's Notebook with "it crawls on its hand with never any impulse to pierce the sky with a posture of protest" (83). In a reference to affect in Notebook, which may be construed as a reference to the water element, we hear "my mouth will be the mouth of those griefs which have no mouth" (89).

As suggested earlier, Césaire's Notebook aims at inducing in its reader a parallel condition to that experienced by Martinicans, West Indians, and other Caribbeans, and that is the condition of extreme alienation from reality. While this experience of alienation for the reader may be instigated, typically, by the esoteric terminology interspersed throughout the text, at times specific lines in Notebook immediately induce one's alienation. One such example is "And you know the rest/ That 2 and 2 make 5" (93). In an introduction to Césaire's text, Mireille Rosello suggests that by making it impossible for both the French Caribbean reader or the Continental reader of Notebook to feel fully at home in the text (with its medical references, on the one hand, and its Caribbean natural world references, on the other hand) Césaire is helping the reader live the experience of helplessness that is the present fate of the Martinicans (56). For Rosello, "poetry is... a powerful cry of revolt which should awaken the mute crowd" (59). 
Césaire locates the enemy, in Notebook, after he asks, "But who twists my voice?" (97). He labels the root cause, assigning blame to "you dirty old hate" (italics mine, 97). Attempting to address the challenge of responding to hate, Césaire's Notebook offers us first a victim's angry voice, "I hate you," followed, shortly thereafter, by the empowered one's "ENOUGH OF THIS OUTRAGE!" (99). Moving into a commanding embodiment of indignation, in a profound reversal of the traditional colonial power dynamics, Notebook proceeds with “Accommodate me. I am not accommodating you!” (101).

In empowering his voice, the narrator of Césaire's Notebook is "breaking through the vitelline membrane that separates me from myself" (101). The powerful experience of self-empowerment by the narrator of Notebook is followed by a sudden and profound transformation in how the narrator views himself. The reader witnesses how "through an unexpected and beneficent inner revolution I now honor my repulsive ugliness" (103). The narrator notices that a "strange pride suddenly illuminates me" (111). There is appreciation of black history, how "my negritude... reaches deep down into the red flesh of the soil" (115). From a refusal to accept the white man's insistence on the black man's invisibility, the black man has gained an identity.

Yet this is not enough for Césaire's narrator in Notebook. For then, through the form of a prayer or incantation, the narrator of Césaire's Notebook aspires to yet another sudden and intense transformation, that being from a self-affirming person to a self-transcending person, to "make me refractory to any vanity but docile to its genius" (117). Along similar lines, the narrator asks to "make me a man of meditation" (117). Finally, in aiming to fully expel the venom of the oppressors, the narrator of Césaire's 
Notebook asks, "oh my heart, preserve me from all hatred" (117).

The profound result of the narrator's incantation or prayer for self-transcendence in Césaire's Notebook is that "I am nothing but a man who accepts, having no anger left (he has nothing left in his heart but an immense love, burning)" (119). The narrator in Césaire's Notebook is incredibly and absolutely strengthened by the surrender of his ego, and so now we see him with "the body of my country wonderfully lying in the despair of my arms" (125). The narrator accepts the condition of the patient, his people, and this acceptance of the patient is perhaps the medicine necessary for the Martinican people's healing from its soul-sickness.

Continuing in this incantation-like form, the narrator of Césaire's Notebook tells us that "I seek for my country...hearts of men which...beat with virile blood" (127). The greatest possible degree of human transformation is being sought. With this, "the old negritude is gradually cadaverising" (127). Victimhood is not of any lasting value. Next, with a metaphoric image of a radical transformation of the deleterious effects of colonialism, the narrator of Notebook tells us that "the slave-ship cracks everywhere" (129). The narrator of Césaire's Notebook closes the poem by asking to "bind my black vibration to the very navel of the world" (135). The narrator in Césaire's Notebook is asking to be the essential nurturer of the world of tomorrow. This will bring the necessary peace in the world, as seen in "rise Dove/ rise/ rise/ rise" (135). Peace is being invited to the Earth.

Whereas Aimé Césaire's Notebook uses poetry as the way in which cultural identity is addressed to effectuate transformation in the world, Stuart Hall, in his 
"Cultural Identity and Diaspora," argues for the transformational value of cinema for intercultural relations. Hall values a complex perspective on cultural identity, one based both on roots and branches. Yet without any sense of irony, he suggests the critical value of a quasi-essentialist construct of cultural identity by mentioning the value of shared cultural identity in "all the post-colonial struggles which have so profoundly reshaped our world" (223). This seems to parallel Césaire's Notebook, where before there was an inspiring self-transcendence there was the self-empowerment of indignation.

Hall goes on to refer to Fanon's recognition that the oppressive elements of the colonizers have been internalized by the colonized, leaving them with disturbed identities. Even liberation from the oppressor will not necessarily resolve this identity disturbance. Hall describes how 'this 'look' from...the place of the other, fixes us, not only in its violence, hostility and aggression, but in the ambivalence of its desire" (233). The result for the colonized has been "a profound splitting and doubling" (233). The colonized person has lost something of himself or herself through living the oppressive relation and, he or she furthermore has two selves, the one represented to their colonizer and the one that knows of the artifice of the self which they are representing to their colonizer. But through having to relate to the colonizer by way of artifice, colonized persons engage in inauthentic inter-relations, thus damaging themselves.

The challenge that Hall sees for the colonized is then to "stage this dialogue... without terror or violence, rather than being forever placed by it" (233). Hall sees that it is a trap to forever remain in a reactive position. One must avert the easy trap of rage. Whereas for Césaire a prose poem was the way out of the trap, for Hall, cinema 
is "that form of representation which is able to constitute us as new kinds of subjects", who may thereby succeed at erasing even the hidden damages of a colonial past (236-37). Hall sees film as holding transcendent potential. I see poetry as especially holding transcendent potential for Cape Verde. It was Eugénio Tavares’ poetry, penned first in the late nineteenth century (in the form of mornas, songs of longing), that provided Cape Verde with its first impressions of itself. 


\section{Chapter Two: A Comparison of Cape Verdean and Martinican Cultural Identity}

A number of factors contribute to significant differences between national cultures. The most significant factors tend to be those of a people's history and their present-day political status. I will use a broad comparison between Martinique and Cape Verde to draw this out because they are both island cultures, there has been an incredible depth and quality of scholarship on both cultures, and because in elucidating how Cape Verde is not Martinique the reader may gain a rich foundation for an understanding of postcolonial Cape Verdeanness available through the social sciences.

In Edouard Glissant's Caribbean Discourse: Selected Essays, the reader is thoroughly introduced to the Martinican experience. The Glissant text's impressions of Martinique generally contrast significantly with a recent representation of Cape Verdean reality as that has been depicted in Richard A. Lobban Jr.'s Cape Verde: Crioulo Colony to Independent Nation. For example, Glissant locates an absence of a history of Martinique. In so doing, he has thereby established a core element of that nation's history. In contrast, since the late nineteenth century, way before its independence, Cape Verde has not wanted for a sense of its own history. For example, according to Lobban, early in the twentieth century, Manuel Lopes' "writing focused on the uniqueness of the Cape Verdean experience" (80).

According to J. Michael Dash, his text's translator, particularly important to Glissant is "the problem of the psychological and cultural dispossession of the Martinican mind" (xvi). It is referred to, more specifically, as "The problem of the dissociated Martinican self' (xvii). This essential problem of cultural identity for Martinicans, while 
it may at times be visible in Cape Verdeans not born on the Islands of Cape Verde, especially those born to individuals who emigrated from Cape Verde prior to Cape Verdean independence, appears absent in persons who were born on Cape Verde after Cape Verdean independence, or born to those persons who left Cape Verde after Cape Verdean independence. Lobban tells us that "a sense of Cape Verdean cultural identity has kept this diaspora unified" (58). Furthermore, Lobban informs us that "important features of African heritage and traditions have persisted" (70).

For Glissant, the tale of Martinique follows, then, as "a historical perspective on the unchecked process of psychic disintegration in Martinique" (xviii). Because Martinique never gained independence from its former colonial oppressor, France, but rather has been incorporated as one of the Departments of France, the resulting assimilation of Martinicans has led to "the inescapable degradation of folk culture, Creole language, and any sense of being Caribbean" (xviii). In contrast, Cape Verde gained its independence from Portugal in 1975 after a lengthy war in which Cape Verde and Guinea-Bissau united in their opposition to Portuguese colonialism.

The result in Cape Verde has been a flourishing of folk culture, the Cape Verdean language, Kriolu, and a compelling sense of Cape Verdeanness. Lobban notes that in Cape Verde "Crioulo is the usual language of expression" (70). Furthermore, Lobban informs the reader that the morna is "the most popular poetic and musical genre of Cape Verde. It is regarded as one of the most characteristic and quintessential expressions of national culture" (78).

While Cape Verde has suffered from social imbalances engendered by ongoing 
massive emigration (especially the loss of able-bodied men from the islands), the ties of Cape Verdeans in the diaspora to Cape Verde, especially for recent emigrants, have worked to enhance life for those remaining on the islands of Cape Verde. Lobban instructs us that "today in Cape Verde, [overseas] remittances account for almost 50 percent of the gross domestic product" (59). The Glissant reader learns that in Martinique "social imbalances are produced by massive migration to France" (xix). While Martinique suffers from "cultural dislocation induced by an artificial affluence and a new consumer culture," Cape Verde is far from affluent, and would not be accurately described as being a consumer culture (xix). According to Lobban, "53.9 percent of the people were still living in rural areas in (Cape Verde) in 1990, areas that are poorly served by utilities, transportation, and communication facilities" (50).

Cape Verdeans tend to have an incredibly proud and strong sense of Cape Verdean identity, and a significant awareness of their collective history, even if there is some disagreement regarding the expected, but not necessarily desired, Cape Verdean destiny. For example, according to Lobban, "after independence, the PAICV leadership began water conservation, reforestation, and deep-well drilling and built desalinization plants and soil erosion control and catchment dams to reduce the disastrous effects" of Portuguese neglect (63). Martinicans lack a sense of their Caribbean identity, and this is based on an absence of awareness of their collective history and their "collective destiny" (xx). Martinicans face "oblivion" if the "urgent need" for a "collective memory" is not soon fulfilled (xix). In contrast, Cape Verdeans merely face the risk of a future that severely disrespects their familiar way of life if over-development, especially due to the 
tourism industry, continues unchecked.

In Cape Verde, Kriolu is not only the language of the people but it is gaining parity with Portuguese in the formal culture, whereas in Martinique, "Creole is constantly being eroded by French," (xxii). Whereas, for Glissant, "Martinique is crippled by an absence of self-sustaining productivity," Cape Verde is a second-world nation which is aiming to engender self-sustaining productivity (xxiii). While "Martinican music has not evolved from the music of the plantation," Cape Verdean music, through its multi-faceted nature, which includes both European and African roots, is a disproportionately huge phenomenon on the world music scene. For example, the Cape Verdean musician, Cesária Évora, won an American Grammy Award for World Music.

The generally passionately engaged world of the Cape Verdean exists in stark contrast to the "alienated world of the Martinican" (xxiv). Lobban describes how "morna texts...frequently express sadness, nostalgia, longing for loved ones, and other serious, romantic, or philosophical subjects" (78). Though in Cape Verde, as well as in Martinique, "Language...enacts the power relations in... society", in Cape Verde these power relations enacted by language are secondary, and somewhat perfunctory, even to the point of their becoming increasingly vestigial, whereas in Martinique these power relations are a primary and central element of Martinican life (xxv). The Martinican writer is compelled, thereby, to "propose language as a shock, language as antidote...through which the problems of the community can be restated" (xxvi). The Cape Verdean writer is not similarly compelled, because as Lobban explains "for most of its history Cape Verde has been a Crioulo society" (71). 
Whereas the history of slavery appears to have significant currency in Martinique, despite its having been abolished over one hundred and fifty years ago, in Cape Verde slavery is both more recent and in possession of significantly less cultural currency. Part of why slavery holds less Cape Verdean currency may be because, as Lobban notes, that "throughout most of its half millennium of history, slaves were a minority of the total population" on Cape Verde" (71). This makes resistance to immobility (the essential nature of slavery) more relevant to the creative process of the Martinican writer than it might be to the Cape Verdean one.

Whereas Martinique is "an example of an extreme case of historical dispossession in the Caribbean, Cape Verde might be viewed as the contradictory example of an extreme case of historical instigation in the Afro-Atlantic (xxxii). Before the Cape Verde Islands were first colonized by Portugal, they held no known stable population of inhabitants. Rather, prior to colonization, the islands of Cape Verde appear to have occasionally and transiently been frequented by various small groups of West African fishermen. Lobban notes that even after colonization had begun "during most of the earlier years, the islands were sparsely populated" (47).

Cape Verde possesses, if anything, an inflated sense of its own significance, seeing itself as the center of the modern world, whereas Martinique has been "caught between the fallacy of the primitive paradise, the mirage of Africa, and the illusion of a metropolitan identity," (xxxii). For Glissant, "Land is central to the process of self-possession," being "the link between... sensation and memory" (xxxv). While Martinicans have remained disconnected from their land, Cape Verdeans possess a sense 
of being tethered to their land (they speak of 'nha terra'-'my homeland') in the way that Jews might be seen to be tied to Jerusalem, and Moslems to Mecca.

Glissant appears to locate Martinique in a central position when he suggests that Martinique is "the essential point of reference for an entire continent" (xxxix). However this representation appears to be more because "universality paradoxically springs from regionalism" than because Martinique possesses something that makes it demand notice (xxxix). Whereas Martinique is perceived as suffering from a "degenerate attachment to metropolitan France," Cape Verde may be viewed as the most successfully individuated of Portugal's late twentieth-century colonial possessions (xl).

Cape Verde's leadership, while not always successful at satisfying its difficult-to-please, highly empowered constituents, has been at least a minimally adequate steward of Cape Verde's rudder, whereas Glissant notes “the absence of responsible leadership" in Martinique (xliv). Not having natural resources besides the sea and sunshine has ironically helped Cape Verde to avert much of the sorts of corruption associated with other mineral-rich African nations. What has likely further helped Cape Verde has been its relative isolation as an archipelago, and its inclusion of diasporic Cape Verdeans in its government. As Lobban informs us, "there are representatives in the Cape Verdean Peoples National Assembly for diasporic Crioulos" (59).

In his text, speaking like a Cape Verdean might, Glissant repeatedly demonstrates his preference for diversity over sameness. Glissant stands "in defiance of a...reductive humanism" (133). But for Glissant, difference should not be ignored or erased. The scream of a people must be made "into a speech that grows from it" (133). Glissant 
believes this scream to be "the memories of cultural contact, which are put together collectively by a people before being dispersed by colonization" (135). Because there was no pre-colonial people or pre-colonial language on Cape Verde before its colonization, Cape Verdean Kriolu, despite its birth within the context of colonization, represents a quasi-natural outcome of inter-cultural contact. As Lobban states, "Crioulo, a hybrid language of commerce and multiculturalism, was born of necessity in the first decades of the settler and slave era" (70).

Glissant, like Cape Verdeans are wont to, makes explicit his valuation of creolization over the illusion of purity in genealogy. For Glissant, "the idea of creolization demonstrates that henceforth it is no longer valid to glorify "unique' origins that the race safeguards and prolongs" (140). According to Glissant, "to assert peoples as creolized, that creolization has value, is to deconstruct in this way the category of 'creolized' that is considered as halfway between two 'pure' extremes" (140).

As Glissant sees it, “composite peoples...do not 'need' the idea of Genesis, because they do not need the myth of pure lineage" (141). Glissant further informs us that "the poetics of creolization is the same as a cross-cultural poetics: not linear and not prophetic, but woven from enduring patience and irreducible accretions" (142). Cape Verde represents such a culture of creolization. Lobban notes how "some Mande words linger on in Crioulo" which is primarily Portuguese-dominated (70).

Like it is viewed by Cape Verdeans, the force of creolization in the world is viewed positively by Glissant as a disorienting element in the world, and it leads Glissant to believe that "one day men will perhaps call a halt [to their present dysfunctional ways] 
staggered by the singular wisdom of creolization that will be part of them-and that they will recognize our hesitant clairvoyance" (3). Glissant views hybridity and heterogeneity as instigators of cultural transformation. Lending support to his point of view, Cape Verde, which considers itself to be a culture of hybridity and heterogeneity, may be seen to have achieved the ultimate in humanity through the successful creolization of their culture, whereas it would seem that "West Indians... have achieved the ultimate in subhumanity," (1).

Whereas Glissant refers to the Martinican abdication of a "collective spirit," that which "allows a people to survive as a people," as Lobban's text sees it, the collective spirit of Cape Verdeans has only grown since that people's achievement of their independence (5). According to Glissant, the Martinicans, along with other French Caribbean peoples, were crushed by two elements: one, their belief that they could not survive as independent nations, and two, that their peoples were merely French (5). On the other hand, with regard to Cape Verde, in the last half of the twentieth century, both of those Martinican elements were opposed. Cape Verdeans believed that they could not survive as a dependent people (according to Lobban, droughts, and their consequent famines, had taken the lives of up to forty percent of the population, at times), and that they were not primarily Portuguese, but rather a transcendent hybridized people (62).

Whereas, beginning early in the twentieth century, prior to the time they were on their path to independence, Cape Verdeans came to increasingly embrace their African roots after centuries of seeing themselves as predominantly Portuguese, Martinique represents for Glissant "a people of African descent for whom the word 
African...generally represented an insult" (6). In Cape Verde's case, the process of cultural cross-fertilization of colonized Portuguese was ironically inadvertently encouraged. For example, during the Portuguese fascist Salazar's lengthy period of dictatorship, within university-sponsored organizations for colonial Portuguese attending Portuguese universities on scholarship, essential new encounters between darker-skinned colonial Portuguese speakers arose. One person who benefited from such encounters was the 'father' of Cape Verde, Amilcar Cabral.

According to historical and political scholars, Amilcar Cabral's careful and courageous leadership of the struggle for the independence of Cape Verde and Guinea-Bissau led to the eventual extinction of Portugal's fascist leadership, whereas, for Glissant, "unbelievable cowardice is a characteristic of the French Caribbean elite" (7). Like his contemporary, the Brazilian revolutionary educational philosopher, Paolo Freire, Glissant notes the intrusion of the colonizer's knowledge that "spreads, without being related to an autonomous process of acquiring appropriate techniques...[and] the entire subjugated community consents passively to surrender itself, its potential development, its real culture" (11-12). The result of such a profound difference is that "Martinicans lead an agitated existence" whereas Cape Verdeans appear to generally live with inner peace (9). It seems here that the relative general neglect Cape Verde received due to Portugal's considerable economic poverty as compared to the abuse which Martinique received from France, a much wealthier European colonizer, militated against Cape Verde succumbing to a similarly tragic outcome as Martinique has, where, according to Glissant, "dispossession is likely to be terminal" (12). 
While Martinique is a country "where illusion has constantly been stronger than reality," life in the Cape Verde Islands, especially prior to Cape Verdean independence, was too brutal to be ignored (12). For example, Lobban informs us that "at independence in 1975, the Cape Verdean life expectancy for males was only 48.3 years; for females, it was just 51.7 years" (48). Whereas present-day Martinique appears to be a consumer-based nation, and Martinicans, according to Glissant, are deluded into complacency by the superficial elements of "social and economic progress," independent Cape Verde is a rather poor second- world nation whose defining element is not its acquisitiveness but rather its informal social support networks (12). Cape Verde has not yet succumbed to consumerism, and hopefully, perhaps, never shall.

Referring to the historical fact of slavery in Martinique, Glissant notes how "domination...produces the worst kind of change" in that "it introduces...the illusion of successful mimesis" (15). In distinguishing between a culture that survived severe uprooting, maintaining "its original nature" from those that did not, that transformed "elsewhere into another people...[Glissant notes] that the latter has not brought with it, not collectively continued, the methods of existence and survival, both material and spiritual, which it practiced before being uprooted" (15). Glissant identifies the Brazilian exception from the Martinican condition.

I would add that Cape Verde represents a similar exception from that Martinican condition. African ways were not wholly lost by the Africans who were transplanted to Cape Verde, and especially for some Africans transplanted to Cape Verde (the Badius) those African ways were very well maintained. On Cape Verde, according to Lobban, 
"some African beliefs relating to animism still survive, such as the notions of spirit possession and the evil eye" (70). Furthermore, Lobban describes a Cape Verde where there has never been an absence of "human porterage (which) is unquestionably African in origin, as is the use of the heavy wooden pilão ('mortar and pestle') for grinding corn and husking rice" (70).

Glissant speaks of the tendencies of reversion and diversion in transplanted populations. For Glissant, "reversion is the obsession with a single origin" (16). According to Glissant, in Martinique, "the community has tried to exorcise the impossibility of return by...the practice of diversion" (18). For Glissant, "diversion is the ultimate resort of a population whose domination by an Other is concealed" (20). As I see it, Cape Verde, despite its population entirely reflecting transplanted populations, has not suffered significantly from such tendencies toward reversion and diversion.

In Cape Verde, Kriolu has been the language of non-elite productivity and responsibility. Furthermore, in Cape Verde only formal encounters have been situated within the colonizer's language. In Martinique, according to Glissant, Creole has not been the language of productivity and responsibility, and so it has mutated into a caricature of itself (21).

It is often not until a Martinican moves to France that he or she first discovers their Caribbeanness that is not merely French in nature (23). For Glissant, the fact that one must look for one's Caribbeanness "elsewhere" represents a sign that Martinicans are kept in the dark about their alienation (23). That is why, for Glissant, "Martinique is the land of ghosts" (23). 
Negritude, the universal identification with black suffering, is, for Glissant, another example of diversion (24). He sees it as a diversion because it pacifies the population rather than empowering it towards the process of decolonization. Martinique has surely suffered from the fact that "many popular revolts [there]... have not resulted in radical changes" (30). Yet Martinique has suffered even more so because those popular revolts have not been heroically mythologized. On the other hand, Cape Verde has mythologized its popular revolts, and, also, more importantly, Cape Verde succeeded in its fight for independence under Amilcar Cabral's sage leadership.

For Glissant, "no community would tolerate the notion of "dispossession"” (37). Yet Glissant recognizes how the dispossession in Martinique "is camouflaged and no one is aware of its corrosive presence" (38). This dispossession is furthered by the fact that "there is no Martinican economy in the real sense" (41). Finally, the French, who, not so curiously, perhaps, were the inventors of mime, inflict a "pressure to imitate [that] is, perhaps, the most extreme form of violence that anyone can inflict on a people" (46). The Portuguese consistently took a generally laissez-faire attitude (essential neglect) towards their Cape Verdean colony, resulting in the fact that Cape Verdeans by the early twentieth century, or even sooner, averted being mired in placid delusions that they were merely Portuguese. In fact, Lobban informs us that "from the late 1930s came...a wealth of essays on Crioulo culture and language" (79).

For Glissant, domination has been completed 'successfully' when there is 'a consumer society with no real production" (49). In Martinique, for example, economic decisions as to what to produce there are made in direct reference not to the needs of 
Martinicans but instead to the needs of France. In Cape Verde, despite recent neo-colonial intrusions, especially with regards to tourism, economic decisions are still primarily made in accord with what is best for Cape Verde.

Cape Verde, as an independent nation, has not been converted into a banana republic as Martinique has been. Glissant notes how the landscape of Martinique has been drastically, perhaps irrevocably, altered by colonialism and neo-colonialism. Whereas there used to be an idiosyncratically Martinican fragrance to the land, "all these flowers have disappeared or almost," and "the land has lost its smells" (52).

Glissant tells us that "the flowers that grow today [in Martinique] are cultivated for export" (52). Glissant notes that "these [new] flowers delight us. But they have no fragrance" (52). The Cape Verdean landscape has been ravaged by colonialism, but because Cape Verde has possessed so little arable land it has not been as plundered and wasted as Martinique has been.

While Glissant notes that "Martinicans are charming by profession," it would rather seem to be the charm of the obsessively neurotic charmer rather than the natural charm suggested by Cape Verdean morabeza [warmth] (53). In a short vignette, Glissant depicts the profound racial disparity inherent in Martinican life. At a primary school, "a tramp pleasantly but unexpectedly appears in one of the classes. He is dirty, untidy, perhaps drunk. But he is white. A little girl gets up and instinctively informs the teacher: 'Miss, the School Inspector'” (58-59). Such a story could not likely emerge in Cape Verde, where persons of dark complexion, while still moderately under-represented in positions of high-status, have long held numerous significant positions of power for 
decades, even for many years preceding Cape Verdean independence. Lobban tells us that "any effort to impose an American, South African, or European model of racial hierarchy onto Cape Verdean society will surely fail” (51).

For Glissant, "the creative link between nature and culture is vital to the formation of a community" (63). Further, for Glissant, "nature and culture have not formed a dialectical whole that informs people's consciousness" in Martinique" (63). To assist in the formation of such a creative link, Glissant aims to remove from historians the sole responsibility for an articulation of a history. For him, history is "consciousness at work and...lived experience" (65). In Cape Verde, nature and culture have formed a dialectical whole. For example, Lobban speaks of "the traditional forms of African weaving on a narrow band loom [that] carry forward in the cloth panos that are still made as a national handicraft" in Cape Verde (70).

Glissant proposes "a daring new methodology, where it responds to the needs of our situation" (65). Significantly, Glissant notes that despite the fact of "our diverse histories in the Caribbean... [one can witness] their subterranean convergence" (66). Thus, "the implosion of Caribbean history...relieves us of the linear, hierarchical mission of a single History that would run its unique course" (66). In Cape Verde, it is perhaps primarily the roots musicians and the poets, not the historians, who possess the primary responsibility to elaborate the people's history.

Cape Verdeans generally possess tremendous pride over their heritage, and have tremendous self-confidence as a people. Even at the end of the colonial period, under the weight of Portuguese fascism, Cape Verdean culture progressed. As Glissant sees it, "a 
self-confident people has the ability to transform into a mythical victory what may have been a real defeat" (68). For Glissant, "the problem is...the suppression of the specific nature of the Martinican people" (68). Martinicanness has been relentlessly subdued.

Glissant proffers that 'the Martinican elite can see 'power' only in the shape of the female thigh" (73). This suggestion implies a dichotomy of the sexes for the Martinican elite, with women objectified, and elite men implicitly pathologized. In Cape Verde, gender roles surely exist, even within the elite strata, but not to the misogynistic degree that they appear to be present in Martinique. According to Lobban, sexism towards women in Cape Verde is visible in "informal polygyny" (83).

Glissant highly esteems national literature. For Glissant, national literature is "the urge for each group to assert itself" (99). Glissant speaks of how literary work "has a hallowing purpose in reuniting the community around its myths, its beliefs, its imagination, or its ideology" (100).

For Glissant, a national literature "must express...the relationship of one culture to another in the spirit of Diversity" (101). Furthermore, for Glissant, "critical thought [expressed through national literature] can demystify a social order" (103). In Cape Verde, it may be that roots music and poetry serve as the national literature. Lobban notes how, "to a remarkable degree, the [Cape Verdean] struggle for "national liberation was expressed in the metaphors of poetry" (78).

Glissant is interested in the development of a national literature for the Caribbean, especially for Martinique. For Glissant, "a national literature emerges when a community whose collective existence is called into question tries to put together the reasons for its 
existence" (104). In a footnote, Glissant identifies that neither poetry nor the novel have a natural history in the Caribbean (106). For Glissant, to create a national literature "what is needed is a consensus that is created either by a common activity or by a struggle conducted by everyone" (112). Cape Verde has had such a revolutionary struggle, and its national literature (taken broadly as its roots music and poetry) attests to this fact.

Glissant studies a range of forms for cultural productions. In his study of music, Glissant identifies that "you must do things in your country in order to sing about it" (112). Glissant compares drumming techniques used in Africa with those utilized in the Caribbean. He has "been struck by the difference" (112).

According to Glissant, "in Africa, the drum is a language that becomes structured speech" (112). On the other hand, in the Caribbean the drum "is more often isolated or used for accompaniment" (113). In Cape Verde's roots music, many of the drumming techniques appear to be primarily or essentially African.

At different points, Glissant comments on Black America's way of being in the world. He feels "it [Black America] has achieved the only true freedom: based on which, acceptance does not mean alienation" (113). In contrasting this with Martinique, Glissant suggests that in Martinique "we see that people have black, skins, but as for the inside, that is another matter" (114).

Later on, again embracing Black America, Glissant notes how he "was so moved when... [he] discovered the rhetorical power of black American speech" (140). For Glissant, the repetition in such "speech is a response to the group" (140). Perhaps because of what Black America has had to accomplish, given that Césaire sees the United States 
of America as the most potentially dangerous oppressor, Glissant has located a sub-altern group in the U.S.A. (Black Americans) as a source of inspiration for oppressed peoples everywhere.

Glissant values a natural as opposed to a forced poetics. For Glissant, "a free or natural poetics is any collective yearning for expression that is not opposed to itself either at the level of what it wishes to express or at the level of the language that it puts into practice" (120). As Glissant sees it, and celebrates it, "the most violent challenge to an established order can emerge from a natural poetics when there is a continuity between the challenged order and the disorder that negates it" (120).

Glissant believes that honesty, authenticity, is the most compelling attribute. Cape Verde is predicated on honesty and authenticity. One sign of that honesty and diversity which Lobban notes is that "the Cape Verde archipelago is remarkably complex and diverse" (47).

Glissant distinguishes orality, which he sees as something natural, from writing, which he views as something that is unnatural. Glissant identifies how Creole, primarily an oral language, is connected to "the movement of the body" (122). Yet while writing disables the body in its capacity for movement, in a footnote Glissant understands that "the freedom to write is necessary for the Creole language" (122).

Cape Verdean Kriolu, while primarily an oral language, has recently become officially standardized as a written language. While writing Kriolu may be significantly more limiting in some ways than speaking Kriolu, Cape Verdeans do not want for authenticity the way Martinicans appear to. Furthermore, there are other authentic things 
that written language can better support than oral language is able to, such as certain forms of poetry.

Glissant paints African literature as being part of an oral culture. For Glissant "in the poetics of the oral African text everything can be said" (137). He sees Martinique as struggling with the dichotomy of the written and the oral. Because Cape Verdean Kriolu has primarily been historically represented by means of a thriving oral culture, it has not had a significant struggle addressing the dichotomy of the written and the oral.

Glissant carefully studies the phenomenology of history. In reviewing the history of slavery, Glissant points out how for the slave "all pleasure is silent: that is thwarted, deformed, denied" (122-123). According to Glissant, Caribbean speech is compromised by this history of disturbed relationship between persons and linguistic self-expression (123). For Glissant, therefore, there is no inner peace for the Caribbean. Despite his profound misgivings regarding Martinican speech, Glissant, nonetheless, does see that, "in the pace of Creole speech, one can locate the embryonic rhythm of the drum" (124). Perhaps because of a relative absence of plantation slavery, despite a history of extensive slavery on the Cape Verde Islands, Cape Verdean speech does not appear to have a similarly disturbed relationship between persons and their linguistic self-expression.

Glissant provides profound analysis of Martinican folktales. Glissant notes how the Creole folktale "excludes the potential for consecration" (129). Glissant points to the "emptiness of the landscapes in the Creole folktale" (129). If a "place is indicated, it is never described" (130).

There is "nothing like a sustained relationship" with nature or people in Martinican 
folktales (131). There is "no reference to daily techniques of work or creation" (131). There is no time for rest or for contemplative wonder in Martinican folktales.

For Glissant, Martinique is therefore not presently a country; it is just some "place you pass through" (130). Cape Verdean folktales appear to be quite the opposite, replete with what makes life vital. Lobban refers to the fact that since Cape Verdean independence, "Cape Verdean folklore has also been substantially expanded, with the oral tradition of the Nho Lobo (Mr. 'Clever' Wolf) folktales now being reevaluated and closely studied" (81).

Glissant has his personal preferences, or what the reader might call his commitments. Contrasting non-Western culture with Western culture, Glissant suggests that while the West has embraced individual private property, "intense feeling for the dignity of the group...appears to be characteristic of many non-Western civilizations" (137). Glissant suggests that "indivisibility of the land-dignity of the community-the explicitness of song" be held in higher esteem than private individual property (137). Glissant articulates a socialist manifesto. The nation of Cape Verde has embraced a socialist manifesto, at least in spirit, in its Second Constitution.

Glissant further notes how "it is difficult to separate theoretically the notion of individual dignity from the oppressive reality of private property" (138). Glissant compellingly suggests that the Western philosophical "aim for a generalizing universality" is premised on this unexamined embrace of the individual over the group (138). According to the dictates of its Second Constitution, Cape Verde appears to be at least as much a communal culture as an individualistic one. 
Glissant demonstrates that he is highly concerned about continuities and discontinuities in cultures that have a colonial history, and about how those continuities and discontinuities are represented in literary productions. Glissant notes the fact that the American literary tradition did not evolve naturally and, thereby, gracefully; rather "ours was a brutal emergence" (146). Glissant believes further that, in contradistinction to Europe and the Northern United States, there is a "tortured relationship between writing and orality" in the Americas (147). In Cape Verde, there does not appear to be that similar tension. This may be due to the fact that, as Lobban notes, "historically, Cape Verdeans had been both slaves and slavers; consequently, they were both victims and victimizers in the colonial structure" (58).

Glissant aims to articulate the crucial postcolonial challenges a people faces. As his ultimate concern, Glissant sees the challenge for persons today as the capacity "to live the relative after having suffered the absolute" (147). By the "relative... [Glissant means] the Diverse, the obscure need to accept the other's difference" (147-148). Glissant exhorts people to eschew their proclivities toward segregation, to see beyond aspects of superficial difference to elements of essential similarity and unity.

In considering Glissant's foundational work in cultural identity, the reader can recognize that certain particular historical factors or elements for a people are correlated to a positive cultural identity for nations with an African colonial heritage. These elements may be grouped together into categories in order to be more adequately appreciated. These elements are: shared cultural heritage, national independence, artistic liberation, constructive power relations within the culture, responsible and effective 
national leadership, the possession of an accurate perspective that colonial oppression was not as bad as it otherwise might have been, and successful creolization/hybridization and cross-fertilization.

If one looks at the positive element of a shared cultural heritage, it includes a shared sense of history, a sense of cultural identity, avoiding reversion and diversion, the flourishing of folk culture and language, a realistic or exaggerated view of their people's own significance, and a sense of connection to the homeland. If one examines the positive factor of national independence from the colonial oppressor, it entails successful individuation from the former colonial oppressor along with the respective Creole language as a cultural source of responsibility and productivity. This will imply whether emigration is essentially destructive or constructive for the nation, whether a nation can successfully avert artificial affluence and a consumer culture through self-sustaining productivity, and whether a nation can encompass a shared sense of an ideal destiny for their people.

If one considers the positive element of artistic liberation, the reader notes that it includes three aspects. The first of these aspects depends on a shared cultural heritage along with cultural pride and self-confidence. This shared cultural heritage manifests itself through the arts' simultaneous embrace of cultural roots and musical evolution.

The second aspect of artistic liberation requires the development of a national literature reflecting, in part, the making and celebrating of myths drawn out of popular revolts. This includes an acknowledgment of cultural continuities and discontinuities. A third aspect of artistic liberation is its authenticity. This includes such things as musical 
techniques of drumming that do not peripheralize the drum, a natural poetics, a creative link between nature and culture, the importance of orality, along with time for rest and contemplative wonder in a culture's artistic productions.

If one views the positive element of constructive power relations within the culture, the reader may primarily and especially note this element as it is made manifest through verbal and non-verbal communication within that culture. For example, one would perceive a relative absence of racism, including one of its subtler effects, negritude. Additionally, one would notice an absence of complacency and illusion in the culture. Furthermore, power relations within the language would be disabled, there would be an undisturbed relationship between persons and linguistic self-expression, and there would be an absence of a dominant misogynistic dynamic in the culture's elites, suggesting successful resolution of the implications of a cultural history of slavery. As well, one would recognize authentic warmth, a valuation of diversity over sameness, and the valuation of community, especially communal land, over individual property.

If one considers the positive element of responsible and effective national leadership, this would include the absence of extensive corruption, a courageous elite, economic decisions reflecting national interest, and the maintenance of the original landscape, including its flora and fauna. If one attends to the positive element of a historically accurate perspective of a relatively less oppressive colonial oppressor than might have otherwise been the case, one would perceive a relatively laissez-faire attitude of the colonizer toward the colonized during the colonial period, and perhaps, too, a construct of positive colonial origination. If one appreciates a final element that correlates 
to positive cultural identity, it is that of the successful creolization/hybridization and cross-fertilization within that culture. Cape Verde appears to possess to at least a significant degree all of the positive elements for a people which are correlated by Glissant to a positive cultural identity for nations with an African colonial heritage. 


\title{
Chapter Three: Social-Scientific Perspectives on Cape Verdean Identity
}

\author{
$\underline{\text { Introduction }}$
}

Cape Verdean cultural identity is, in part, a product of its heritage of nationalism, colonialism, and racism, matters that have just been under consideration in the previous chapter. Because nationalism, colonialism, and racism have played themselves out in idiosyncratic ways in Cape Verde, making Cape Verde a unique transnational, postcolonial, and post-racial culture, particular scrutiny of the social-scientific literature on colonial and postcolonial Cape Verdean identity can inform the reader as to how Cape Verdeanness has taken shape and evolved over the years.

For example, Mai Palmberg, in “Expressing Cape Verde: Morna, Funaná and National Identity," tells us that Cape Verdean cultural identity was first consciously embraced as a construct in the 1930s, in Mindelo, São Vicente, by a group of writers, mostly poets, who were engaged with a new literary review known as Claridade (124). If true, that implies that the construct known as Cape Verdean cultural identity is barely eighty years old! This chapter will focus on the nature of postcolonial Cape Verdean cultural identity as seen through the eyes of a variety of social scientists. It aims to identify and gather together the elements of postcolonial Cape Verdean cultural identity which have been articulated in a range of social sciences in order to suggest the attributes of this cultural identity, which may be referred to as Cape Verdeanness. Then these elements of postcolonial Cape Verdeanness will be juxtaposed against those that emerge from the study of postcolonial Cape Verdean poetry. 


\section{$\underline{\text { The Social-Science Literature on Cape Verdean Cultural Identity }}$}

Especially since the 1970s, there has been a large body of social-scientific work on the subject of Cape Verdean cultural identity. This suggests that the history of Cape Verdean cultural identity has interested more than a few social-science scholars. Furthermore, it hints at the fact that Cape Verdean cultural identity may diverge significantly from traditional understandings of cultural identity.

One such difference, identified by Pedro Góis, is the fact that Cape Verdean cultural identity has been historically transnational in nature. A concrete aspect of this Cape Verdean transnational identity is the permission granted by a number of nations, including those in the European Union and the United States, for Cape Verdean dual citizenship. Another concrete aspect of Cape Verdean transnational identity is the recognition and rights statutorily enumerated for diasporic Cape Verdeans by the Cape Verdean Constitution.

Góis has further suggested that Cape Verdeans are made up of two primary cultural groups. One group is those who were born in the archipelago of Cape Verde and the other group is made up of those who were born in the Cape Verdean diaspora. According to Góis, Cape Verdean cultural identity is always in dynamic flux, and, crucially, since it is constantly being re-created, it is all but impossible to describe. For Góis, therefore, all one can legitimately do is somewhat superficially distinguish native-born Cape Verdeans from those of a diasporic origin.

Yet Cape Verdean cultural identity appears to be a contested construct. Other social scientists, including Gina Sánchez Gibau, Isabel P. B. Fêo Rodrigues, Dawna M. 
Thomas, Mai Palmberg, and Katherine E. Carter \& Judy Aulette suggest that Cape Verdean cultural identity can, indeed, be described as it appears in a particular time and place, and that this can be done without necessarily essentializing Cape Verdean identity. Going perhaps further, Gina Sánchez Gibau, in her study of Boston, Massachusetts, Cape Verdeans, has located a root attribute of Cape Verdean diasporic identity formation. In "Contested Identities: Narratives of Race and Ethnicity in the Cape Verdean Diaspora," she suggests that it "is constructed out of processes of negotiation and contestation" (405). Interestingly, "Boston is said to be the biggest Cape Verdean city in the world" (Palmberg, 130). That is only so if "Boston" means the larger Boston Metropolitan Area, which extends through Brockton to Providence, New Bedford, and Onset.

Gina Sánchez Gibau calls out America’s issues with race. In part, Sánchez Gibau bases her construct of the root diasporic attribute of Cape Verdean identity on her understanding of the "dilemma of negotiating identification within a racialized society" (406). Sánchez Gibau sees identity as, at least in part, self-constructed. For example, for Cape Verdeans in Boston, “'Black' is understood as a racial identity, not to be confused with the term 'Black American', which connotes a distinct, cultural group” (423). For Boston Cape Verdeans, possession of a dark skin color and/or other Afro-centric factors of appearance do not establish membership in Black American culture. Yet, simultaneously, pushing the envelope on the self-construction of identity, this non-African-American construction of blackness for diasporic Cape Verdeans further includes "the reinvention of the islands [of Cape Verde] as culturally, politically, and geographically tied to the African continent" (429). Previously, the islands have been 
imagined as set somewhere in between Europe, Africa, and the New World.

For Sánchez Gibau, diaspora is “a 'process' through which individuals and groups forge new, shifting identities out of multiple loyalties to various 'home' and 'host' locales” (406). In particular, Sánchez Gibau sees identity construction as influenced by one's immediate surroundings. To that effect, "Cape Verdeans...construct their identities in relation to how their neighbors perceive them as well as how they wish to be distinguishable from these neighbors" ( 413). Thereby, Sánchez Gibau shows us just how identity formation is a process that is neither very passive nor unconscious.

Since Cape Verdean independence, in 1975, according to Sánchez Gibau, "whole new communities emerged in the cities of Providence, Pawtucket, Brockton, New Bedford, and Boston that were qualitatively different from the earlier generations of Cape Verdeans living in these locales" (409-10). These new immigrants "were raised with the pride of having a distinct Cape Verdean heritage" (410). Earlier arrivals from Cape Verde were more often than not less Cape Verdean-identified and more Portuguese-identified than Cape Verdean immigrants to the U.S.A. since Cape Verdean independence.

According to Sánchez Gibau, speaking Kriolu, the Cape Verdean language, is viewed by post-independence Cape Verdean American immigrants as a primary marker of Cape Verdean cultural identity (418). For post-independence Cape Verdean immigrants, "the assumption was that Cape Verdean Americans were lost souls whose fundamental elements of Cape Verdean-ness (e.g. language) had been washed away by the waves of Americanization" (416). Yet Sánchez Gibau stipulates that "today, there exist multiple generations of Cape Verdean Americans... who do not speak Kriolu" (409). 
This includes the children of Cape Verdeans who arrived in the U.S.A. prior to Cape Verdean independence and the children of Cape Verdeans who left Cape Verde as children after Cape Verdean independence.

In addressing this duality with regards to diasporic Cape Verdean cultural identity, Sánchez Gibau explains that "the Cape Verdean diaspora of today is immensely complex in composition. It is marked by differences associated with generation, migration history, language, culture, and social class status" (410). These differences engender sub-groupings of Cape Verdeans based on the use of Kriolu, relevant cultural practices, and the nature of the relationship with the islands of Cape Verde (Sánchez Gibau, 410).

According to Sánchez Gibau, in considering Cape Verdean Americans in the particular locale of Boston, Massachusetts in the 1960s and 1970s, there was "a climate where racial ambiguity was not tolerated" (425). This fact complicated diasporic Boston Cape Verdean cultural identity formation. It resulted in many Cape Verdeans thereby integrating themselves into the local African-American community "as a means of social survival in a racialized environment" (426). This is one amongst many signifiers which suggest to Sánchez Gibau that "the politics of Cape Verdean identification, therefore, is one of resistance" (431). This includes the enactment of situational identities on an as-needed basis (Sánchez Gibau, 433).

Significant differences within the Cape Verdean American community have emerged, in part, because there were over thirty years that transpired in the twentieth century under U.S. immigration legislation that restricted Cape Verdean migration to the United States (Sánchez Gibau, 418). The result of the differences within the Cape 
Verdean community can be witnessed in the mutual avoidance practiced by the two primary diasporic Cape Verdean groups: Cape Verdean immigrants since independence (and their progeny), and Cape Verdean immigrants prior to independence (and their progeny), according to Sánchez Gibau (418). This causes “animosity, resentment, and misunderstanding” (Sánchez Gibau, 418).

Like Sánchez Gibau, Thomas notes the "Cape Verdeans' interrupted migration history to the US", and its implication that there are two groups of Cape Verdean Americans, those who arrived prior to independence and those who have come since (180). Thomas also shares with Sánchez Gibau an understanding that "how Cape Verdeans racially and culturally identify themselves is complex; it blurs the boundaries established between race and ethnicity in American society" (180). Darker-skinned Cape Verdeans, as well as lighter-skinned Cape Verdeans, confound many white Americans' simple-minded linkages of race to ethnicity.

In distinction to Sánchez Gibau, who focuses on central elements of Cape Verdean American cultural identity accrued from her field research, in "Culture and Disability: A Cape Verdean Perspective," Thomas describes her own impressions of Cape Verdean American cultural proclivities without informing us as to the basis for those viewpoints. This may be because her work is aimed at an audience seeking basic relevant information about a relatively little understood cultural group. Thomas' work would therefore best be considered to be secondary research, not primary research.

Thomas portrays Cape Verdean culture as a time-honored culture. She describes how "Cape Verdean American family life is centered within deep traditional values that 
include blood relatives, extended community members, and for many close connections to Cape Verde" (181). Furthermore, "there is also a strict code of conduct dictating that children are expected to respect and obey all adults, elders, and those of authority in the community" (181). The impact of family separation due to migration is also viewed as a central element to Cape Verdean community life, one which is seen as a source of emotional distress and depression (181). Women gain an enhanced social power from the absence of men, yet this does not militate against the fact that Cape Verdean culture is essentially patriarchal (181).

Thomas tells us that "Cape Verdean family life often has strong ties to the church and religious beliefs" (181). Supporting that cultural dynamic is the fact that the overwhelming majority of Cape Verdeans religiously identify as Catholics. Yet in my own experience of Cape Verdean culture, over the past six years, regular church attendance and other religious practices seem less important to Cape Verdeans than a general spiritual world-view.

This spiritual world-view shows itself in the Cape Verdean response to illness, in the form of a belief that such conditions reflect God's will. Yet Cape Verdean families tend to view psychiatric disability as mysterious whereas physical disabilities are perceived as remediable (181). Significantly, there is "a sentiment of embarrassment associated with mental illness and depression. The perception is that one should 'cheer up"' (181). The morna (the melancholy traditional music of Cape Verde) may be one of the few acceptable outlets in Cape Verdean culture for depression, and through its invocation of shared sadness it may serve an anti-depressant function in Cape Verdean 
culture.

Looking further at the response to disability, Thomas notes the construct of gender operating in Cape Verdean culture. Thomas states that "gender roles are an important factor in understanding the social stigma of disability and how it impacts the social status of males and females" (182). For example, Cape Verdean men are expected to provide for their families. Therefore, “if a disability impedes a Cape Verdean man's ability to fulfill" this role, it will stigmatize him, whereas a woman with disabilities will not be generally stigmatized because she will be taken care of by her husband and/or family (182). This is a traditional patriarchal aspect of Cape Verdean culture that tends to benefit females.

Thomas contrasts Cape Verdean American culture from mainstream American culture. These cultural differences include the "collective orientation" of Cape Verdean Americans and their tendency towards "private, indirect, guarded communication" (183). Furthermore, many Cape Verdean Americans utilize lay healers and shamans within their culture to address health crises, who may employ herbs and prayer to treat their Cape Verdean patients (184). A potential implication for the cultural identity of Cape Verdean Americans is that they are non-conformists with regards to the larger culture but extremely conformist within their own community.

The work of Katherine E. Carter and Judy Aulette, in "Creole in Cape Verde: Language, Identity and Power,” is a challenge to Sánchez Gibau's ambivalence regarding consideration of Kriolu as a sign of Cape Verdean cultural identity. Carter and Aulette speak of Creole (Kriolu) as the marker of Cape Verdean cultural identity both within and 
outside of the islands (214). As Carter and Aulette see it, "the imagery used in the [Kriolu] mornas and other forms of poetry was the way Cape Verdeans preserved their ethnic consciousness during the years of [Portuguese] repression” (218). For Carter and Aulette, then, Kriolu has carried the Cape Verdean soul.

Carter and Aulette identify other markers of Cape Verdean cultural identity. For example, a salient aspect of cultural identity is that of the normative lifestyle. According to Carter and Aulette, "the streets in Cape Verde are filled with people talking, walking, and playing" (218). Significantly, however, it is primarily women and children, and especially persons of lower status, who are found on the streets of Cape Verde; this is because men have left in large numbers to find work overseas, and the wealthy remain in their enclaves (218).

The way that language is used by lower-status women in Carter and Aulette's study also exposes a significant aspect of Cape Verdean identity. For low socio-economic status women, humor and irony offer a valuable means for communication (231). By lower-status women using humor and irony, they allow men to save face (231). This suggests something crucial about gender relations in Cape Verde. One witnesses a Cape Verdean construction of gender relations whereby men of any stature are not to be shamed by lower status women. Such women must express their dissatisfactions with men indirectly.

Attentive even more so to the dynamics of gender relations, Isabel P. B. Fêo Rodrigues is especially attuned to aspects of cultural identity where the implicit is concealed by the explicit, particularly as that pertains to the specific silences around the 
history of poverty and gender relations in Cape Verdean culture. In "Our Ancestors Came from Many Bloods: Gendered Narrations of a Hybrid Nation," Fêo Rodrigues tells us, for example, that "the incorporation of transnational genealogies is a significant part of Cape Verdean culture and history recounted in multiple genres, in written as well as in oral narratives" (218). As Fêo Rodrigues sees it, it is these hybrid genealogies that have been the most evident element of Cape Verdean cultural identity (218).

Mai Palmberg, as well, suggests that Cape Verde's “identity is based on difference" (129). Yet Fêo Rodrigues restores a voice to what has been silenced in this traditional privileging of the explicit. For example, the construct of hybridity is also seen by Fêo Rodrigues to somewhat ingenuously "stress the normalcy of mixture and the legitimacy of doubleness" (221). Furthermore, for Fêo Rodrigues, "this focus on fusion instead of tensions portrays a Cape Verde where the creolization process became unproblematic as if a natural outcome of racial mixture" (225). Fêo Rodrigues figuratively looks under the rug and, in so doing, turns the tables upside down on particular prevailing postulates regarding Cape Verdean cultural identity.

Fêo Rodrigues suggests that one silence in the Cape Verdean culture, hidden by the quasi-mythical construct of hybridity, conceals "the multiple...material challenges faced by this young post-colonial nation-state" (219). For example, Carter and Aulette note "many homes [in Cape Verde] whose walls were made of cardboard or stuffed with plastic bags or families that lived on the other side of a public dump" (221). For Fêo Rodrigues, serene images of Cape Verde paper over the facts of poverty, hunger, and social inequality (219). Local narratives of Cape Verde continue to cloak the dark side of 
life on the islands.

Fêo Rodrigues suggests that at least part of why these narratives of hybridity have been embraced by Cape Verdeans is because they successfully mask the central element in the genesis of hybridity, which is a pattern of gender relations that demonstrate "continuities between the colonial past and the postcolonial present" (219). One must not forget that for the majority of its recorded history, Cape Verde has been the site of race-based slavery. During the period of race-based slavery, there were always many more Portuguese men than Portuguese women on the Cape Verde Islands. That fact matters significantly as pertains to the history of sexual relations on the Cape Verde Islands.

Hybridity on Cape Verde, especially in the first four hundred years of its five hundred year colonial history, more often than not arose from sexual relations between persons significantly unequal in multiple elements of power. Fêo Rodrigues reminds us that "we cannot lose sight of the social tensions inherent to any process of domination and reproduction through the subjugated enslaved female population" (224). Slave women were hardly in an empowered position to refuse Portuguese male sexual advances.

Through conciliatory narratives of hybridity, "the lines between colonized and colonizer are blurred in intimate histories of likely and unlikely fusion" (220). Portuguese males took advantage of their privileged status with African female slaves to instigate a culture of hybridity. For Fêo Rodrigues, "kinship remains the most unquestioned mechanism of this Creole genesis and the most seemingly apolitical" (231). Yet Fêo 
Rodrigues also understands the reasons behind this Cape Verdean narrative's success.

Fêo Rodrigues notes how “Cape Verdean notions of creolization do challenge the permeability of the [otherwise rigid] dichotomies between colonizer and colonized, white and black, and Europe versus Africa' (221). Whereas other African cultural identities have been primarily forged out of independence struggles, or relatively homogeneous pre-colonial histories, Cape Verdean hybridity as cultural identity pre-existed national independence (221). This suggests that hybridity may have worked as an unwitting anti-colonial practice.

Fêo Rodrigues suggests that it is not, then, the fact of Cape Verdean hybridity that makes Cape Verde an exceptional African state. Rather, it is the narratives of hybridity that distinctively mark the culture (222). As Fêo Rodrigues sees it, "hybrid ancestries in a context of social stratification and profound tensions between past and present, remain a source of plasticity and cohesion" (222).

Another explicit central element of Cape Verdean identity is seen by Fêo Rodrigues to be the de-peripheralization of the Islands. Cape Verde is placed at the center of narratives of mixed genealogy (227). Part of this theme of Cape Verdean centrality renders the indeterminability of the origins of ancestors into a source of pride (228).

Cape Verdeans take great pride in their most accomplished brethren. Mai Palmberg begins her inquiry into Cape Verdean cultural identity by citing Manuel Veiga, a renowned Cape Verdean (a linguist by training, who has been The Minister of Culture of Cape Verde and has been the premier proponent of Kriolu's officialization and standardization), who has suggested that "Cape Verdean identity rests on three 
pillars...the sea, maize, and music" (117). To Palmberg, "Cape Verde is...a very homogeneous society with many shared identity markers" (129). Palmberg, implicitly agreeing with Carter and Aulette, states further that "Kriolu is an identity glue, and most Cape Verdeans are Catholics" (129). For the Cape Verdean people, according to Palmberg, "the use of Kriolu in the lyrics for the music became a source of pride and cultural assertion" (129).

Palmberg describes cultural identity within the familiar terms of Stuart Hall. Specifically, she describes Hall's perspective that one way of conceptualizing cultural identity consists in the appreciation of a shared culture (118). Another way Hall is seen to conceive of cultural identity by Palmberg is in terms of the way history has idiosyncratically intersected with a people (118). In this latter sense, cultural identity is ever fluid (118). Hall and Palmberg both advocate the integration of these two means of conceptualizing cultural identity. That is, for Palmberg, "identities are the ways we position ourselves within the narratives of the past" (118).

Palmberg suggests a historical reality that implicitly contests Fêo Rodrigues' choice to situate Cape Verdean centrality as an act of quasi-mythicality. Palmberg notes how shortly after the first Portuguese settlers arrived in Cape Verde, the Islands "became a relay station at the cross-roads of the slave trade" (118). Further supporting her perspective of Cape Verdean centrality, Palmberg reports how “Cape Verde's location at the cross-roads of many shipping routes open up [the culture] for many different influences" (119). This makes Cape Verdean centrality a contested subject of discourse.

On the other hand, Palmberg's point of view is consonant with the perspective of 
Fêo Rodrigues on the matter of historically oppressive gender relations on the Islands. Palmberg reports about how "the fact that... [engendering hybridity] was based on extremely unequal gender relations has escaped many" (119). Regarding matters of postcolonial gender relations, Palmberg informs us that "whatever else might have changed after independence, single mothers whose husbands or lovers have left the scene, are still a common phenomenon in Cape Verde" (120). Palmberg's work suggests that despite the salve provided by constructs of hybridity many Cape Verdean women and children today bear the scars of postcolonial Cape Verdean family disintegration.

Like Fêo Rodrigues, Palmberg addresses explicit Cape Verdean hybridity, except in Palmberg's case this is primarily performed by recognition of the early fused nature of Cape Verdean musical forms (121). Palmberg warns that in seeking the sources of Cape Verdean culture, "there is a risk that one is looking for the roots but missing the flower" (121). That is, the point of the inquiry may lead one to ignore the beauty and grace of the music that is under consideration. Interestingly enough, the morna, now an iconic Cape Verdean musical form, is said by Palmberg to have arisen only in the early twentieth century (124). For Palmberg, it is the morna that is inscribed with sodade, a term meaning "'longing', 'nostalgia', 'feeling of loss', and a destiny of deprivation” (124).

Further commenting on Cape Verdean music, Palmberg informs us about the significance of 'Cape Verde' to Cape Verdeans. She tells us that "perhaps no other country's popular music contains so many references to the country as do the mornas (and coladeras) of Cape Verde" (124). Looking specifically at Cape Verdean morna music lyrics, Palmberg notes that "probably only the word cretcheu (darling, loved one) 
can compete with 'Cabo Verde' [Cape Verde] in frequency" (124). One may inquire why 'Cape Verde' is so significant to Cape Verdeans. The answer may be that for a diasporic transnational people, one's homeland holds especially great power, and it must be more actively imagined because it is not as inevitably experienced.

In her review of Cape Verdean musical forms, Palmberg determines "that the morna in particular but also the coladera and the new funaná function as icons in the construction" of Cape Verdean identity (130). Palmberg expresses concern over the fact that the morna, with its sodade [sodadi], has become the archetypal "expression of the Cape Verdean soul" (130). She invites us to wonder what it means if a culture's primary sense of itself is associated with sodade [sodadi] (130).

\section{$\underline{\text { Conclusions }}$}

In this chapter, I have endeavored to identify the elements of postcolonial Cape Verdean cultural identity which have been described by various social-scientific scholars. A number of attributes of postcolonial Cape Verdean cultural identity have perhaps been established here. First of all, Góis tells us that what one can truly be sure of regarding Cape Verdean cultural identity is the distinction between native-born Cape Verdeans and those of a diasporic origin. From him we realize that Cape Verdean cultural identity has been historically transnational in nature. Góis may be seen to have overstated the difficulty of articulating Cape Verdean cultural identity.

Sánchez Gibau elucidates a root attribute of Cape Verdean diasporic identity formation that is constructed out of processes of negotiation and contestation. She 
informs us that post-independence Cape Verdean immigrants to the U.S. have been raised with pride in their heritage. Additionally, she states that Kriolu is viewed by post-independence Cape Verdean American immigrants as the primary marker of Cape Verdean cultural identity. Furthermore, one learns from her that Cape Verde has been imaginatively reconstructed as an African country. Finally, in addressing the duality with regards to diasporic Cape Verdean cultural identity, Sánchez Gibau reports on the complexity of today's Cape Verdean diaspora, which is marked by multiple differences, especially related to migration history and the consequent use of Kriolu.

Thomas tells us that Cape Verdean American family life reflects traditional values, and that it may involve close connections to Cape Verde. Furthermore, the reader now knows that Cape Verdean children are expected to defer to the adults around them. Finally, it can be appreciated that many Cape Verdean Americans utilize lay healers and shamans within their culture to address their health concerns.

Carter and Aulette describe how Creole (Kriolu) is the most widespread and clear symbol of Cape Verdean identity. They also show us that there is an active life of play and conversation on the streets of Cape Verde. Yet the reader also now understand that it will be mostly women and children of low-status whom one sees on the streets of Cape Verde because numerous men have left to find work overseas, and the wealthy have other persons doing their bidding for them.

Fêo Rodrigues shows us that Cape Verdean narratives are replete with transnational genealogies. Fêo Rodrigues explains how Cape Verde is placed at the center of narratives of mixed genealogy. Yet Fêo Rodrigues convinces us that the Cape Verdean 
choice to focus on the synergy of hybridity instead of the entropy of dissension has incorrectly suggested that Cape Verde has been a site of pure serenity. Fêo Rodrigues points out that at least part of why these quasi-mythical narratives of hybridity have been embraced by Cape Verdeans is because they successfully mask the central element in the genesis of hybridity, which is the Islands' ongoing history of oppressive gender relations. Yet Fêo Rodrigues encourages us to recognize that the Cape Verdean focus on hybridity has positively functioned to grease its culture's wheels.

From Palmberg, one learns that Kriolu, maize, and the sea are elements of Cape Verdean glue. One comes to understand how all people, and specifically, Cape Verdeans, position themselves within the narratives of the past. The reader witnesses Palmberg's case for a Cape Verdean-centric perspective of history.

You can see that Palmberg implicitly agrees with the perspective of Fêo Rodrigues on the matter of historically oppressive gender relations on the Islands. Regarding matters of postcolonial gender relations, one understands from Palmberg that there is still much work ahead. From Palmberg, one hears that Cape Verdean popular music contains many references to Cape Verde and to cretcheu (darling, loved one). Significantly, one is informed from Palmberg's review of Cape Verdean musical forms that the morna, the coladera, and the new funaná are somewhat iconic elements of Cape Verdean identity. In the end, Palmberg makes us wonder what it means if a culture's primary sense of itself is associated with sodadi.

In summary, then, one aspect of postcolonial Cape Verdean cultural identity is its transnational nature. A second element of this cultural identity is that it is neither 
homogenous nor fixed. Especially in the diaspora, where the majority of Cape Verdeans reside, this cultural identity appears to be built out of continuous negotiation and contestation. Cape Verdeans can be especially distinguished in their cultural identity by whether they or their forbearers have left the Islands, and, if they or their forbearers have left the Islands, if emigration transpired prior to or since Cape Verdean independence.

Those who have resided in Cape Verde since independence maintain extraordinary pride in their native land, have a profound bond with their mother tongue, Kriolu, and possess a sense of territorial connection with Africa. Cape Verdean cultural identity remains strongly influenced by traditional patriarchal values, and by a syncretic spirituality primarily identified with Catholicism. The denial of the Cape Verdean history of oppressive gender relations may at least in part be at the heart of Cape Verdeans' long-standing eager embrace of narratives of hybridity. Yet such narratives of fusion have likely served to engender more harmonious relations in the lives of Cape Verdeans than would have otherwise arisen.

Cape Verdeans tend to place Cape Verde at the center of the action of the past half millennium on this planet. The sea is central to the Cape Verdean ethos, with all that it is has meant for the people of the Cape Verde Islands. The food (especially corn) and the music of Cape Verde, especially the mornas, the coladeras, and the new funaná, hold somewhat iconic status for Cape Verdeans. With its sodadi, we see in Cape Verdean cultural identity an incredibly enduring and endearing melancholy that provides a window into Cape Verdean reality. By reviewing the scholarly literature on postcolonial Cape Verdean poetry, and through an analysis of representative postcolonial Cape 
Verdean poetry, it will be interesting to examine how postcolonial Cape Verdean poetry represents Cape Verdean identity and both follows this social-scientific discourse and noticeably diverges from it. 


\section{Chapter Four: Cape Verdeanness in Postcolonial Cape Verdean Poetry: The Scholars}

\section{$\underline{\text { Introduction }}$}

Social-Scientific perspectives on postcolonial Cape Verdean identity suggest what may be lurking representations of Cape Verdeanness in postcolonial Cape Verdean cultural productions. I now turn to postcolonial Cape Verdean poetry as a means for gleaning elements of explicit and implicit postcolonial Cape Verdeanness. This will involve careful examination of the scholarly literature on postcolonial Cape Verdean poetry as well as an original study of eleven representative selections of this poetry. I will provide an impression of postcolonial Cape Verdeanness by way of locating its signs in postcolonial Cape Verdean poetry.

First, I will articulate the distinct thematic periods in colonial-era Cape Verdean poetry. Then, I will give consideration to the English-language scholarship on postcolonial Cape Verdean poetry. Thereafter, I will carefully analyze eleven representative postcolonial Cape Verdean poems to extract their representations of Cape Verdeanness. Finally, I will compare and contrast my findings from an analysis of postcolonial Cape Verdean poetry with the findings of scholars of postcolonial Cape Verdean poetry.

\section{A Short History of Cape Verdean Poetry}

To my knowledge, there are only four English language publications that involve 
significant general study of postcolonial Cape Verdean poetry. These include Moser's aforementioned Changing Africa: The First Literary Generation of Independent Cape Verde 1992 study; Carmen Lucia Tindó Secco’s aforementioned 2007 work, "Postcolonial Poetry in Cape Verde, Angola, and Mozambique: Some Contemporary Considerations;" David Brookshaw's 1996 chapter, "Cape Verde," in Patrick Chabal's The Post-Colonial Literature of Lusophone Africa; and Norman Araújo's "New Directions in Cape Verdean Literature? The First Numbers of Raizes," in Donald Burness' Critical Perspectives on Lusophone African Literature, from 1981.

Additionally, in more narrowly focused work, Donald Burness is the author of a book chapter published in 2003, "The Poetry of Adelina Da Silva: The Voice of a Capeverdean Expatriate," in Seasons of Harvest: Essays on the Literature Of Lusophone Africa, and George Lang has studied the literary use of Kriolu during the postcolonial period in his 1996 publication "Literary Crioulo since Independence in São Tomé, Guinea-Bissau and Cape Verde."

Moser's aforementioned text studies the transition between colonial-era Cape Verdean poetry and postcolonial Cape Verdean poetry. Secco's noted work gives significant consideration to the themes of postcolonial Cape Verdean poetry. Brookshaw's work is the most thorough English-language study of postcolonial Cape Verdean poetry. These three texts, in particular, shall receive ample consideration, in addition to the others noted, so that they may provide a foundational context for an analysis of postcolonial Cape Verdean poetry.

According to David Brookshaw, prior to national independence Cape Verdean 
poetry passed through several distinct stages. Brookshaw states that the colonial era's first stage of poetry was its classical stage, which might be considered its stage of denial, when the Cape Verdean poetry then produced by elites might now be seen to have been fairly indistinguishable on the matter of Cape Verdeanness in its content and form from other Portuguese poetry of its period (180). But in the late nineteenth century and the first half of the twentieth century, Cape Verdean poetry shifted to reflect much more the experience of life in Cape Verde.

These poetic transitions were first visible in the late nineteenth century and early twentieth century mornas [poems of sodadi (longing) set to music] penned by Eugénio Tavares, from the Island of Brava. Cape Verdean attributes associated with these mornas are suggested by Gerald M. Moser to be "fatalism and resignation" arising from "centuries of hardship" (2). Yet mornas may represent an acceptable Cape Verdean means by which sadness may be expressed, and depression thereby thwarted. Perhaps it is by authentically singing the 'blues', that is, by singing mornas, or listening to them well sung, that someone might transcend their despair.

For Brookshaw, life on the Cape Verde Islands became especially well depicted by the Claridade ("Clarity", my trans.) generation through their literary works beginning in the 1930's up through 1960 (181). The literary journal Claridade was, for Brookshaw, "the first real attempt to interpret the Cape Verdean psyche in terms of the social and geographical environment of the archipelago" (182). The Claridosos (the writers for Claridade) portrayed Cape Verdean life as suffused with drought, famine, death, and emigration, the latter typically represented by the sea. Yet for Brookshaw, "the writers of 
the Claridade generation injected an existential dimension into the theme of departure and return. Sea and land are depicted as ambivalent forces: the sea is a jailer, but also the path to freedom; the land is barren and unforgiving, but it is also the motherland...the cradle of the culture which the islander takes with him wherever he goes" (198).

Brookshaw tells us next about Cape Verdean writers who contested the deficiencies of the Claridosos. He states that in the 1950s and 60s the Claridosos "came under fire from new groups of Cape Verdean intellectuals" (184). They aimed their critique at the perceived escapist stance of the Claridosos (184). The Claridosos were "rebuked for what was interpreted as being an essentially Eurocentric attitude towards Cape Verdean culture, and a refusal to accept the African contribution to either the Creole language or the folk culture of the islands" (184). The Claridosos were considered to be implicitly complicit with their colonizers. Furthermore, Onésimo Silveira and Manuel Duarte "referred to the inferiority complex of Cape Verdeans and sought to shed the Claridade mantle" (209).

Within the post-Claridade work, Cape Verdean poetry shifted to actively contest the source of the oppressive conditions of life in the Cape Verde Islands, rather than merely being lamentations on its consequences. The idea of Cape Verdeans maintaining fidelity by struggling to evade emigration, despite it being all but compelled by Cape Verdean living conditions, became prominent. This challenge to the oppressive conditions of life in Cape Verde culminated in the combative Cape Verdean poetry written during the movement for Cape Verdean independence. Finally, since gaining its national independence, Cape Verdean poetry has blossomed in incredibly divergent ways. 
In consideration of postcolonial Cape Verdean literary production, Moser notes that postcolonial Cape Verdean authors are "the first generation which could create in a society free from Portuguese tutelage and censorship" (4). Brookshaw amplifies Moser on this. Brookshaw describes how the poet's autonomy has ascended in relation to political power in the discourse pertaining to literary theory and practice in the Islands during the late 1970s (186). Supporting that perspective, Moser notes that "the Cape Verdean Constitution guarantees freedom of literary creation" (9). It can be seen from this that with independence the stage has been set for Cape Verdeanness to emerge in a more unfettered manner.

George Lang specifically situates the postcolonial literary production of Cape Verde within the nation's recent history. According to Lang, "the point of departure for post-independence Cape Verdean literature in both Crioulo and Portuguese was thus a variety of 'Fanonist' Third World aesthetics which promoted politically and socially committed writing, anti-colonialism, pan-Africanism, and the construction of a revolutionary national culture" (56). Noting an element of Cape Verdeanness, Lang points out that "as literary conceit the Badiu [descendants of former slaves in Cape Verde] connotes the deepest strains of Cape Verdean authenticity" (57).

Lang particularly examines the role of Kriolu in the various works of Cape Verdean postcolonial literature. For Lang, independence has apparently not affected literary Crioulo [Kriolu] very much (60). Lang notes that "when the first postcolonial generation began to coalesce, it perceived the Kauberdianu [a national movement to enhance the status of the Crioulo language] agenda to be parochial and to some degree 
oppressive" (61). Lang concludes that "the first literary generation of an independent Cape Verde aspired...to a pluralism which is at once Cape Verdean and universal" (61). Moser tells us that Tomé Varela Da Silva "is the only writer of his generation to write almost exclusively in Creole [Kriolu]" (18). The reluctance of other Cape Verdean writers to do so is understood by Brookshaw to be related to the question of readership (213). Despite Kriolu's status as one of the earliest identified elements of Cape Verdeanness in Cape Verdean poetry (for example, the mornas of Eugénio Tavares were written in Kriolu), Kriolu does not receive especially significant postcolonial representation in the most recently published Cape Verdean poetry.

In looking for new directions in a broad range of postcolonial literary productions, Brookshaw finds that Cape Verdean "writers nowadays tend more and more to conceive of a Cape Verdean identity in terms of a multi-faceted experience in which more generally felt human emotions are set against the specific background of island culture and society" (233). For Carmen Lucia Tindó Secco, "in the aftermath of independence euphoria at the end of the 1980s and in the early 1990s, in their works the new generations of Cape Verdean writers begin to denounce the archipelago's cultural void and verify that political liberation has not ended poverty and hunger" (119). Furthermore, for Secco, "post independence euphoria poetry no longer celebrates only collective social patriotism" (119). Elements of postcolonial Cape Verdeanness which are seen here by these scholars include a peripheralization of the Cape Verdean setting, with the consequent privileging of universal attributes, such as human emotions, the contestation of the cultural and societal deficiencies of present day Cape Verde, and a celebration of 
individuality.

Perhaps taking the traditional Cape Verdean tendency for outward, and inward, tolerance poorly, or misunderstanding it, Moser appears to lament a "civic silence" in Cape Verde "that neither approves nor disapproves anything" (10). Moser associates this silence with the "scarcity of literary creation" necessitating conviviality between authors (11). Yet Moser here ignores the significant value assigned by Cape Verdeans to morabeza, one aspect of which is harmonious cohabitation on the nine inhabited islands of Cape Verde. Respectful interpersonal regard is actually an enumerated obligation of Cape Verdean citizenship identified in the Second Constitution of Cape Verde, and Moser may not recognize its importance for Cape Verde.

Brookshaw, Secco, and Moser all speak of the significance of one particular postcolonial Cape Verdean anthology of poetry, Mirabilis de Veias ao Sol, published in 1991. According to Brookshaw, "independence in 1975 brought with it a process of both continuity and change" (185). One example, is how "the themes of imprisonment and freedom, so favored by past generations of Cape Verdean writers...reappear in some of the poems in this anthology" (225). Cape Verdeanness, then, has apparently had both continuity and rupture in the postcolonial period. The colonial era theme of feeling imprisoned and seeking freedom has not disappeared with Cape Verdean independence. It has just expressed itself in new ways.

The anthology, Mirabilis, is transnational in nature in that several of its anthologized poets were born abroad or lived abroad at the time of its publication. This supports an understanding of the transnational nature of Cape Verde. The anthology is 
associated with a Cape Verdean literary movement referred to by Brookshaw and Moser as 'Pró-Cultura'. According to Moser, Pró-Cultura rejects condescension, believing that they must understand the other before seeking to change him or her (8). Brookshaw sees the aim of the Pró-Cultura movement as being "to try and universalize the Cape Verdean experience" (188). For Brookshaw, this is visible in the attempt "to throw off the superficial aspects of local colour, which may make the islands unique, but nevertheless hedge them in, in order to universalize the Cape Verdean experience" (189). Clearly, there is a postcolonial tendency in Cape Verdean poetry to seek to understand someone else in their own terms.

Brookshaw specifically examines "how the theme of departure and return has been treated by published writers since 1975" (199). He considers the fiction of Teixeira de Sousa and notes how a "thirst for adventure is...no longer incompatible with attachment to the land" (201). Brookshaw reports how "a new generation of writers...have sought to shroud their native identity under a more general existential cloak" (204). Postcolonial Cape Verdean poetry may also demonstrate patterns of reconciling things that were presented, in the colonial era, as relatively incompatible dichotomies.

Yet with all this mention of the peripheralization of the Cape Verde Islands, the highlighting of Cape Verde is not wholly absent in postcolonial Cape Verdean poetry. For example, according to Brookshaw, T.T. Tiofe [aka João Varela], in his poetry, published in 1975, "evokes the lives and history of the Cape Verdeans from their African and European origins" (210). One must recognize here, though, that 1975 was just the beginning of Cape Verde's postcolonial era. Citing another example of Cape 
Verde-centric work, in the oeuvre of Corsino Fortes, Brookshaw informs the reader that there has been a transposition of elements of Cape Verdeanness: "gone is the theme of dispersal and migration, to be replaced by celebration and reconstituted memory" (212).

Furthermore, as Brookshaw sees it, during the postcolonial period the favored themes of the Cape Verdean oral tradition have finally entered the literary canon. These themes include "the supernatural, the proximity of the world of the living and the world of the dead, and the return of the dead to life" (218). Brookshaw sees such themes in the magical realism of Orlanda Amarílis (222). Brookshaw also cites literary references to "the traffic and crowds of the new nation's capital... [suggesting] an impersonality unknown in previous [Cape Verdean] literature" (227). Alienation has become identified and represented. In works of fiction, this is juxtaposed against the fact that "this rural rather than urban Santiago [the island of Cape Verde where the Capital, Praia, is located] has somehow preserved its purity" (229).

It remains to be seen just how much postcolonial poetry mirrors the range of changes notable in postcolonial Cape Verdean fiction. Clearly, though, from the poetry of Tiofe and Fortes it appears that postcolonial Cape Verdean poetry has not forgotten Cape Verde entirely. Postcolonial Cape Verdean poetry has included a focus on national celebration and reminiscence.

Certainly, Vera Duarte's postcolonial work represents seismic changes in the history of Cape Verdean poetry, in terms of its manner of consideration of the emotions associated with love. Brookshaw scrutinizes Duarte's poetry very carefully. For Brookshaw, Duarte provides us with "the expression of love as an all-absorbing, life 
giving, but at the same time suicidal emotion" (230).

Even more, Brookshaw suggests how, for Duarte, love "is ultimately more powerful than any of the cultural superstructures which might have controlled it in the past-whether an imposed Catholic morality, or a freely accepted revolutionary one” (231). According to Brookshaw, in Duarte's most recent collection of poetry, "love has become akin to a state of delirium, something close to madness... which is anathema to any type of social convention" (231). Brookshaw sees Duarte's depictions of love as nevertheless remaining true to her Cape Verdean roots (232). Brookshaw see this fidelity to her homeland as being visible in her "topographical references, frequent use of marine imagery and echoes of traditional Cape Verdean themes, such as departure as an escape from constraint" (232). Duarte clearly can be seen to embrace a Cape Verdean context for her postcolonial examination of women's experience of love.

Augmenting Brookshaw, Secco views Vera Duarte's poetry as demonstrating a woman's capacity for erotic self-representation (121). This focus by Duarte on female subjectivity represents part of what Secco considers a new feminist strain in Cape Verdean poetry (120). According to Secco, in postcolonial Cape Verdean poetry we see that women's previously silenced poetic voices have become audible, that women's lived realities are now communicated, that traditional images like the sea now gain new meanings, and disappointments of postcolonial Cape Verdean life are being recognized and confronted. For Secco, whereas in earlier poetic eras "women found themselves bound to the wharf, submissively awaiting the return of their lovers, sons, or husbands who had set sail to fish, hunt for whales, or who had left to study in Portugal," in the most 
recent Cape Verdean poetry the sea has been reclaimed "as the magma of memory of the feminine unconscious... which follows the interior labyrinths of the desire of the woman-poet" (121). Secco's figurative image of colonial-era Cape Verdean women being "bound" may represent her intent to suggest the history of women's oppression on the Cape Verde Islands.

Secco supports her point of view on postcolonial Cape Verdean poetry by citing the perspective of Simone Caputo Gomes, who, in an article published in Portuguese, has described postcolonial Cape Verdean poetry by suggesting that "matters traditionally linked to Creoleness or Cape Verdeanness-drought, rain, hunger, work, whaling, the seas, insularity, emigration-are revisited in another context, in conjunction with new issues such as conflicts and social inequalities seen in a postcolonial context, disenchantment, despair, solitude, death, personal existence, humor, irony, the search for God, and seeking to consolidate national and universal concerns" (122). That Gomes citation by Secco closely mirrors Moser's translation of the editor's preface to Mirabilis, where he identifies how "the changing social reality...required a new, different treatment of the old themes of love, work, social inequalities, Christian belief, the 'incongruities' of daily living" (8). Clearly, a number of scholars are suggesting that postcolonial Cape Verdean poetry has reworked old metaphors to examine a whole range of general human and particular Cape Verdean concerns.

Establishing a juxtaposition of postcolonial Cape Verdean women poets, Moser considers Adelina C. Da Silva's poetry to be "passionate, though more restrained than the less frustrated and frankly sensual Vera Duarte" (21). One wonders whether Moser is 
equating Da Silva's sensual restraint with frustration here, because Vera Duarte seems to be depicted as being amply frustrated by Brookshaw. She has been referred to by Brookshaw as associating love with "madness," which suggests that love is an untenable aspiration (231). In the end, for Moser, "art, freedom, diversity and humanism are the ideas that the [Mirabilis] Generation is attempting to carry out" (25). Contributing towards that effort, according to Moser, is the fact of Cape Verdean transnational diasporic reality (26).

Continuing her examination of postcolonial Cape Verdean poetry, Secco cites Canabrava's poetry in Mirabilis, noting how the meaning of departure has been transformed to ineluctably include return (123). For Secco, this reflects how Canabrava understands that insularity has no future in an expansive Cape Verde (123). Canabrava is seen by Secco as suggesting that without an outward orientation internal pressures on the Cape Verde Islands could instigate narrowness in literary productions (124). There is, then, an apparent self-conscious intent in postcolonial Cape Verdeanness to take in the world rather than to be removed from it.

Picking winners and losers in the postcolonial Cape Verdean poetry sweepstakes, Moser has unilaterally selected "seven individuals [who]... have come to represent the [Mirabilis] Generation" (13). Two of these poets are the relative 'elders', that is, the inspiration for the other five, according to Moser. The elders are Arménio Vieira and Corsino Fortes. For Moser, Vieira "stands out as an individualist in a society that discourages individuality" (13). Moser appears to make this critique of Cape Verdean culture with a judgmental tone, perhaps because he privileges individualism over 
collectivism. Yet in Cape Verde's Second Constitution, Cape Verde is represented as a collectivist enterprise.

Moser notes that Vieira "appears to be haunted by the transitoriness of life, fame, memory, affection" (14). Yet, Moser also addresses how after independence, Vieira "broadened his outlook, seeing a future Cape Verde as participating in a fuller life for all of humankind, a more humane civilization” (14). Moser appreciates the poetic 'elder', Fortes, for how he "expressed the anti-evasion sentiment vehemently [seeking at all costs to avoid emigration]...in the seventies" (15). One notices elements of postcolonial Cape Verdeanness visible here that include the existential and the utopian.

Moser appears to simultaneously hold the poet José Luís Hopffer C. Almada (a.k.a. Zé di Sant'y Agu), the editor of Mirabilis, in both high and low regard. In seeing that poet as having great unrealized potential, he is suggesting that José Luís Hopffer C. Almada both has future promise and present creative limits (16-17). Continuing with his consideration of the Mirabilis Generation of writers, Moser describes how for 'Binga' (a.k.a. Alberto Ferreira Gomes) "much of his writing is dominated by the general human wish to escape from a depressing reality into a fantasy world" (17). Significantly, Moser notes that one fairly common element of Mirabilis poetry is the absence of mention of particular people or family members, in contradistinction to Cape Verdean poetry in other eras (18). Yet as I see it, this may be primarily because new interests have gained the attention of the Cape Verdean Islands' poets. Additionally, Cape Verdean poetry has never been extraordinarily confessionally-oriented in its nature, what with the traditional Cape Verdean preference for self-restraint in the public domain. 
Importantly, as well, it may be that in earlier eras of Cape Verdean poetry the mention of particular people or family was performed in a manner consistent with the Cape Verdean tradition to highly value considerateness. For example, people sorely missed those that had emigrated and were therefore no longer in their midst. Because of this valuation of considerateness, even now, in a time that Cape Verdean poetry has been liberated from its previous predicament of being a product of Portuguese colonialism and censorship, partly because of a Cape Verdean propensity for verbal indirectness, it may take some time before explicit confessionals regarding one's family members or others are entertained by Cape Verdean writers.

In conclusion, it is quite evident from the scholarly literature noted here that postcolonial Cape Verdean poetry has shown both continuity and transformation, even to the point of rupture, from previous incarnations of Cape Verdean poetry. The continuity is visible both in poetic content references particular to Cape Verde and in the selection of concerns, such as freedom and imprisonment, that have been previously addressed in the Cape Verdean poetic record. The rupture and transformation of Cape Verdean poetry may be witnessed in the extraordinary enlargement of the topical base to encompass universal human concerns, and, perhaps, even more so, in a forwardness and directness pertaining to matters of love and sexuality that was wholly absent prior to Cape Verdean independence. Cape Verdeanness appears to now be both as small as Cape Verde and as large as the universe. 


\title{
Chapter Five:
}

\section{Cape Verdeanness in Postcolonial Non-Diasporic Cape Verdean Poetry}

\author{
Introduction To The Analyses Of Postcolonial Cape Verdean Poetry
}

According to literary scholars, Cape Verdeanness appears to now be both as small as Cape Verde and as large as the universe. An examination of examples of postcolonial Cape Verdean poetry will move us in the direction of confirming, challenging, and expanding on the previously suggested features of Cape Verdeanness. I have read through most all of the postcolonial Cape Verdean poetry which has been published in English, and I have chosen nine poets' works for this study.

This small sample of poets and poetry cannot presume to suggest anything definitively about Cape Verdeanness, but it can surely augment an understanding of Cape Verdeanness that might be gleaned from the extensive body of prior social scientific work on Cape Verdean cultural identity, or that might be implied from the history of Cape Verdean literary criticism. My choice of the eleven particular postcolonial Cape Verdean poems utilized for this study has been based on my finding something in each of them that particularly speaks to me about postcolonial Cape Verdeanness. They capture distinct elements of postcolonial Cape Verdeanness, they provide compelling reading, and their respective meanings seem at least somewhat accessible for the reader. I have also decided to limit myself to poetry which was located in one of the three published works where postcolonial Cape Verde poetry in English has had its greatest representation: Maria M. Ellen's Across the Atlantic: An Anthology of Cape Verdean 
Literature, from 1988, Gerald M. Moser's Changing Africa: The First Literary Generation of Independent Cape Verde, from 1992, and Jarita Adia Davis' As Minhas Mornas, from 2003.

For this study, I have chosen Alberto Ferreira Gomes' (aka: Binga) "Indecision,” Corsino Fortes' “Eastwind From End to End,” José Luís Hopffer C. Almada’s (Zé di Sant'y Agu) "Permanence," Tomé Varela Da Silva's “The Time Had Come," Tacalhe's “Distant Poem for a Creole Girl,” João Rodrigues" "Who Said We had Departed?,” David Hopffer Almada's "Song for Cape Verde," three poems by Jarita Adia Davis: "Atlantic Coasts," "One Criolinha Speaks," and "You Cannot Prepare for this Trip," and Adelina Da Silva's "Return to the Homeland." In analyzing this postcolonial Cape Verdean poetry, I find that Alberto Ferreira Gomes' (aka: Binga) "Indecision" more than any other poem in the collection here illustrates how ambivalence is at the center of postcolonial Cape Verdean reality. Furthermore, I have chosen to present together, in a different chapter, the poetry of Jarita Adia Davis and Adelina Da Silva (encompassing a group of four poems) because their work has the commonality of poetically representing diasporic Cape Verdean experience.

\section{$\underline{\text { Indecision }}$}

"Indecision," by Alberto Ferreira Gomes (aka: Binga), from Moser's Changing Africa: The First Literary Generation of Independent Cape Verde, appears to incredibly aptly capture the ambivalence that appears to be at the heart of postcolonial Cape Verdean reality. In "Indecision," the expression "I don't know" begins the first stanza 
(being repeated a second time immediately after its first instantiation in the stanza); it also begins the second stanza, the third stanza, the fourth stanza, the fifth stanza, and the sixth stanza (again being repeated a second time immediately after its first instantiation in the stanza). This repetition of "I don't know" quite obviously suggests indecision, which is the poem's title. Yet the repetitions of "I don't know" might also serve another purpose, that of allowing the poem's speaker to intimate the muting of the visible expression of intense emotional responses in the poem. The poem's speaker perhaps either does this to feign a sense of emotional propriety or, in a tongue in cheek manner, to augment the affective response for the reader of this poem.

There are multiple (all compelling) references to rain in the poem "Indecision." For example, in the first stanza of this poem, one hears "the rain is singing / Its songs on the rooftop and is stroking the ground." In the third stanza of the poem, the reader sees "Should I listen to the patter /.../../ on this rainy night in September...." In the fourth stanza of the poem, one notices "I'll disrupt the dripping water... / The storm stopped the show in the movies / Its fury has cut the current". In the fifth stanza of the poem, the reader observes

Screams and booms I hear

Thunder and shouts of youngsters

Youngsters cleansing themselves in the troublesome rain...

I shall break the fetters of raindrops

Further along, in "Indecision", the reader is given more references to rain. For example, in the sixth stanza, one is handed "While outside the water makes love to the earth / And the rain keeps composing its own lyric song." Additionally, in the seventh 
(the final) stanza of this poem, the reader is told that "water from heaven so warmly / Is running off into earth's womb." All of the references to "rain" in "Indecision" may be seen as moistened with one or another of the complex and contradictory set of emotions related to interpersonal romantic intimacy (witness the affect associated with interpersonal romantic intimacy elicited, in order, by "singing," "stroking the ground," "listen to the patter," "this rainy night," "disrupt the dripping," "The storm stopped," "the fury has cut the current," "Screams and booms I hear," "Youngsters cleansing themselves," "troublesome," "break the fetters," "outside the water makes love to the earth," "keeps composing its own lyric song," and "water from heaven so warmly / Is running off into earth's womb").

While it might first seem that the central element of "Indecision" is the choice between generativity in writing and the pursuit of one's romantic life, a closer study suggests that "Indecision" is both explicitly and implicitly about indecision regarding interpersonal romantic intimacy. It is interpersonal romantic intimacy, in life, after all, if we are honest and scrupulous, that tends to raise us to our deepest depths of indecision. In interpreting this poem in this manner, I see "writing" and "rain" as both being repeatedly utilized as central metaphors for interpersonal intimacy.

Quite obviously, in "Indecision," the poem's speaker is literally fraught with indecision about writing while it is raining. The reader sees the indecision about writing immediately in the poem's first stanza in

I don't know, I don't know

If writing this poem is the right thing While the rain is singing 
Its songs on the rooftop and is stroking the ground

In the second stanza of this poem, one hears more such doubt about writing in "I don't know / If the hour is propitious / For plucking a poem." In the third stanza of this poem, the reader notes the indecision about writing in "I don't know / Should I listen to the patter / Or write and follow its rhythm." In the poem's fourth stanza, one finds the indecision about writing in "I don't know / If by writing my unrhymed lines / I'll disrupt the dripping water..."

More of this indecision about writing can be seen in the fifth stanza of "Indecision," when the reader encounters

I don't know... what am I to do...

Screams and booms I hear

Thunder and shouts of youngsters

Youngsters cleansing themselves in the troublesome rain...

I don't know if by writing these verses

I shall break the fetters of raindrops

There is still more of this indecision about writing in this poem's sixth stanza, with

I don't know, I don't know

If writing this poem is the right thing

While outside the water makes love to the earth

And the rain keeps composing its own lyric song

Finally, one sees this indecision about writing in the poem's seventh stanza (which is its last), in

I don't know if it's proper For my pen on the bedstand To be kissing the parchment At such a solemn moment like this When water from heaven so warmly Is running off into earth's womb And a body of beeswax 
Is melting ever so slowly

Crowned by its merciless flame...

No, I don't know

I'll stop now, but wait...I don't know...

Though there is, as just noted, much rumination, and implicit indecision, expressed by the poem's speaker in "Indecision" on the timing of the writing process, it appears that this rumination about the timing of the writing process serves as a useful metaphor for indecision regarding interpersonal romantic intimacy. Supporting that point of view, there are about as many quite apparently positive descriptions of interpersonal romantic intimacy in this poem as there are expressions of doubt regarding the timing of the writing process. One can note, as well, that the descriptions of interpersonal romantic intimacy within any particular stanza of this poem are neither all positive nor all negative. Thus the poem's stanzas may be seen as representing a sequence of particular instantiations of indecision about interpersonal romantic intimacy.

Let us consider, now, in "Indecision", that "rain" (and its signifiers) may generally well serve as a running metaphor for positive and negative attributions associated with interpersonal romantic intimacy, and writing (and its signifiers) may also generally well serve as an ongoing metaphor for both positive and negative attributions associated with interpersonal romantic intimacy. As a first example, in the first stanza of "Indecision," the reader witnesses

I don't know, I don't know

If writing this poem is the right thing

While the rain is singing

Its songs on the rooftop and is stroking the ground

Clearly "singing" and "stroking the ground" can represent quite positive aspects of 
interpersonal romantic intimacy, while the "I don't know, I don't know / If writing this poem is the right thing" may represent the unstated negative aspects of interpersonal intimacy, together exemplifying indecision about interpersonal intimacy.

Then, in the second stanza of "Indecision," the reader notes

I don't know

If the hour is propitious

For plucking a poem

In the candle's dim light

While the current has failed

One can see "plucking a poem" as a metaphor, here, for a sexual liaison, by way of viewing "poem" as a synonym for "writing". Furthermore, the "candle's dim light" can be viewed as a metaphor for diminished interpersonal romantic intimacy. The fact that "the current has failed" might well metaphorically suggest that the connection between the two persons has just disappeared. The poem's speaker admits 'I don't know / If the hour is propitious." Clearly, here, one can see the opposing strands; there is the pull towards interpersonal romantic intimacy (in the form of sexuality) and the push away from it, and these strands together demonstrate indecision about interpersonal romantic intimacy.

In the third stanza of "Indecision," the reader is given

I don't know

Should I listen to the patter

Or write and follow its rhythm...

I awakened and thought I would write

On this rainy night in September...

The contrast here between the positive and the negative aspects of interpersonal romantic intimacy may be noted as it was in the first two stanzas. You see "Should I listen to the 
patter," which is an ambivalent term, but which may be seen negatively since it is contrasted in this stanza with "Or write and follow its rhythm.../ I awakened and thought I would write / On this rainy night in September," which seems clearly positive. Here, then, again, indecision about interpersonal romantic intimacy is being encapsulated within a specific stanza.

In the fourth stanza of "Indecision," the reader is informed

\section{I don't know}

If by writing my unrhymed lines

I'll disrupt the dripping water...

The storm stopped the show in the movies

Its fury has cut the current

(That's what I saw through the window)

The positive attribute of intimacy here may be noted in "writing my unrhymed lines" (a metaphor, perhaps, for lacking pretense in interpersonal romantic intimacy). The negative attribute of interpersonal romantic intimacy here may be seen in "The storm stopped the show... / Its fury has cut the current." "The storm""s "fury" "has cut the current" is a metaphor, perhaps, for the connection between the partners. The poem's parenthetical remark closing the fourth stanza ("That's what I saw through the window") demonstrates a truly tentative consideration of the apparently negative immediately preceding matter ("The storm stopped the show in the movies / Its fury has cut the current") for the poem's speaker. Nonetheless, one can see here, in this stanza, another demonstration of indecision about interpersonal romantic intimacy.

In the fifth stanza of "Indecision," the reader notes

I don't know... what am I to do...

Screams and booms I hear 
Thunder and shouts of youngsters

Youngsters cleansing themselves in the troublesome rain...

I don't know if by writing these verses

I shall break the fetters of raindrops

The positive elements of interpersonal romantic intimacy may be represented in this stanza by "Screams and booms I hear", and in "Youngsters cleansing themselves." The negative aspect of interpersonal romantic intimacy may be noted in "troublesome rain." Ambivalence about whether it is possible to overcome the negative element of interpersonal romantic intimacy may be suggested by "I don't know if by writing these verses / I shall break the fetters of raindrops" (wondering if interpersonal romantic intimacy can erase the present restrictions on interpersonal romantic intimacy). Here, then, is another stanza rendering itself as a representation of indecision related to interpersonal romantic intimacy.

In the sixth stanza of "Indecision," the reader encounters

I don't know, I don't know

If writing this poem is the right thing

While outside the water makes love to the earth And the rain keeps composing its own lyric song

And here in the room while standing before me The merciless candle Is lapping my room's heavy air

In this stanza, the indecision about interpersonal romantic intimacy is at the forefront ("I don't know, I don't know / If writing this poem is the right thing"). The positive attribute of interpersonal romantic intimacy then follows ("Outside the water makes love to the earth / And the rain keeps composing its own lyric song"). On the negative side of interpersonal romantic intimacy, "The merciless candle / Is lapping" could potentially 
represent either time or one partner snuffing out the positive elements of interpersonal romantic intimacy. That stanza's closing phrase, “my room's heavy air," may well represent indecision pertaining to interpersonal romantic intimacy. Clearly, then, one has, here, another stanza of indecision about interpersonal romantic intimacy.

In the seventh (the final) stanza in "Indecision," the reader sees

I don't know if it's proper

For my pen on the bedstand

To be kissing the parchment

At such a solemn moment like this

When water from heaven so warmly

Is running off into earth's womb

And a body of beeswax

Is melting ever so slowly

Crowned by its merciless flame...

No, I don't know

I'll stop now, but wait...I don't know...

In this stanza, right after a moment of indecision about interpersonal romantic intimacy ("I don't know if it's proper"), there is the clearly positive "For my pen on the bedstand / To be kissing the parchment." Then the stanza continues with the quite positive "such a solemn moment like this / When water from heaven so warmly / Is running off into earth's womb". Next, the stanza turns, however, and one sees "a body of beeswax / Is melting ever so slowly / Crowned by its merciless flame.” Although a melting body could suggest a very receptive partner, the reference to a "merciless flame" appears to convey the "ever so" slow loss of the partner, a loss apparently regulated by either the partner's or time's mercilessness.

The reader may note how the poem's speaker has re-worked that last image in the poem, perhaps for intensification purposes, from one in the previous stanza of 
"Indecision" (from the sixth stanza's "The merciless candle / Is lapping my room's heavy air" to the seventh stanza's "And a body of beeswax / Is melting ever so slowly / Crowned by its merciless flame...”). The seventh stanza ends with extreme indecision (“No, I don't know / I'll stop now, but wait...I don't know...”), the kind often associated with inner and interpersonal debates about whether to engage in sexual intimacy with another, and since it is the final stanza of this poem, the poem ends as it began in its title, with indecision. Clearly, then, based on the fact that all seven stanzas of "Indecision" can reasonably be viewed as individual commentaries on indecision about interpersonal romantic intimacy, "Indecision" may fairly be construed as a poem that is primarily about indecision regarding interpersonal romantic intimacy.

In "Indecision," when looking for Cape Verdeanness, one sees a celebration of a positive outcome for Cape Verde, especially for its young, where in the fifth stanza of this poem one witnesses "Youngsters cleansing themselves." If this poem is saying at least as much about indecision about interpersonal romantic intimacy as it is saying about rain, its appropriation of a colonial-era concern of Cape Verdean poetry ("rain") for the purposes of representing a postcolonial concern (indecision about interpersonal romantic intimacy) makes the poem an excellent example of postcolonial Cape Verdean poetry.

Postcolonial Cape Verdeanness also seems visible at several other points in the poem "Indecision." The reader can note it in the references to the weak electrical system of Cape Verde located in the poem's second stanza ("In the candle's dim light / While the current has failed") and in its fourth stanza ("The storm stopped the show in the movies / Its fury has cut the current"). One may also view some ongoing colonial-era Cape 
Verdeanness in the repeated references to "youngsters" in the fifth stanza ("Thunder and shouts of youngsters / Youngsters cleansing themselves”), for Cape Verdeans have long placed an extraordinarily high value on their young people.

\section{Eastwind From End to End}

"Eastwind From End to End," by Corsino Fortes, is from Moser's Changing Africa: The First Literary Generation of Independent Cape Verde. "Eastwind From End to End" begins its first five lines with a reference to Cape Verde:

From the muscles tensed from sea to sea

To the broad rock of the soul

We are

Ten faces of raw earth

And a homeland of few cereals (I. 1-5).

The "ten faces of raw earth" are the ten islands of Cape Verde. The "muscles tensed from sea to sea" appear also to be representations of the Cape Verde Islands, with the tension of the muscles suggesting stress and power, both. The "broad rock of the soul" seems to be a reference to the entire geographic space, both land and sea, that includes the islands of Cape Verde. The "raw earth" reference suggests vulnerability. The fifth line above ("And a homeland of few cereals") reflects the fact that there is little agricultural production possible on Cape Verde.

Another reference made to Cape Verde in "Eastwind" is "To the green bone heap of history," a suggestion that Cape Verde has to confront its past ecological exploitation (I.13). Some of Cape Verde's past history of famine and a Cape Verdean 
tenaciousness in response to it is identified in "Drought is a weapon And hunger!

Defiance" (I.18). The poem goes on with references to the experience of life on the Cape Verde Islands, witness "The island is life And dryness is living" (I. 19). In the first section of that quote, you see that for most Cape Verdeans emigration has, perhaps surprisingly, never even been an option. In the second section of that quote, you see that Cape Verdeans have had to accommodate to drought and famine.

Next, "Eastwind" moves on to the Cape Verdean longing for rain, with "Love! May rain bring / The white flag / Of truce in our war between heaven \& earth" (I. 20-22). Clearly, with images of war ("The white flag" and "truce in our war between heaven \& earth"), there has been a palpable intensity to the Cape Verdean struggle for survival in an inhospitable natural environment. Yet "the white flag" and "truce" speak to something that can improve in the relationship between Cape Verde and nature. This section of the poem acts as a prayer for this transformation, as it invokes "Love! May rain bring."

Section one of "Eastwind" goes on:

Even if heaven does not send us rain

And the Sun and the Moon

be

broken strings on the island guitar (I. 24-27).

Here there is a reference to the possibility of "broken strings on the island guitar," an important metaphoric reference to Cape Verdean music (I. 27). But it is a reference that suggests that something might be amiss in Cape Verde, since music is in many ways, like Cape Verdean food and Kriolu, the Cape Verdean language, at the essence of the Cape Verde Islands, and the guitar may not be fully functioning. The reader may note that even 
if it is an impaired guitar it is not a broken guitar and that all of the strings may not necessarily be broken if any are. If the guitar with broken strings is a symbol for Cape Verde, this implies that something may be wrong, but not inextricably wrong, with Cape Verde. It is quite simple, in fact, to re-string a guitar. What may be wrong with the "island guitar" may have something to do with the absence of rain, and its attendant consequences.

That first section of "Eastwind" ends with the implication that Cape Verde is no longer oppressed, as one regards "Even then! No longer are we / The eastwind's scourged victims" (I. 37-38). In the second section of the poem, one is again brought into contact superficially with Cape Verde's poor agricultural situation in "upon limbs/ of truant seedlings" (II. 4-5). Yet seedlings that are truant are alive but not appearing where they should be, and this might better be viewed as an agricultural metaphor for those people who have emigrated from Cape Verde to the diaspora.

Soon, again, in "Eastwind," the land of Cape Verde is referred to. One sees "The knees and the elbows of the island / chiseled" (II. 18-19). Knees and elbows are places where bones meet. They are places where bending takes place. Their being chiseled suggests that the knees and elbows are strong and in perfect shape. They can be seen to represent Cape Verdean flexibility under duress.

In "Eastwind From End to End," when searching for elements of postcolonial Cape Verdeanness, one finds references to Cape Verde and its agriculture. There are references to present-day life on the islands. There are references to Cape Verdean flexibility, tenacity, and resiliency. There are references to vulnerability as well as the stress and 
challenges Cape Verde faces. Finally, there is celebration of the end of victimization by the colonial power, Portugal, and there is a prayer for better times. There are elements of colonial-era Cape Verdeanness in the references to those who have left Cape Verde, in references to a sense of Cape Verdean space, encompassing all of the land and sea in the range of the archipelago, to Cape Verdean history, and to its music and climate, including the hope for rain.

\section{Permanence}

"Permanence”, by José Luís Hopffer C. Almada (Zé di Sant'y Agu), is from Moser's Changing Africa: The First Literary Generation of Independent Cape Verde. The second half of Almada's pen-name represents his connection to Cape Verde, as Sant'y Agu is meant to be sounded out as Santiago, Cape Verde's most populous island, and the site of its greatest Africanness. The poem "Permanence" commences with "Stone remains inert / Night remains indefinite" (1-2). These first two lines appear to refer to the fact that the islands are still not actualized in their potential, and that this deficiency shall continue for an unknown amount of time. Somehow, Cape Verde has a predicament that involves both under-development and the absence of a figurative light at the end of the tunnel.

As one moves along in "Permanence," it is clear that hope readily abides in Cape Verde, witness "Dreaming remains eternal" (4). Yet, again, you find that the future is still indeterminate for Cape Verde, in the lines "projected into a future still / tunnel and lamp" (6-7). With a "tunnel" there is a path, and with a "lamp" there is a light guiding one in but 
not necessarily all the way through the tunnel. The "future" is not moving closer to us. It is "still." Progress is not truly being made.

Going on, in "Permanence," one sees the potential for positive transformation in Cape Verde in "Sex served on the urban platter remains uninhibitedly seminal" (12). What is extraordinary about this representation is its sexual explicitness, something that would be more than quite unheard of (and perceived as even beyond gauche or risqué) prior to Cape Verdean independence. The sexual metaphor is being used here to represent Cape Verdean fecundity. As the poem continues, one is forced to encounter its cynicism, witness

Illusion remains verdant (like the verdant moon of serenades) in this country of stones on nights of folly of stones that dream (19-22)

So it is not the land of Cape Verde that is green, it is, instead, "illusion." This illusion is as delusional as "the verdant moon of serenades." Cape Verde is being represented as "stones on nights of folly," that is, pursuing things foolishly. That segment of the poem ends with more neutrality in "of stones that dream," for dreams may be delusional but they may also come true.

In "Permanence," in searching for elements of postcolonial Cape Verdeanness, the reader witnesses references to the present-day Cape Verde Islands. One is reminded that Cape Verde's potential has yet to be realized. One sees a future for Cape Verde that is indeterminate. One notices that hope abides. A sexual metaphor is being used here to represent Cape Verdean fecundity. One can see the positive potential for transformation 
of Cape Verde. Yet the reader also encounters significant cynicism that borders on, or reaches, hopelessness, in the perception that no progress is being presently made and that no progress might ever be made.

\section{$\underline{\text { The Time Had Come }}$}

“The Time Had Come,” by Tomé Varela Da Silva, is from Moser’s Changing Africa: The First Literary Generation of Independent Cape Verde. "The Time Had Come" makes multiple references to the land of Cape Verde. For example, in the second stanza of the poem the reader encounters

Cape Verde, you had slept aplenty:

Until our fifteenth century

you slept in the sea.

They discovered you

This segment of the poem is about Cape Verde's history up through its initial discovery by the Portuguese. It suggests that the Portuguese discovery of Cape Verde is viewed positively, if the possibility of not being asleep is seen as preferable to being asleep, which distinguishes the experience of Cape Verde from that of other 'discovered' lands.

"The Time Had Come" follows in the third stanza with references to the way that the physical and spiritual environments were despoiled by the Portuguese, as one encounters

Beatings ferule slaps:

You did not wake up!

They violated your body your soul as well:

you did not stop sleeping!

You were a virgin: 
they made you bear their children: (italics mine)

For this poem, possibly being enamored with Portuguese begins and ends with the discovery of the Cape Verdean Islands. The abuse of the "body" (the land) and the "soul" (the spirit of the people) by the Portuguese has reduced any initial positive feelings towards the Portuguese to the single historical 'moment' of discovery. There is an implication of the rape of a virgin ("You were a virgin: / they made you bear their children"), suggesting the degree to which Cape Verde has been oppressed and lost its purity, both (as it also, perhaps, suggests that there is a double standard with rape, regarding virgins and non-virgins). This also may be a metaphorical reference to the fact that in the history of Cape Verde dark-skinned African slave women were routinely raped by lighter-skinned Portuguese males of privilege.

In "The Time Had Come," the fondness for the land of Cape Verde, as nurturing, like mother's milk, is evident in the fourth stanza when encountering

You adopted your children you gave them your affection!

$\cdots$

you sustained your children

$\ldots$

You nursed them yourself

You brought them up by yourself

This nurturing land was highly accommodating ("You adopted your children"). This nurturing was done without outside help from the Portuguese ("You brought them up by yourself").

"The Time Had Come" moves along in the fifth stanza to extraordinarily numerous 
references to traditional Cape Verdean cuisine, such as

You gave them your cornmeal

corn soup with meat

beans with salt pork.

Popcorn sweet potatoes

noodles with chicken

corncake with milk.

Porridge with butter

corncake with honey:

Thereafter in the poem are further references to native Cape Verdean fruits and more

Cape Verdean cuisine. The reader sees that the seventh stanza of the poem adds "Guavas

oranges bananas / mangoes jambos papayas." The cornucopia continues in that seventh

stanza by way of

Cassava with meat potatoes

with fish cassava with milk.

Sugarcane to chew cane juice

to drink rum to get warm.

The extent of the food references in this segment of the poem appears to mirror the scale of the land's more abstract nurturing previously referred to above.

After all of the relentless giving by the land of Cape Verde, "The Time Had

Come" continues along with quite different references to the land in the ninth stanza

dramatizing drought and the consequent famine. This is represented by

No shower opened

your dried-out body:

your children cried!

The oxen bellowed

the goats begged

the horses died!

Your children fell ill

died fled.

Nobody recognized you 
The degree to which Cape Verde was eviscerated by the Portuguese made it a specter of its former self. The contrast with its previously represented verdant past is stark.

"The Time Had Come" continues in the eleventh stanza with more references to the land of Cape Verde. The reader encounters

Lots of fish in the sea fowls in the bush monkeys on the rocks. Salt to take from the sea black soil going to waste beaches to exploit.

These references to the land of Cape Verde appear to be about how Cape Verde will utilize its present-day resources for either potentially constructive or destructive ends. In “The Time Had Come," searching for elements of postcolonial Cape Verdeanness, one sees, at the end of the poem, descriptions of present-day Cape Verdean resources that may be tapped for either the benefit of Cape Verde or that may be abused in a manner that neo-colonially replicates the ecological devastation wrought by the Portuguese during the colonial era. Furthermore, there is the postcolonial self-consciousness visible in a metaphorical reference to the fact that dark-skinned African slave women were routinely raped by lighter-skinned Portuguese males of privilege. Finally, there may be a similar postcolonial self-consciousness if I am correct that there is the suggestion here that there is a double Cape Verdean standard with regards to the rape of virgins vs. non-virgins.

Otherwise, the bulk of this poem's references to Cape Verdeanness are continuous with those of the Cape Verdean colonial era. These include a number of references to 
Cape Verdean history. For example, the Portuguese discovery of Cape Verde appears to be viewed positively, something that distinguishes the experience of the colonization of Cape Verde from the colonization of other lands.

Continuing to find continuous elements of Cape Verdeanness from the colonial era in "The Time Had Come," the poem tells us that Cape Verde has lost its purity to an extraordinary degree, so much as it has reached a point where one can see how it has come to be defiled by its discoverers. The measure to which Cape Verde was eviscerated by the Portuguese has made it a specter of its former self. The contrast with its mythologized verdant past is profound.

Furthermore, the reader can witness continuity from colonial-era Cape Verdeanness in "The Time Had Come" through noticing evocative references to the land as extraordinarily nurturing, accommodating, and self-reliant. This land is depicted in both abstract and concrete ways. The nurturing is more concretely depicted by the extensive descriptions of Cape Verdean cuisine.

\section{Distant Poem for a Creole Girl}

"Distant Poem for a Creole Girl," by Tacalhe, is from Maria M. Ellen's Across the Atlantic: An Anthology of Cape Verdean Literature. In "Distant Poem for a Creole Girl," there is an interesting juxtaposition of temperatures in both the first and final stanzas. There, one encounters "Hot / Hot like the cold warmth of this absence" in the first two lines of each of those two stanzas (italics mine). The other two references to temperature in this poem refer to the "Creole girl." For example, in the twelfth stanza one is told 
"Only the hot body of my comrade Creole girl / Warms, in my steps, / the right direction to the goal" (italics mine).

The juxtaposition of temperatures in the first and final (fifteenth) stanzas appears to represent an effort by the poem's speaker to suggest that the combination of there being both a warmth and coldness in the distance from the beloved holds a special power or intensity. The warmth in the distance may reflect an abiding love. The coldness in the distance may reflect the pain of separation. The title of this poem, itself, juxtaposes "Distant" and "for," suggesting that this poem is about the dichotomy of warmth and coldness.

The most frequent direct and implied references in "Distant Poem for a Creole Girl" are those to the "Creole girl." One may fairly well assume from this fact, and the nature of those references, a theme of the compelling power of the Creole girl. One sees references to the Creole girl first in the poem's title. Then, one sees the power of the Creole girl in the first stanza of the poem, in "You throb Creole girl / In the red heart of Rotterdam at night." One also witnesses similar references in the second stanza of the poem, in

You throb Creole girl

In the veins of my long

Silence

Long as the sea that separates us

and in its fourth stanza, where the reader is shown another ironic juxtaposition, as well, in "Profound with you, simple / Gathering the roses the pioneers breath." The suggestion in the ironic juxtaposition appears to be that there is profoundness in simplicity, and that a 
shift into simplicity is facilitated by the "Creole girl."

In the fifth stanza of "Distant Poem for a Creole Girl," the reader notices

You make me remember

Always remember

You our my country

Country as a yellow green cab

Sure promise of a grand harvest

This seems to suggest that the "Creole girl" plays a central role in her beloved's

connection with his roots. In the sixth stanza, the "Creole girl" is directly addressed by

the poem's speaker. One finds there

Like you, Creole girl

I always come with my arms full

Of the stars' brightness

That the sky of the new dawn

Also covers me far away

This seems to be a statement to the "Creole girl" that he is not disempowered by her, and that they are both wrapped in the same atmospheric cloth (of "sky" and "stars").

In the twelfth stanza of "Distant Poem for a Creole Girl," the reader finds "Only the hot body of my comrade Creole girl / Warms, in my steps, the right direction to the goal." This suggests that the "Creole girl" compellingly induces the right livelihood of her beloved. In the poem's fifteenth (the final) stanza, the reader observes the "Creole girl" being referred to in "You-Creole girl: my gusto and country / Will sing in my arms / The poem of our love." This encapsulates the power of the Creole girl. She is a source of passionate inspiration as well as an iconic conjurer of her beloved's homeland.

There is a significant tendency in postcolonial Cape Verdean poetry for there to be an incorporation of the memory of the heroic struggle for Cape Verdean independence. 
One can see an example of that tendency in "Distant Poem for a Creole Girl" in the fourth stanza's "Gathering the roses of the pioneers breath," and in the poem's thirteenth stanza's "Only my brothers-heroes a thousand times / Made succulent their steady steps." Furthermore, postcolonial Cape Verdean poetry frequently acknowledges the remaining challenges faced by the Cape Verdean people, wherever they may be living (in Cape Verde or in the Cape Verdean diaspora). One can see this in "Distant Poem for a Creole Girl" in the seventh and eighth stanzas'

Far away to fill

My country of naked children running about

Even greater

Running about on the bank of the sea

Running about in far-off lands

Running about in foreign factories

One is also exposed to this in the tenth stanza of the poem in "Oh, seedless fields / Without water / Without machines!," as well as in the thirteenth stanza's "Only my islands without place on the map / Only my people without an echo in the world."

In searching for elements of postcolonial Cape Verdeanness throughout the poem "Distant Poem for a Creole Girl," one immediately considers the references to "pioneers" in the fourth stanza and to "heroes" in the thirteenth stanza. These represent accolades to the freedom-fighters such as Amilcar Cabral, who made Cape Verdean independence possible. The manner of utilizing iconic Cape Verdean references to the sea and maize in new, self-referential ways also reflects postcolonial Cape Verdeanness in this poem. The reader can see this in the ninth stanza in the connection between mother and nutriment 
made in "My belly-button, my maize." It is also in the reference to "my sailboat of smiles" in the fourteenth stanza's "But one day I will return / To be with the calm breeze / In my sailboat of smiles.”

Continuities with colonial-era Cape Verdeanness can also be noted in "Distant Poem for a Creole Girl." For example, note the title's reference to the "Creole Girl," and all of the other references to the "Creole girl" in the poem. One can also witness a continuity of colonial-era Cape Verdeanness in the reference in the second stanza to the sea ("Long as the sea that separates us"). This continuity of colonial-era Cape Verdeanness is also visible in this poem in its references to the land and culture of Cape Verde. For example, in the poem's tenth stanza one hears about a Cape Verdean-like landscape of "basalt roads, / Of serious curves and tree-less footpaths!"

\section{Who Said We had Departed?}

“Who Said We had Departed?”, by João Rodrigues, is from Maria M. Ellen’s Across the Atlantic. In "Who Said We Had Departed?", there are several repetitions of the title throughout the poem. Twice, the poem's title is represented, itself, as a stanza (the first stanza and the final, eleventh, stanza). In the fourth, fifth, seventh, and eighth stanzas "Who said we had departed" represents those stanzas' first lines. One might reasonably assume, then, that the poem's speaker is quite indignant about the presuppositions made by those who have assumed that Cape Verdeans have abandoned their islands. It appears that indignation regarding accusations of ubiquitous emigration is at least one significant element in "Who Said We Had Departed?". 
Further indignation of the poem's speaker in "Who Said We had Departed?" may be seen in the second and third stanzas of the poem, where the reader is informed about those who may have presupposed "we had departed." The reader is told: "do not believe them." One can see indignation thrice represented in the fourth stanza of the poem when encountering

Who said we had departed-

if in the dark hills images of black faces still remain if in the dry creeks we left rivers of bitter sorrow if in each street corner a poem protests?

In that fourth stanza, a repetitive parallel construction of "If in..." commences the second, fourth, and sixth lines. That repetition works, perhaps, to deepen the intensity of the expression of indignation.

In searching for elements of postcolonial Cape Verdeanness in "Who Said We Had Departed?" one is the magical realism which is visible in the third stanza of this poem

$\cdots$

o tanned nymphs

of the rocky hills of our islands

nor you

tender nereids of our sea of tears.

Another element of postcolonial Cape Verdeanness in the poem is the use of Kriolu, which one encounters in the ninth stanza of this poem, in "colá na mim, colá na bô,".

Continuity with colonial-era Cape Verdeanness in "Who Said We Had Departed?" is visible in the multiple references to "departure" and "return." One sees this departure/return dynamic in the oft-repeated question throughout this poem, "Who said 
we had departed?". One also sees it in the seventh stanza of this poem

...

if the sea that brought us here

will soon take us away

if each sunset is a prelude

to the dawn of our return?

One can further note this departure/return dynamic in the eighth stanza of this

poem in

...

if soon we shall return

to join our hands

to your hands

our voices

in a round dance

$\cdots$

Another example of the continuity of colonial-era Cape Verdeanness may be found in the ninth stanza, which describes Cape Verdean religious festivals, in

corn in the pestle

cuscus on the night of São Silvestre

drums rolling in São João

colá na mim, colá na bô,

Still another example of the continuity of colonial-era Cape Verdeanness in this poem is the reference to the "Creole woman" in the tenth stanza.

Additionally, "Who Said We Had Departed" depicts the continuity of colonial-era Cape Verdeanness in the reference to rain in the eighth stanza of the poem, witness

our voices

in a round dance

like children,

to sing the song of rain 
our song of plenty:

A further example representing a continuity of colonial-era Cape Verdeanness in this poem is its multiple implicit references to the landscape of the islands of Cape Verde, which you see in stanza two, in "our beloved desert", as well as in the third stanza, in "the rocky hills of our islands". A final element in the continuity of colonial-era Cape Verdeanness in this poem may be seen in the tenth stanza, in the reference to the Cape Verdean musical form of "morna."

\section{$\underline{\text { Song for Cape Verde }}$}

"Song for Cape Verde," by David Hopffer Almada, is from Across the Atlantic: An Anthology of Cape Verdean Literature, by Mary M. Ellen. In "Song for Cape Verde," certain expressions and phrases repeat themselves. One example is "I sing," which begins stanzas $9,10,11,12,13$ (the latter in which it also appears a second time in the stanza), 14 , and 15, and which is also contained within stanzas five and seven. Another repeated phrase in "Song for Cape Verde" is "a different song." That phrase is located in the first, second, and fifth stanzas. A further example of repetition in "Song for Cape Verde" is "Cape Verde." The reader sees "Cape Verde" in the poem's title, and in stanzas 1, 4, 5, 9, 12, and 16. The particular intensive repetitions of "I sing," "a different song," and "Cape Verde" make the poem seem like an anthem, which may well be its intent, considering the poem's title.

It seems that the poem's speaker's desire for, or appreciation for, transformational change in Cape Verde is a central attribute of "Song for Cape Verde." A reader notices 
that transformational change is clearly represented in fourteen out of the poem's sixteen stanzas. In the first stanza of the poem, the reader sees "I want / a different song /for Cape Verde." In the second stanza of the poem, the reader is told

I want

a different song for these islands, for this country, for these people.

In the third stanza of the poem, one hears

We are no longer

'Victims of the East Wind,' which we overpowered.

We are no longer contracted laborers like beasts of burden heading South, for we have conquered dignity.

Additionally, in the fourth stanza of the poem, one sees "We need to sing / a different song / to Cape Verde."

In the fifth stanza of "Song for Cape Verde," the reader sees evidence of the element of desired/appreciated transformational change for Cape Verde in
And so
I sing,
differently, a different song
to Cape Verde.

In the sixth stanza of the poem, one hears

I'll forget and bury the laments and sadness, and the pain of those who wish to remain thwarting the fate of having to leave.

The seventh and eighth stanzas in the poem are tied together by the seventh stanza's last 
sentence, which begins there but only completes itself in the eighth stanza.

In that seventh/eighth stanza segment of "Song for Cape Verde," one sees further documentation of the element of desired/appreciated transformational change in Cape

Verde. Specifically, one encounters

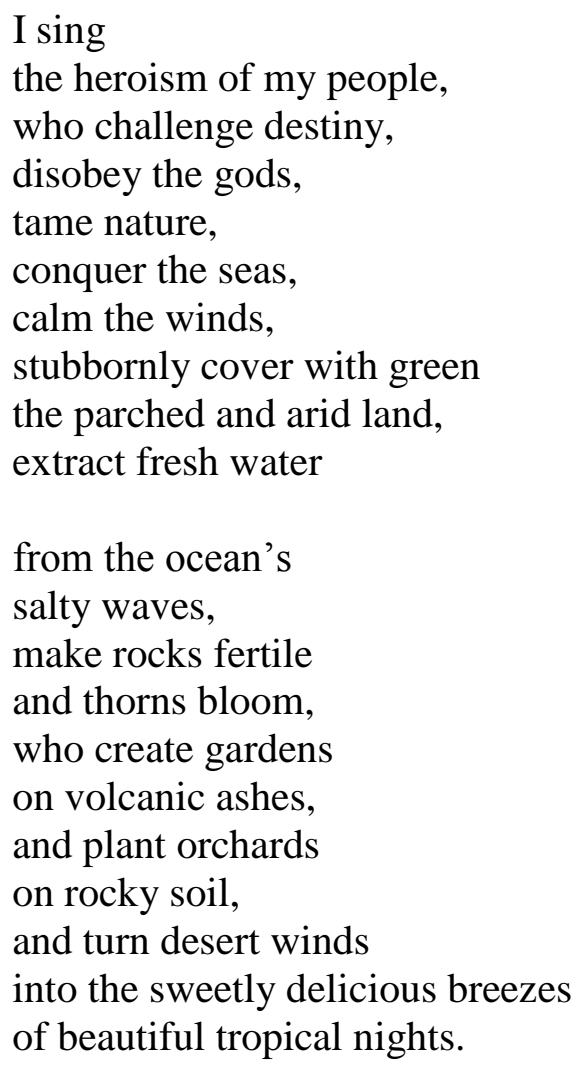

Then, in the ninth stanza of "Song for Cape Verde, there is the element of

desired/appreciated transformational change for Cape Verde in

I sing

this triumphant Cape Verde

liberating itself

from yesteryear,

raising, on one hand,

the banner of peace and harmony

and, on the other,

the torch of brotherhood and liberty. 
In the tenth stanza of "Song for Cape Verde," the reader is exposed further to the element of desired/appreciated transformational change for Cape Verde. In that stanza of the poem, one sees

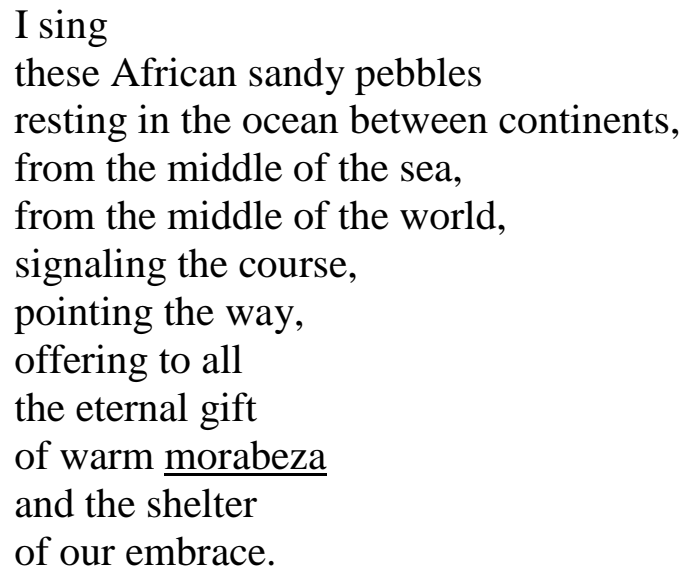

In the eleventh stanza of the poem, desired/appreciated transformation makes itself known in "wanderers who carry / progress and well-being to foreign lands." In the twelfth stanza of the poem, that element of desired/appreciated transformation in

I sing

This independent, sovereign and free country: this Cape Verde, master of its fate, architect of its path, builder of its steps.

In the fifteenth stanza of "Song for Cape Verde," one again notes the element of desired/appreciated transformational change in Cape Verde. There one hears:

I sing for these people a joyous song of sabura [delight], of confidence, of certainty, 
of tomorrow-

breaking the bad fortune,

the bad fate,

breaking the sadness

and the despair

of having to tread

roads leading to São Tomé,

breaking all the chains

of contracted,

exploited laborers.

Then, finally, in the sixteenth (the final) stanza one encounters a final example of desired/appreciated transformational change in Cape Verde,

Yes,

I want a new song

for Cape Verde,

a new song

for this country

that stone by stone

rebuilds itself,

that little by little,

vigorously,

out of no past

builds its future.

Looking for evidence of postcolonial Cape Verdeanness in "Song for Cape Verde,"

the reader notices the celebration of the success of the heroic independence struggle,

referred to here in the third stanza,

We are no longer

"Victims of the East Wind,"1

which we overpowered.

We are no longer contracted laborers

like beasts of burden heading South,

for we have conquered dignity.

in the seventh stanza ("the heroism of my people"), and in the ninth stanza ("this

triumphant Cape Verde"). In this poem, however, one also witnesses recognition, 
especially in the final stanza of "Song for Cape Verde," that the transformation of Cape Verde, while it is surely well underway, is still an incomplete matter, requiring post-independence vigilance. In that sixteenth (the final) stanza, one encounters

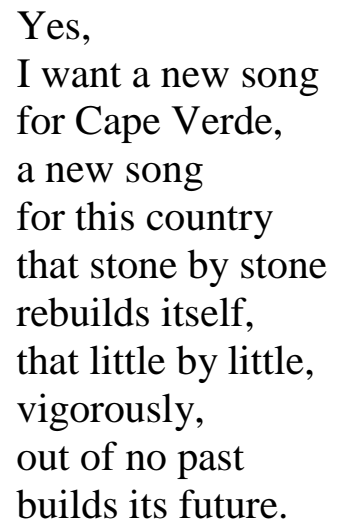

The reader also sees an example of postcolonial Cape Verdeanness in the use of Kriolu in this poem (see "morabeza" [warmth] in stanza 10; "funaná" [a heavily African-influenced Cape Verdean musical form] and "coladeira" [a Cape Verdean musical form which can be categorized as something like an upbeat "morna"] both in stanza 14; and "sabura" [delight] in stanza 15).

Searching for elements of continuity of colonial-era Cape Verdeanness in the poem "Song for Cape Verde," one finds such elements in references to "Cape Verde" in the poem's title, and in stanzas 1, 4, 5, 9, 12, and 16 of the poem. Furthermore, one sees it in references to "these islands," "this country," and "these people" in the second stanza of the poem. Continuity of colonial-era Cape Verdeanness may also be found in the references to Cape Verdean history in the form of allusions to Sao Tomé (a labor camp for Cape Verdeans during the later part of the colonial period) in the third and fifteenth stanzas. References to the land in stanzas seven ("the parched and arid land"), eight, 
from the ocean's

salty waves,

make rocks fertile

and thorns bloom,

who create gardens

on volcanic ashes,

and plan orchards

on rocky soil,

and turn desert winds

into the sweetly delicious breezes

of beautiful tropical nights.

ten,

I sing

these African sandy pebbles

resting in the ocean between continents,

from the middle of the sea,

from the middle of the world,

and thirteen, in this poem,

I sing

the country of blue seas, open skies and lofty mountains.

I sing the Fort of Santiago, the carnival of Mindelo, the First of May in São Filipe.

are further examples here of continuities of colonial-era Cape Verdeanness.

Continuities of Cape Verdeanness from the colonial-era are also visible in the "Song for Cape Verde" in the celebration of Cape Verdean feasts noted in the thirteenth stanza of the poem. There, one encounters "the carnival of Mindelo, / the First of May in São Filipe." More continuity of colonial-era Cape Verdeanness can be seen in the pride shown in the country in the tenth and eleventh stanzas of the poem. In the tenth stanza, 
one encounters

I sing

these African sandy pebbles

resting in the ocean between continents,

from the middle of the sea,

from the middle of the world,

signaling the course,

pointing the way,

offering to all

the eternal gift

of warm morabeza

and the shelter

of our embrace.

Additionally, in the eleventh stanza, one hears of "wanderers who carry / progress and well-being to foreign lands."

\section{Conclusions:}

\section{$\underline{\text { Seven Postcolonial Cape Verdean Poems From a Non-Diasporic Point Of View }}$}

The representations of Cape Verdeanness in the above seven postcolonial Cape Verdean poems written from a non-diasporic view cover an extraordinary range of aspects, from the concrete, to the abstract, to the subtle, and to the self-referential. Elements of continuity of Cape Verdeanness from the colonial era in this set of Cape Verdean poems include the land and climate of Cape Verde; the eternal prayer for rain; the profound power of the land to be experienced, despite its material deficiencies, as nurturing and accommodating; the uniqueness and the importance of the history of Cape Verde; the strengths of the Cape Verdean people, including hope, flexibility, tenaciousness, and resiliency; the Cape Verdean way of life, including its music, 
celebrations, and food; and the Cape Verdean way of conceptualizing life, including the way Cape Verdeans conceive of geographic space and time. Postcolonial elements of Cape Verdeanness in these seven non-diasporic poems include the tremendous challenges faced by Cape Verde, which includes ambivalence regarding prospective Cape Verdean outcomes; Cape Verde's unrealized fecund potential; the possible outing of sexual double-standards that favor virgins; cynicism about the future that can border on hopelessness; and the intense inner conflicts faced in interpersonal romantic intimacy. 


\section{Chapter Six: Cape Verdeanness in Postcolonial Diasporic Cape Verdean Poetry}

\section{An introduction to the Poetry of Jarita Adia Davis}

Jarita Adia Davis represents a special case as a producer of Cape Verdean poetry. Neither Davis, nor her Cape Verdean-American mother (whose father was from Cape Verde), was born in the Cape Verde Islands. Davis' father is an African-American, and Jarita Davis self-identifies as an African-American (personal communication, October, 2010). Yet Davis titled her Creative Writing doctoral dissertation As Minhas Mornas, finding that it was primarily Cape Verdean-related material that she felt compelled to express in that work. Nearly all of the forty-two poems in her doctoral dissertation have a Cape Verdean focus. Clearly, Davis is not Cape Verdean, while her dissertation, As Minhas Mornas, is.

In her dissertation's forty page introduction to her poetry, Davis describes her Cape Verdean connection at length. She states that "the poems are constructed form the shards of memory, history, and daydreams I discovered and adapted into my work while writing about Cape Verdean culture" (viii). Davis had compelling extended family childhood experiences that connected her to the Cape Verdean culture.

Davis tells her readers, "I began as I stumbled over fragments of memory that pointed to my link to Cape Verdean heritage" (viii). She goes on to say that "although I felt my ties to this community were weak, flashes of the past continued to remind me of the effect this culture has had upon me. The detailed glimpses into my childhood presented no logic or obvious connection, but they continued to appear and demand 
recognition" (viii). The non-linearity of Davis' experience of her Cape Verdean heritage represents the power of culture to work on us unconsciously.

Davis continues by sharing that "the undeveloped and youthful conception of [her] ancestry offered an incomplete picture of the influence Cape Verdean culture has upon shaping [her] life" (x). Further, Davis tells us that she "first explored memories from [her] own childhood and interactions with other Cape Verdeans in America in hopes of establishing a fuller understanding of how [her] identity has been formed.” (x). Immersion in a culture of one's past heritage has the capacity to elicit one's unconscious links to that culture. Her "subconscious insisted this culture was a part of [her], and [she] wrote these poems during [her] attempt to learn more about it” (x). Davis utilized an immersion into the Cape Verdean culture to allow her unconscious Cape Verdean heritage to speak to her.

Davis tells us that she "explored how this [Cape Verdean] history continues to influence [her] life" (xiv). In this process, she "discovered...bits of a contemporary Cape Verdean-American culture in... [her] own home" (xiv). Sometimes, one might not notice that what is around us in our homes reflects the subconscious voices of our heritage. Davis furthermore informs us that Cape Verde had always been the 'old country" to her (xvii). She believes that her privilege of having grown up in America "cost [her] a closer connection to [her] heritage" (xxii). This realization suggests some grief for Davis over this loss of a greater connection to her heritage.

Davis makes clear that her "poems do not represent Cape Verdean culture and tradition with precise authority, [although] they offer an expression of the influence [of] 
this community and its past" (xxxii). Davis is acknowledging here that these poems represent the previously silenced voice of her Cape Verdean heritage. Davis speaks of "precise authority" in the above quoted sentence seemingly as an essentialist might. All that anyone can offer up of their culture is their idiosyncratic expressions of exposures to that culture.

Davis suggests that "Cape Verdeans employ their memories to continue to build onto the existing culture" (xxxiii). In that position, Davis is like the earlier noted social scientists of cultural identity, Stuart Hall, and Mai Palmberg, who suggest that there are shared and idiosyncratic aspects within cultural groups. Furthermore, Davis tells us that "illusions are necessary to counterbalance the sense of separation many Cape Verdeans feel for their families that may be scattered throughout the world" (xxxv). Interestingly, Davis believes that "altered and illusory memories are the most vital parts of the Cape Verdean culture upon which [she has] built this collection" (xxxvi, italics mine). For Davis, "this romanticized nostalgia is a life-sustaining force that should not be dismissed as fantasy, but recognized as an element that unifies the Cape Verdeans scattered across the globe" (xxxvi). In this perspective, regarding the value of romanticized nostalgia, Davis seems to parallel Fêo Rodrigues' insights noted earlier here regarding the important value of invented Cape Verdean constructs of unproblematic hybridity.

Going on, regarding the ubiquity of Cape Verdean migration, Davis tells us that the fact that Cape Verdeans "share this experience draws them together spiritually" (xxxvi). This is, then, a shared suffering for Cape Verdeans of the sort that other diasporic cultures have experienced at times. For Davis, "Cape Verdeans have learned to develop a 
comforting expression of nostalgia to ease the strain of the seemingly inevitable separation that shapes their lives" (xxxvii). Shared sodadi thereby provides communal comfort for Cape Verdeans. For Davis, "Cape Verdeans have incorporated sentimentalism into their cultural identity by recognizing separation as a communal circumstance" (xxxviii).

Davis sees Cape Verde as a place that "readily incorporates...new elements into existing traditions" (xxxix). Davis recognizes that Cape Verdeans take in whatever arrives on their shores and adapt whatever lands on the Islands to their needs. For Davis,

"Cape Verdeans have been so successful at creating new forms through adaptation that they have developed an entire genre of music out of this cultural phenomenon of distance, alienation and sentimentality. They have taken the difficulty of their circumstances of separation and loneliness into the creation of the morna, a genre of music particular to Cape Verde with a low, sad melody and the lyrical themes of sodade [sodadi], which can loosely be translated as a sense of nostalgia, separation, homesickness, and loneliness"(xli).

Davis tells us that the title of her dissertation has emerged from her "own separation from the Cape Verdean community" (xli-xlii). The title of her dissertation, As Minhas Mornas, suggests that Davis is mournful about that separation from her Cape Verdean cultural heritage. Davis informs us that in her poems she was "inspired by the spirit of Cape Verdean culture more than [she] was concerned about representing 'facts' with accuracy and exactness" (xlii). As a poet, Davis appreciates that the spirit of a culture is more compelling than the facts of that culture. She explains that her "search for 
a better understanding of the clipped memories of Cape Verdean influences in [her] childhood led [her] toward participation in an evolving culture" (xliii).

Significantly, within her dissertation, Davis has reviewed two of the three poems that I will analyze here. Specifically, those two poems are "Atlantic Coasts," and "One Criolinha Speaks." In reviewing her own poem "Atlantic Coasts," Davis tells us that "it demonstrates an attempt to reign in [her] daydreams of a distant and elapsed Cape Verde and to focus upon the immediate time and place" (xiv). Davis seeks to honor both her fantasies about Cape Verde and her understandings of Cape Verdean reality, though appears to favor the latter over the former. Davis informs us that "although the poem begins by imaging that these boys 'could be in Praia', it later takes the reader from that nostalgic daydream to reinforce the importance of the boys themselves and their experiences in New Bedford rather than the past they might represent" (xv).

In reviewing her own poem "One Criolinha Speaks," Davis tells us that she is "reconstructing a new shape for the pieces of [her] culture that [she has] found" (xlv). She informs us that by "taking separate fragments and joining them to make a new work of art, the pieces of the past become an act of creative memory" (xlv). As my review of that poem shall demonstrate, the text of that poem suggests the fragility of that process for Davis.

Importantly, Davis tells us that her "collection does not define the Cape Verdean or Cape Verdean-American experience, however, it is a contribution to this culture" (xlvi). While acknowledging the limits of her own Cape Verdeanness, clearly Davis is suggesting here that her work is a Cape Verdean poetic production ("a contribution to this 
[Cape Verdean] culture"). Davis informs us that she "would like to write more poems about the conflicts between racial and ethnic identities" (xlvii). Given the diversity of her background, her desire to integrate it, and her capabilities as a poet, one can be grateful that Davis has provided the Cape Verdean piece of her puzzle such incredibly valuable attention.

\section{Postcolonial Cape Verdean Diasporic Poetry}

Jarita Adia Davis and Adelina Da Silva both share a diasporic Cape-Verdeanness in their poetic productions. While Adelina Da Silva was born in Cape Verde and emigrated to Massachusetts, and has a two parent Cape Verdean heritage, Jarita Davis' mother has a father who was born in Cape Verde. I believe that there are unique features to a postcolonial diasporic Cape Verdeanness, and that the poetry of Davis and Da Silva will support this perspective.

In particular, in order to flesh out postcolonial diasporic Cape Verdeanness, I will analyze three poems from Jarita Adia Davis' As Minhas Mornas and one poem by Adelina Da Silva. The poems by Jarita Adia Davis are "Atlantic Coasts," "One Criolinha Speaks," and "You Cannot Prepare for This Trip." Adelina Da Silva's poem is "Return to the Homeland." I will examine the poetry of Jarita Adia Davis first.

The particular Jarita Adia Davis poems have been chosen for review for a number of reasons. For one, the first two of them have been reviewed by the author in her dissertation, which can only help guide a reader's consideration of those poems. Secondly, these three selected poems of hers come across to me as the most relevant to an 
enhanced understanding of postcolonial diasporic Cape Verdeanness. The order of my rendering of the Jarita Adia Davis poems is purely alphabetical here.

\section{$\underline{\text { Atlantic Coasts }}$}

In the Jarita Adia Davis poem "Atlantic Coasts," the reader notes that there is some repetition. The expression "take a picture of this," and the related expressions "to photograph," "taking pictures of," and "I picture" are scattered in the third, fourth, fifth, sixth, and eighth stanzas (half of the stanzas) of this poem. "Cabo Verde" (the Portuguese for 'Cape Verde') appears twice in this poem; it is in stanzas two and nine. "Praia" (the capital of Cape Verde, located on the island of Santiago) appears twice in the poem, as well; it is found in stanzas one and four.

The significant number of repetitions related to photography in "Atlantic Coasts" seems significant, and thereby worthy of some attention. The photography-related repetitions noted may suggest that the poem's speaker is interested in capturing impressions so they may be remembered. Supporting this perspective, the reader can see that memory is referred to directly in the poem's ninth stanza ("their home, to remember lost / family in Cabo Verde. This").

The repetitions of references to "Cabo Verde" and "Praia" in "Atlantic Coasts" suggest that those are important signifiers for the poem's speaker here. They can be viewed as metaphors for one of the two "Atlantic Coasts" referred to in the poem's title. The title of this poem suggests the centrality of cultural identity to the poem.

The bifurcated aspect of cultural identity can be gleaned especially from the second 
word of the poem's title, "Coasts." That bifurcated status is most directly suggested in the fourth and fifth stanzas of "Atlantic Coasts," when the reader is told

and the sea washing up smooth rocks and jelly fish for them.

But they're not in Praia, they're here, we're all here, in New Bedford where

they dig at the beach with sticks and face the Atlantic from the other side....

The poem's mention of "and face the Atlantic from the other / side" especially implies the fact of there being two Atlantic coasts (the Cape Verdean side and the Massachusetts side).

Not only does cultural identity seem important to this poem's speaker, but also one's general identity. The importance of general identity to the poem's speaker can be seen in the previously noted repetitions of the photography/memory motif at various points in this poem. A closer examination of "Atlantic Coasts" shall allow the reader a deeper understanding of the importance of identity and cultural identity for this poem.

In the first stanza of "Atlantic Coasts," one notes that the poem's speaker is suggesting an appreciation of cultural identity ("These boys could be in Praia, / I think."). The particular images in that first stanza suggest attention to elements of Cape Verdean cultural identity. For the poem's speaker, Cape Verdean cultural identity is to be implicitly located in "Dried sea salt coarse / across their shoulders. They dig / their feet into the sand,". The fact that the "Dried sea salt" is "coarse" suggests a roughness to diasporic Cape Verdean cultural identity. The fact that the "sea salt" is "Dried," and not 
moist, suggests (even though one may ordinarily think of salt as dry) that the consciousness of one's Cape Verdeanness has been lost in the diasporic Cape Verdean circumstance.

In the second stanza of "Atlantic Coasts," the reader is led to sense the continuity between generations, and that continuity's dependency on the adequate ongoing construction of impressions, relating to cultural identity, which will be "leaving smudges like their grandfathers / left on Cabo Verde at this age." In that stanza's "glimmers of polished glass / and trail tracks along the shore," the reader is provided with two more instantiations of the significance of impressions of memory as pertains to cultural identity ("glimmers" and the "trail tracks"). A look at the poem's third stanza, immediately brings one back in time "Across the ocean and decades / before, two boys called each other / in Crioulo." The lines "These boys could be in Praia" in the poem's first stanza and "decades / before, two boys called each other / in Crioulo" in the poem's third stanza both instigate the sense of linkage in a historical chain, encouraging an appreciation of cultural identity.

In the fourth stanza of "Atlantic Coasts," cultural identity is pinned, in part, to geography ("But they're not in Praia, they're here, / we're all here, in New Bedford"). In that stanza, one views "the sea washing up smooth / rocks and jelly fish for them." That suggests several things simultaneously. For one, "the sea" is clearly a source of sustenance or at least support "for them." Secondarily, since the fish are "jelly fish," one might imagine how the consistency of "jelly" (very fluid but sticky) compares with that of "smooth / rocks" (very solid, frictionless, and separate). One might thereby decide that 
these two contrasting aspects, solidity, which is frictionless and separate, along with sticky fluidity are component elements to a Cape Verdean cultural identity. There you would have distance that is tangible and connection that is impossible to extricate oneself from.

In the fifth stanza of "Atlantic Coasts", the reader may wonder if the expression "they dig at the beach" has dual meanings, first the obvious literal one, and, additionally, "they dig [being] at the beach." In that stanza, having to "face the Atlantic from the other / side" the boys can be said to be looking at life from their New Bedford, American cultural identities. In the poem's sixth stanza, the boys "collect / their stash," and "the younger one suggests" immediately to " "take a picture of this"." What one chooses to collect says a great deal about someone's identity, and "the younger one," perhaps, seeks the power of a memory (a photograph) of this "stash" for his perhaps less developed sense of identity.

At the end of the sixth stanza, which grammatically is joined to the beginning of the seventh stanza in "Atlantic Coasts," the reader sees "the younger one" there "holding // a twisted clump of seaweed / and goo." At the same time, "The older boy is serious. / He carries stones with important / colors for me to photograph." In this juxtaposition of "the younger one" and "the older boy" one may clearly read that "the older boy" has a clear sense of his gender whereas "the younger one" is more or less genderless. Furthermore, "the younger one" is acting much differently (more playfully) than "The older boy." Hence, chronological age is twice here being associated with identity.

The reader has just seen "the younger one" with "a twisted clump of seaweed / and 
goo.", and "The older boy [who] is serious. / He carries stones with important / colors". One may consider that "seaweed / and goo" are things that, even if they are attached to the sea bottom, rise above the sea bottom, whereas "stones with important / colors" are generally located on the ground, whether on the sand at the beach or on the sea bottom. One may assume from this differentiation that "The older boy," who already has been identified by the poem's speaker as "serious," may be more grounded than "the younger one." It appears that the poem's speaker in "Atlantic Coasts" favors "The older boy" in the ascription of "important" to the "colors" of the "stones" that "He carries."

In the eighth stanza of "Atlantic Coasts," the reader is handed the central binding element of cultural identity for the poem's speaker, and that is "the water" ("Our tie to each other / and to the past is the water."). The remainder of that eighth stanza ("They do not discover / and uncover bits from shore,") may be read two ways. For one, it may be read with its obvious literal meaning. On the other hand, it might also be reasonably read as "They do not discover / and uncover [merely] bits from [the] shore."

The end of the eighth stanza in "Atlantic Coasts" is continuous grammatically with the beginning of the poem's ninth stanza. There one sees,

They do not discover and uncover bits from shore, their home, to remember lost family in Cabo Verde. This

Clearly this sentence in the poem across the two stanzas relates in two direct ways to cultural identity. One is by suggesting that the "shore" is "their home and the other is by implying that "to remember lost / family in Cabo Verde" is important. 
If the reader examines what can be reasonably identified as the second half of the ninth stanza in "Atlantic Coasts" ("This / is where they are. This is where / we are. 'Take a picture of this,"'), the poem is very geographically-minded in a way that one only otherwise sees in this poem in its title and in the fourth stanza, with "But they're not in Praia, they're here, / we're all here, in New Bedford." This second half of the ninth stanza reinforces the powerful influence of geography on identity that was established in the poem's title and in the fourth stanza. This point about the power of geography seems additionally reinforced by the poem's suggestion and/or command in that ninth stanza, “"Take a picture of this'," which asks for this particular image to gain privileged status as a memory. Memory, the source of identity, is thereby linked with geography in this stanza of "Atlantic Coasts."

The end of the ninth stanza in "Atlantic Coasts" grammatically runs into its tenth (its final) stanza. Bringing the stanzas together grammatically yields, “Take a picture of this,' // the younger one offers, grinning / at the snail peering from its shell.” This association of "the younger one" with "the snail peering from its shell" suggests that "the younger one," like the snail leaving its security in the veil of the shell, is leaving behind some of his innocence, as well, on his way to a new identity, perhaps that of boyhood. In this poem it seems that through the involvement of "the younger one" with "The older boy" a developmental process of identification has subliminally been engendered, with its consequent implications at least suggested by the final stanza.

In searching for elements of postcolonial diasporic Cape Verdeanness in "Atlantic Coasts," the reader sees how the poem addresses identity, and, especially, Cape Verdean 
cultural identity. Additionally, the implicit valuation of the continuity of cultural identity in "Atlantic Coasts" may, itself, be seen to represent an element of postcolonial diasporic Cape Verdeanness in this poem. The reference to "Crioulo" (the Cape Verdean language, Kriolu) in the third stanza of the poem seems also to be an instantiation of a representation of postcolonial Cape Verdeanness.

There are also multiple elements of continuity of colonial-era Cape Verdeanness that may be identified in this poem. For one, there are the references to "Cabo Verde" and "Praia." Secondarily, there are multiple references to "the sea," in this poem, and, in fact, in the eighth stanza, it "is the water" that is identified as "Our tie to each other / and to the past." Finally, given that "New Bedford" has a long and enduring Cape Verdean-American history, the reference to that Massachusetts city in the fourth stanza of "Atlantic Coasts" can be seen as yet another demonstration of the poem's representation of the continuity of colonial-era Cape Verdeanness.

\section{$\underline{\text { One Criolinha Speaks }}$}

In the Jarita Adia Davis poem, "One Criolinha Speaks," one finds that there are three repetitions of the word "voice;" they are located in the second, fourth, and seventh lines of the poem. There is no punctuation in this poem, but were the poem naturally punctuated, the word "voice" would appear in each of this poem's first two sentences (including twice in the second sentence). Each use of the word "voice" in this poem is connected with something distinctly different from each other usage of that word.

In the first instance of "voice" in the poem, one hears "I am not/ the voice / of 
Cabo Verde." In the second appearance of "voice" in the poem, one is told "I am a voice / calling for Cabo Verde / a lonely..." Finally, in its third representation in the poem, one encounters

a lonely voice

naked

on the edge

of a stranger's bed

The first and second usages of the word "voice" in "One Criolinha Speaks" both relate directly to "Cabo Verde." In the first instance of the word "voice," the poem's speaker does not want to be seen as a representation of Cape Verde. In the second appearance of the word "voice," the poem's speaker seems to be asking either for recognition of Cape Verde or for Cape Verde to comfort and /or protect her. In the third presence of the word "voice," the poem's speaker appears to be describing her sense of isolation (“[I am] a lonely voice”), her naturalness or vulnerability (“[I am] naked”), and either a suggestion of transition, fear, or distress (" $[\mathrm{I}$ am] naked / on the edge / of a stranger's bed").

Since the word "voice" appears three times in "One Criolinha Speaks", and the Portuguese name for Cape Verde, "Cabo Verde," appears twice in the poem, and the title of the poem is "One Criolinha Speaks" ("Criolinha" is a Portuguese word, as well), one may wish to consider that the concept of identity, especially Cape Verdean identity, is a central element of this poem. In support of this consideration of identity, especially Cape Verdean identity, as a central element of this poem, the word "I" appears in this poem in the first and fourth lines. In both instances of its appearance in this poem, the word "I" is 
semantically connected to the word "voice."

In its first appearance in the poem, the reader sees "I" in "I am not / the voice / of Cabo Verde." In its second usage in the poem, the reader sees "I" in "I am a voice / calling / for Cabo Verde." One may note the juxtaposition of an affirmation and a negation in the two instances of the uses of "I" in this poem. Identity might well be defined as a process of distinction between the 'I' and the 'not I'.

If the reader wishes to examine "One Criolinha Speaks" with an eye to identity, especially Cape Verdean identity, as a central element, he or she must then pore through the poem to find the instantiations of identity, and, especially, of Cape Verdean identity. I have already noted that the title of this poem suggests identity, and, especially, Cape Verdean identity. The first implicit sentence in this unpunctuated single stanza poem is "I am not the voice of Cabo Verde." It can be seen as a direct sentiment about the poem's speaker's identity, especially by implying how that identity is not equal to Cape Verdean identity.

A second implied sentence in "One Criolinha Speaks" may be seen to be "I am a voice calling for Cabo Verde.” This implied second sentence of the poem may also be viewed as a direct statement about the poem's speaker's identity. Though not wanting her identity to be equated with Cape Verdean identity, as earlier noted, this poem's speaker makes it known here that Cape Verde is a significant part of her identity. The second implied sentence in this poem may suggest that the poem's speaker either wishes to give recognition to Cape Verde or else to receive comfort and protection from Cape Verde, perhaps in the manner of calling out to one's ancestors, a phenomenon which has been 
described by Malidoma Somé (in his text, The Healing Wisdom of Africa) as a central element in the history of spiritual practice for at least some West-African peoples.

Looking at the third implied sentence in "One Criolinha Speaks," one can see

a lonely voice

naked

on the edge

of a stranger's bed

In this third implied sentence of the poem, the poem's speaker appears to be describing her sense of isolation (“[I am] a lonely voice"), naturalness or vulnerability ("[I am] naked”), and either transition, fear, or distress (“[ $\mathrm{I}$ am $]$ naked/ on the edge/ of a stranger's bed"). All of these acknowledgments by the poem's speaker in the third implied sentence of the poem may mildly or intensely relate to her identity. It cannot be known from the text of the poem whether or not the poem's speaker is describing only a single instance of being in such a situation. That could mean something distinctly different for the identity of the poem's speaker than if this third implied sentence of the poem represented a rather repetitive experience for her.

Turning attention to the fourth (the final) implied sentence in "One Criolinha Speaks," the reader can see

[I am] slipping each poem

in turn onto a thin gold chain like painted beads from the necklace broken at my feet 
Here, when the reader goes looking for references to identity, they notice that the poem's speaker has been involved with poems ("slipping / each poem"), which surely acknowledges that poetry is part of her identity, though it is not made clear within the poem if these poems are those she or somebody else has authored.

In "One Criolinha Speaks," in that fourth implicit sentence, poems are being slipped "onto a thin / gold chain." The act of "slipping" a poem "onto a thin / gold chain" would seem like quite a delicate process, so that would suggest something about the speaker of the poem's identity being vulnerable. Also, the fact that the poems are being cumulatively slipped onto a "chain" suggests that the poem's speaker wishes to bring these poems together. Furthermore, since it is the collection of poems that are finding their way onto the "gold chain," the reader would do well to assume that gold and the collection of poems are both prized by the poem's speaker. The fact that the "gold chain" is "thin" could suggest its vulnerability or delicateness. Since it is the poem's speaker's "thin / gold chain" on which they are placing "each poem," one might well see more evidence here that the poem's speaker's identity includes a sense of vulnerability or delicateness.

Going further along in the fourth implicit sentence of "One Criolinha Speaks," one sees
slipping each poem in turn onto a thin gold chain 
like painted beads

from the necklace

broken

at my feet

The "feet" are, generally speaking, what one stands on, and for the poem's speaker here "painted beads" are there at their "feet." This section of the poem suggests that the poem's speaker may deeply wish to be able to take a broken identity ("the necklace / broken / at my feet") and through the successful linking together of "each poem" instigate an integrated self.

Clearly, in this poem, "One Criolinha Speaks," there appears to be a central element of identity. There is a visible continuity of colonial-era Cape Verdeanness in this poem in its references to a "Criolinha" in its title and in its mention of "Cabo Verde" (in the third and sixth lines of the poem). In this poem, postcolonial diasporic Cape Verdeanness can be seen in the importance of identity that is expressed throughout this poem. The importance of Cape Verdean identity is clear, especially in the poem's implied second sentence ("I am a voice calling for Cabo Verde."). The fragility of postcolonial diasporic Cape Verdean identity may be suggested, as well, in the poem's implied third and fourth sentences:

[I am] a lonely voice naked on the edge of a stranger's bed [I am] slipping each poem in turn onto a thin gold chain like painted beads 
from the necklace

broken

at my feet

\section{$\underline{\text { You Cannot Prepare for This Trip }}$}

In "You Cannot Prepare for This Trip," all of the final five stanzas begin with the word "go," suggesting that the poem's speaker is very much exhorting particular action. There are only three words capitalized in "You Cannot Prepare For This Trip" aside from the words in the poem's title, and they are all located in the poem's fourth stanza. If you examine that stanza, you see that those capitalized words include "Are," "Cape Verdean," and "Yes."

go so the next time someone asks, Are you

Cape Verdean? you can say, Yes. instead of my grandfather was.

The capitalization here might merely be suggesting dialogue and a proper noun. Yet capitalization, when it is utilized in such an idiosyncratic manner as it is in this poem, may well be intended to garner particular attention for those capitalized words from the reader. When brought together, this poem's capitalized words ("Yes," "Are", "Cape Verdean") imply the importance of a Cape Verdean identity to the poem's speaker.

The central element of "You Cannot Prepare for This Trip" appears to be that of Cape Verdean identity. This particular element is most clearly visible in this poem's fourth stanza, where the reader is told go so the next time someone asks, Are you Cape Verdean? you can say, Yes. instead of my grandfather was. 
The fact that the poem's title, "You Cannot Prepare for This Trip" seems cryptic, on its surface, asks us to look deeper into it. In general, unless Westerners are in crisis situations (war, terrorism, natural catastrophes, kidnapping, and the like) they generally feel that trips may be carefully prepared for. Yet, here, in this poem, the reader is told by the poem's title that they "Cannot Prepare for This Trip." What could make a trip to Cape Verde so different than any other trip, perhaps, say, a trip to Ireland for a person of Irish descent? What the poem's content seems to be suggesting is that at least for someone with Cape Verdean ancestry a trip to Cape Verde will be like no other intentional journey (as in the way it is oft stated that one can never fully prepare for the project of parenthood).

Let's see what, in particular, in this poem "You Cannot Prepare for This Trip" supports the idea that for those of Cape Verdean ancestry, at least, a journey to Cape Verde will be colored by the unexpected. There is more to learn about the unexpected that we may find in Cape Verde if one looks to the poem's third stanza, to

go to learn the value of water. to appreciate the bowlful brought up a steep mountainside upon the heads of women and girls whose husbands and fathers and brothers left them for work across the Atlantic.

For sure, "the value of water" is generally quite differently appreciated in Cape Verde than it is in the West.

You also may look for a hint of the unexpected in Cape Verde in the fifth stanza of "You Cannot Prepare for This Trip," which asks the reader to go with this picture of your grandfather in your pocket. 
the name of his father and village written on the back. go because someone you have not yet met is waiting for you there.

Clearly, it is not generally common in the West to go abroad with the name of your great-grandfather and his "village," and find "someone you have / not yet met is waiting for you there." Perhaps, then, these unexpected encounters with the porting of water and with familial relations are central components of what might well make it impossible for someone of Cape Verdean ancestry to fully prepare for a journey to Cape Verde. Perhaps, too, this impossibility to fully prepare for a return to the homeland is part of what makes up diasporic Cape Verdeanness.

The first stanza of "You Cannot Prepare for This Trip," excepting for the final line of that stanza ("and make this list to take with you:") seems to suggest the ordinary sorts of preparations Westerners make for their trips abroad. That final line of that first stanza gives quite a new twist to the meaning of the word "list." The poem's speaker has handed the reader a "list" not made up of must-see sights in Cape Verde but of why one must go (which is detailed in the second, third, fourth, fifth, and sixth stanzas), and one unusual item, noted in the fifth stanza, which one must carry there ("this picture of your grandfather in your pocket. / the name of his father and village written / on the back.”).

Clearly the purposes suggested by the poem's speaker, here, to persons of Cape Verdean ancestry, for their going to Cape Verde, seem distinct from the ordinary reasons Westerners might be encouraged to visit the lands of their forbearers, if they are even so encouraged. For example, someone of Irish descent might go to Ireland to see the land of their Irish forbearers, but their doing so might not as likely lead to as great a deepening of 
their sense of their own Irishness as the Cape Verdean might experience from going to Cape Verde. Part of the relative power of Cape Verde over its 'progeny' when compared to other places of ancestry may be in its integrity. Generally not having yet been overtaken by development, Cape Verde still retains much of its natural charm.

The reader can see more about diasporic Cape Verdeanness in "You Cannot Prepare for This Trip" if they continue along into the poem's second stanza. There, one is told to

go because your grandfather asked you even though when he did, he was too old to understand and called you by your mother's name.

This stanza of the poem suggests that filial obligation is a very central element to Cape Verdeanness, and that, perhaps, especially, given the Portuguese patriarchal tradition, there is an obligation to one's male forbearers. Jarita Adia Davis, the poem's author, identifies herself as the daughter of a maternal Cape Verdean grandfather, and that could also be why a male forbearer is referred to in this poem.

As one reads the third stanza of "You Cannot Prepare for This Trip," one hears of "women and girls / whose husbands and fathers and brothers left / them for work across the Atlantic." An aspect of continuity of colonial-era Cape Verdeanness that may be gleaned from this section of the third stanza of the poem is an appreciation of Cape Verdean history, for one, and secondly, an understanding that due to able-bodied male emigration, adult females in Cape Verde have for some time significantly outnumbered adult males on the Islands. That fact would suggest several significant implicit 
consequences for work and family life on Cape Verde, including a diminished availability of prospective husbands for the presumed heterosexual females, the absence of fathers from the children they have sired on Cape Verde, as well as a dearth of able-bodied adult males for the Cape Verdean work-force.

Moving into the fourth stanza of "You Cannot Prepare for This Trip," one is told

go so the next time someone asks, Are you

Cape Verdean? you can say, Yes. instead of my grandfather was.

It seems important to this poem's speaker that part of Cape Verdeanness is its significant incorporation into an identity, its internalization, something that is much more than a peripheral artifact of one's existence. The fact that "my grandfather was" Cape Verdean appears to be too superficial of a Cape Verdean cultural identification for the poem's speaker.

If the reader goes back to the somewhat cryptic fifth stanza of "You Cannot Prepare for This Trip," one must "go because someone you have / not yet met is waiting for you there." Who might it be that is waiting there, especially given the fact that one is, perhaps, visiting their great-grandfather's village in Cape Verde? If you are of Cape Verdean ancestry, it is, perhaps, not merely a "someone" (such as a relative) but also a something that is "waiting for you there," with that something being one's deepening Cape Verdeanness, transforming your prior self into your future self. The importance of connecting with one's cultural roots may be another element of postcolonial diasporic Cape Verdeanness. 
In the sixth stanza of "You Cannot Prepare for This Trip," the reader is told to go for a sense of direction. to feel the weight

of south and east and to walk in reference

to where the sun and ocean lie.

This stanza of the poem suggests that "sun" and "ocean" are long-standing central elements of Cape Verdeanness, and that those of Cape Verdean ancestry should "walk in reference to" them. What might it mean to "walk in reference / to where the sun and ocean lie."? As I see it, "walk" is a metaphor for our respective journeys in life, and "where the sun and ocean lie" is a metaphor for Cape Verde. So, postcolonial Cape Verdean diasporans' life journeys are encouraged to be taken "in reference / to" a connection with Cape Verde.

In that final stanza of "You Cannot Prepare for This Trip," the reader is told "to go for a sense of direction. to feel the weight / of south and east." What might it mean "to go for a sense of direction," "to feel the weight," and to what might the "south and east" refer? As I see it, "to feel the weight" is a metaphor for the word gravity, especially in its figurative sense, as in Cape Verde's significance for them. The "south and east" appears to refer to the location of Cape Verde in reference to the United States of America. Those Americans of Cape Verdean ancestry are apparently being asked by this poem's speaker, in the final stanza, here, to gain "a sense of direction" in their lives that is based on a deeply felt and valued connection to both Cape Verde and their Cape Verdeanness. This element of Cape Verdeanness may be seen as a steadfastness of cultural identity.

The poem, "You Cannot Prepare for This Trip" appears to deeply consider the construct of postcolonial diasporic Cape Verdeanness. By implying that some or even 
many of those in the Cape Verdean diaspora have lost central elements of their Cape Verdean identity which they need to reconnect with, this poem presents a challenge and aspiration for enhancement of the Cape Verdean story. That challenge and aspiration for the enhancement of the Cape Verdean story is a repeated motif in postcolonial Cape Verdean poetry.

In the poem, "You Cannot Prepare for This Trip" the reader sees numerous elements of a continuity of colonial-era Cape Verdeanness. First of all, the reader sees a direct reference to being "Cape Verdean" in the poem's fourth stanza. Furthermore, Cape Verdeanness is visible in the reference made to the value of water in the poem's third stanza:

go to learn the value of water. to appreciate the bowlful brought up a steep mountainside upon the heads of women and girls whose husbands and fathers and brothers left them for work across the Atlantic.

Finally, this continuity of colonial-era Cape Verdeanness is also visible in this poem's sixth (its final) stanza, when the reader is metaphorically given the geographic coordinates of Cape Verde ("of south and east").

\section{$\underline{\text { Return to the Homeland }}$}

Adelina Da Silva's poem "Return to the Homeland," which comes from Moser's Changing Africa: The First Literary Generation of Independent Cape Verde, provides a complementary example of postcolonial diasporic Cape Verdean poetry to the work of Jarita Adia Davis. Immediately, in "Return to the Homeland" the issue of Cape Verdean 
identity arises. One witnesses in the first stanza

I feel like a stranger amidst these bare rocks only yesterday walls of a wretched cabin that had been my home.

Here the poetic speaker is writing in the first person with the poem's first word, "I." This suggests that the individual diasporan is at the center of a diasporic Cape Verdean's focus. That may, indeed, be a distinguishing feature of the diasporic Cape Verdean from the Cape Verdean who is living on the Cape Verde Islands.

Taking a closer look at those first five lines of "Return to the Homeland," one can see that the speaker feels "like a stranger." Alienation has ensued from separation. If this poem is autobiographical, it might help to know that Adelina Da Silva spent her first eighteen years in Cape Verde, and that she has lived in Massachusetts, in the United States of America, since.

Still attending to these first five lines of "Return to the Homeland," one notices that the rocks are "bare." Rocks are often bare, so it puzzles the reader, perhaps, what about these rocks instigate the poem's speaker to refer to "bare rocks." It could be that the poem's speaker is made to feel bare, no longer hidden from themselves, regarding their painful feelings of alienation by those very "rocks."

In "Return to the Homeland," still peering at those first five lines, if the poem's speaker sees "only yesterday walls" where there had once stood "my home," one may assume that the speaker feels distant from her past. We always remain somewhat distant from "yesterday" (and tomorrow). It is only today which we can fully embrace. 
Still looking at those first five lines in "Return to the Homeland," one notices that the speaker's former "home" is represented as "a wretched cabin." It is not clear if the cabin has become wretched or was always that way, but "a wretched cabin" it is now. The speaker's former home may be "a wretched cabin" because it reminds the speaker of the wrenching pain of her alienation from her past. It may also literally be "a wretched cabin" because it has fallen into disuse or fallen apart from time. It may also be "a wretched cabin" because the speaker, after living in the U.S.A. for many years, now views the normal Cape Verdean abode as a hovel. It is also possible that the speaker viewed this domicile as "a wretched cabin" even when she inhabited it.

As the poem moves along in the first stanza, the speaker in "Return to the Homeland" then remembers a Cape Verdean past. The past is the place of a postcolonial diasporic Cape Verdean's link with their homeland. The reader observes

Step after step along your beaches a child's dim shape continues walking which at your breast saw the light of day.

It is Cape Verde that is the "breast" that nurtured this speaker in her youth. The poem's lines "which at your breast / saw the light of day" suggest that there was something profound about the influence of Cape Verde on the speaker's development. The child has a "dim shape" because much time has passed for the speaker, but even more so because her life has been ruptured by a departure from her homeland. Yet, too, "dim shape" may refer to the fact that the speaker considers children somewhat dimly, or that she, herself, 
was somewhat innocent or dim-witted as a child. Because of the past and present extent of malnutrition on the Cape Verdean Islands, many children have suffered from a failure to thrive.

In that memory of Cape Verde, noted above in "Return to the Homeland," there is a sense of distress associated with a "dim shape" that "continues walking," as if it is further and further out of the speaker's reach. It suggests a longing for something which the speaker has lost and desires to reclaim about being Cape Verdean (perhaps being able to see "the light of day"). The sentiment represented in the above paragraph associated with seeking that half-forgotten self gets reinforced in the first stanza of the poem's subsequent "come touch me, / feel me/ we're one." The speaker is requesting their raised in Cape Verdean half, their child-self, to be agentic, believing that the Cape Verdean child-self can move through time and space to "touch" and "feel" her. Quite magically, at least for a moment, the speaker's request is granted. Witness, "we're one."

Yet that unity of identity is represented as fleeting in "Return to the Homeland," and the reader encounters in the second stanza

What I'm hearing is not the voice of yore the bond that bound me is slipping I feel it

So, now the speaker is "hearing" something but it "is not / the voice of yore / the bond that bound me." Perhaps the speaker is noting the current absence of her prior Cape Verdean identity, yet it is unclear what the speaker is hearing. There may be a realization 
for the speaker that she can never again be the person whom she was then. Over time, "the bond that bound" her to her past self "is slipping," and she can "feel it." Perhaps she feels it as a loss, as emptiness, or with just plain acceptance of the inevitability of change.

"Return to the Homeland" closes with "How strange to fell like a prodigal son!" There are several important aspects about that choice of an expression, as I see it. For one, there is often for postcolonial diasporic Cape Verdeans a perception that just by leaving their Cape Verdean home they have done something unacceptable. Secondly, diasporic Cape Verdeans are usually reminded every day in their adopted lands of the relative material abundance that has come their way, with all of the material opportunities presented by the developed world, where they generally reside after leaving Cape Verde. People in Lisbon or Boston are not seen, as they frequently might be in Cape Verde, walking hundreds of yards carrying jugs of water resting on their heads. So without even debauching themselves, becoming a diasporic Cape Verdean can make one feel like "a prodigal son." Yet, perhaps, the loss of the capacity to see "the light of day," a capacity to see through a non-diasporan Cape Verdean's eyes, is the most salient aspect of the "prodigal son" ascription.

Looking at "Return to the Homeland," the reader finds a number of elements of postcolonial diasporic Cape Verdeanness. For one, it seems that the self is at the center of a postcolonial diasporic Cape Verdean's focus, and that, especially, he or she is preoccupied with a sense of identity. That may, indeed, be a distinguishing feature, especially, of the postcolonial diasporic Cape Verdean who has emigrated from the Cape Verdean Islands. This may be the result of the alienation which has ensued for the 
diasporic Cape Verdean due to their separation from their original home.

There may be a wrenching pain for the postcolonial diasporic Cape Verdean regarding their alienation from their past. Cape Verde had nurtured the diasporan in their youth prior to their emigration. There was something profound about the quality of this nurturing by Cape Verde that significantly influenced their development. A profound sensibility engendered by that nurturing from Cape Verde has become further and further out of the postcolonial diasporan's reach.

There is a realization that the postcolonial diasporic Cape Verdean can never again be the person whom they had previously been. There is often for postcolonial diasporic Cape Verdean emigrants an understanding from leaving their Cape Verdean homeland, especially if they have emigrated since Cape Verde's independence, that they have done something unacceptable. Postcolonial diasporic Cape Verdeans are usually reminded every day in their adopted lands of the relative material abundance that has come their way. Consequences of this relative material abundance include feeling further disconnected from Cape Verde and its people.

Furthermore, one can note that Cape Verdean cultural identity is an element of postcolonial Cape Verdeanness, and, especially, more self-consciously so for diasporans. One also sees that positive memory of a relationship to Cape Verde is another such element of postcolonial diasporic Cape Verdeanness. Finally, one sees that an aspect of postcolonial Cape Verdeanness, for diasporan emigrants, may be a feeling of guilt and/or shame that one has lost something of one's Cape Verdean identity. Postcolonial diasporic Cape Verdeanness is clearly a fraught condition. 


\section{Conclusions Regarding Postcolonial Cape Verdean Poetry}

\section{From a Diasporic Point Of View}

Taken together, these three poems of Jarita Adia Davis and the one of Adelina Da Silva demonstrate salient elements of postcolonial diasporic Cape Verdeanness. These elements include concern with one's identity, including the experience of alienation from and connection with one's Cape Verdean identity, an appreciation of one's personal narrative of Cape Verdean influences, the importance of Cape Verdean history, geography, and folkways, the importance of the sea, the importance of intra-ethnic group connection, the importance of time and memory, the significance of water, and personal disappointment, shame, or guilt.

Postcolonial Cape Verdean poetry demonstrates two distinct sets of concerns: those held by Cape Verdeans who have remained in their homeland and those held by Cape Verdeans who have emigrated from their homeland (or who are first or second generation offspring of persons who have emigrated from Cape Verde). Cape Verdeans who have remained in their homeland since its independence, while concerned with matters of identity, generally differ from postcolonial Cape Verdeans who have emigrated (or who are the offspring of émigrés) in that their concern about identity are not Cape Verdean-specific whereas those of émigrés (or their offspring) are. Furthermore, while postcolonial émigrés or their offspring such as the poets Davis and Da Silva may possess disappointment, guilt, or shame about their absence from their homeland, Cape Verdeans presently living on the Islands do not possess such disappointment, guilt, or shame. Finally, one sees in the poetry of Davis and Da Silva that memory has more import for 
postcolonial Cape Verdean émigrés or their offspring than it appears to have for Cape Verdeans who have not left, or who have returned to, their homeland. 


\section{Chapter Seven: Cape Verdeanness in Postcolonial Cape Verdean Poetry}

The scholarly literature suggests that postcolonial Cape Verdean poetry has shown both continuity and transformation, even to the point of rupture, from previous incarnations of Cape Verdean poetry. The continuity is visible both in poetic content references particular to Cape Verde and in the selection of concerns, such as freedom and imprisonment, that have been previously addressed in the Cape Verdean poetic record. The rupture and transformation of Cape Verdean poetry may be witnessed in the extraordinary enlargement of the topical base to encompass universal human concerns, and, perhaps, even more so, in a forwardness and directness pertaining to matters of love and sexuality that was wholly absent prior to Cape Verdean independence. In the scholarly literature on Cape Verdean poetry, Cape Verdeanness appears to now be both as small as Cape Verde and as large as the universe.

My analyses earlier here of the postcolonial Cape Verdean poems have suggested that there are two main branches of postcolonial Cape Verdean poetry, diasporic and non-diasporic. Postcolonial Cape Verdean poetry can be seen to thereby have two distinct sets of concerns: those held by Cape Verdeans who have remained in their homeland and those held by Cape Verdeans who have emigrated from their homeland (or who are offspring of persons who have emigrated from Cape Verde). The elements of diasporic Cape Verdeanness include concern with one's identity, including the experience of alienation from and connection with one's Cape Verdean identity, an appreciation of one's personal narrative of Cape Verdean influences, the importance of Cape Verdean 
history, geography, and folkways, the importance of the sea, the importance of intra-ethnic group connection, the importance of time and memory, the significance of water, and personal disappointment, shame, or guilt.

In contrast, the representations of Cape Verdeanness in the postcolonial Cape Verdean poems written from a non-diasporic point of view cover an extraordinarily wider range of aspects, from the concrete, to the abstract, to the subtle, as well as to the self-referential. Elements of continuity of colonial-era Cape Verdeanness in such poems include the land and climate of Cape Verde; the eternal prayer for rain; the profound power of the land to be experienced, despite its material deficiencies, as nurturing and accommodating; the uniqueness and the importance of the history of Cape Verde; the strengths of the Cape Verdean people, including hope, flexibility, tenaciousness, and resiliency; the Cape Verdean way of life, including its music, celebrations, and food; and the Cape Verdean way of conceptualizing life, including the way Cape Verdeans conceive of geographic space and time. Uniquely postcolonial elements of Cape Verdeanness in the non-diasporic poems include the tremendous challenges faced by Cape Verde, which includes ambivalence regarding prospective Cape Verdean outcomes; Cape Verde's unrealized fecund potential; suggesting sexual double-standards that favor virgins; cynicism about the future that can border on hopelessness; and the intense inner conflicts faced in interpersonal romantic intimacy.

Postcolonial Cape Verdeans who have remained in their homeland, while concerned with matters of identity, generally differ from postcolonial Cape Verdeans who have emigrated (or who are the offspring of émigrés) in that their concerns about 
identity are not Cape Verdean-specific whereas those of émigrés (or their offspring) are. Furthermore, while postcolonial émigrés or their offspring may possess disappointment, guilt, or shame about their absence from their homeland, Cape Verdeans living on the Islands do not possess such disappointment, guilt, or shame. Finally, memory has more import for postcolonial Cape Verdean émigrés or their offspring than it appears to possess for Cape Verdeans who have not left, or who have returned to, their homeland.

The scholarly literature on postcolonial Cape Verdean poetry appears to have missed one significant element of postcolonial Cape Verdeanness that my poetic analyses have suggested. The missing element that has been suggested by my poetic analyses is the discrepancy between the postcolonial poetry produced by diasporic Cape Verdeans as opposed to that produced by non-diasporic Cape Verdeans. This discrepancy between the poetry produced by these two groups appears profound. It suggests, like the social science research presented earlier here, that Cape Verdeanness is not unitary, that it is truly divided by emigration status.

In one of the chapters in his text Imaginary Homelands: Essays and Criticism 1981-1991, specifically in the chapter "Imaginary Homelands," Salman Rushdie speaks to this kind of discrepancy. Rushdie vividly implies there that the common experience of Cape Verdean emigrants and their progeny, of cultural alienation and the attempted resurrection of cultural identity, as depicted in the postcolonial diasporic Cape Verdean poetry of Davis and Silva, is not unique. Rushdie identifies how emigrants tend to share in a phenomenology of cultural loss along with the mutual desire to eradicate that loss (10). 
But Rushdie counsels the reader that "we will not be capable of reclaiming precisely the thing that was lost; that we will in short, create fictions, not actual cities or villages, but invisible ones, imaginary homelands" (10). What may be different for the Cape Verdean emigrant, however, is their refusal to despair despite the magnitude of the challenge of cultural self-resurrection. The Cape Verdean emigrant poet appears to trust that by engaging in their art they will re-experience what is most essential to them about their lost Cape Verdeanness, and that through repeated such experiences their Cape Verdean cultural identities may be satisfactorily re-established.

Why this is so may in part reflect the fact that artistic creation, especially in the realm of music performance, is a central aspect of life on Cape Verde. It was suggested by the renowned diva of Cape Verdean music, Cesária Évora, before she passed away, that music is Cape Verde's natural resource. This music-making may, at least in part, reflect Cape Verdeans' response to the experience of sodadi, a longing for what is absent. 


\section{Chapter Eight:}

\section{Beyond Sodadi and Morabeza in Postcolonial Cape Verdeanness}

It is now possible to compare the findings of this work's earlier social-scientific findings regarding Cape Verdeanness with its findings regarding postcolonial Cape Verdean poetry. I will first review the findings regarding postcolonial Cape Verdeanness in the social-scientific literature. Then I will review the findings regarding postcolonial Cape Verdeanness as it has been seen to be represented by both scholars in postcolonial Cape Verdean poetry and myself. Finally, I will compare and contrast the social-scientific with the humanistic findings.

According to Góis' social-scientific scholarship on postcolonial Cape Verdeanness, one of its salient aspects is its transnational nature. Another salient aspect of this Cape Verdeanness, according to Sánchez Gibau and Thomas, is that it is neither homogenous nor fixed. For Sánchez Gibau, especially in the diaspora, where the majority of Cape Verdeans reside, this Cape Verdeanness appears to be built out of continuous negotiation and contestation. For Sánchez Gibau and Thomas, Cape Verdeans can be especially distinguished by whether they or their forbearers have left the Islands, and, in the cases where they or their forbearers have left the Islands, if emigration transpired prior to or since Cape Verdean independence.

According to Sánchez Gibau, those who have resided in Cape Verde since independence maintain extraordinary pride in their native land, have a profound bond with their mother tongue, Kriolu, and possess a sense of territorial connection with 
Africa. According to Thomas, Cape Verdeanness remains strongly influenced by traditional patriarchal values, and by a syncretism that is primarily identified with Catholicism. For Fêo Rodrigues, the denial of the Cape Verdean history of oppressive gender relations may at least in part be at the heart of Cape Verdeans' long-standing eager embrace of narratives of hybridity.

According to Palmberg and Fêo Rodrigues, Cape Verdeans tend to place Cape Verde at the center of the action of the past half millennium on this planet. Additionally, for Palmberg, the sea is central to the Cape Verdean ethos, with all that it is has meant for the people of the Cape Verde Islands, and the food (especially corn) along with the music of Cape Verde, especially the mornas, the coladeras, and the new funaná, hold somewhat iconic status for Cape Verdeans. With her noting of sodadi, Palmberg shows us how part of Cape Verdean cultural identity is an incredibly enduring and endearing melancholy.

My findings regarding postcolonial Cape Verdeanness as it has been represented in postcolonial Cape Verdean poetry, both according to scholars such as Brookshaw, Moser, and Secco, as well as in my own poetic analyses, suggest, specifically, that postcolonial Cape Verdean poetry has shown both continuity and transformation, even to the point of rupture, from its previous incarnations. Postcolonial continuity from the colonial era is visible both in poetic content references particular to Cape Verde and in the selection of concerns, such as freedom and imprisonment, that have been previously addressed in the Cape Verdean poetic record. The rupture and transformation of Cape Verdean poetry may be witnessed in the extraordinary enlargement of the topical base to encompass universal human concerns, and, perhaps, even more so, in a forwardness and directness 
pertaining to matters of love and sexuality that was wholly absent prior to Cape Verdean independence. Cape Verdeanness appears to now be both as small as Cape Verde and as large as the universe.

Significantly, as well, my poetic analyses here have suggested that there are two main branches of postcolonial Cape Verdean poetry, diasporic and non-diasporic. The elements of diasporic Cape Verdeanness represented in postcolonial Cape Verdean poetry include concern with one's identity, incorporating both the experience of alienation from and connection with one's Cape Verdean identity, an appreciation of one's personal narrative of Cape Verdean influences, the importance of Cape Verdean history, geography, and folkways, the importance of the sea, the importance of intra-ethnic group connection, the importance of time and memory, the significance of water, and personal disappointment, shame, or guilt. In contrast, the representations of Cape Verdeanness in postcolonial Cape Verdean poetry from a non-diasporic point of view cover an extraordinarily wider range of aspects, from the concrete, to the abstract, to the subtle, as well as to the self-referential.

Elements of continuity of colonial-era Cape Verdeanness in the non-diasporic poems of the postcolonial period include the land and climate of Cape Verde; the eternal prayer for rain; the profound power of the land to be experienced, despite its material deficiencies, as nurturing and accommodating; the uniqueness and the importance of the history of Cape Verde; the strengths of the Cape Verdean people, including hope, flexibility, tenaciousness, and resiliency; the Cape Verdean way of life, including its music, celebrations, and food; and the Cape Verdean way of conceptualizing life, 
including the way Cape Verdeans conceive of geographic space and time. Uniquely postcolonial elements of Cape Verdeanness in the non-diasporic poems include the tremendous challenges faced by Cape Verde, which includes ambivalence regarding prospective Cape Verdean outcomes; Cape Verde's unrealized fecund potential; the suggestion of sexual double-standards that favor virgins; cynicism about the future that can border on hopelessness; and the intense inner conflicts faced in interpersonal romantic intimacy.

In the years since Cape Verdean independence, Cape Verdeans who have remained in their homeland, while also concerned with matters of identity, generally differ from Cape Verdeans who have emigrated (or who are the offspring of émigrés) in that their concerns about identity are not Cape Verdean-specific whereas those of émigrés (or their offspring) are. Furthermore, while post-independence émigrés or their offspring may possess disappointment, guilt, or shame about their absence from their homeland, post colonial Cape Verdeans living on the Islands do not possess such disappointment, guilt, or shame. Finally, memory has more import for post-independence Cape Verdean émigrés or their offspring than it appears to possess for Cape Verdeans who have not left Cape Verde, or who have returned to, their homeland.

Comparing the social-scientific findings about postcolonial Cape Verdeanness with the humanistic findings, one finds that both sets of scholarship share in the appreciation of there being significant non-homogeneity of Cape Verdeans. Specifically, both research streams identify a core difference between Cape Verdean residents of the Islands and diasporans. However, while the social-scientific literature finds pride in Cape Verde, a 
bond with Kriolu, and a connection with Africa for non-diasporic Cape Verdeans, the humanistic findings suggest pride in Cape Verde and a bond with Kriolu but do not confirm identification with Africa for the non-diasporans.

In both the social-scientific and humanistic findings Cape Verde is seen as holding a uniquely important historical position. Similarly, both the social-scientific and humanistic findings identify the sea, food, and Cape Verdean music as aspects of Cape Verdeanness. Furthermore, both the humanistic and social-scientific findings identify how diasporans struggle differently with matters of Cape Verdean identity than non-diasporans. But while the social-scientific finding is that diasporans are engaged in an ongoing identity formation process involving negotiation and contestation, the humanities finding suggests that diasporans address matters of alienation from their cultural heritage, that time and memory are more salient for them, and that diasporans possess unique guilt and shame due to their estrangement from their homeland.

The findings of the two research streams diverge even further when the social-scientific findings describe Cape Verdean narratives of hybridity which have not been located in the humanistic inquiry. An additional difference in the two research domains is that while in the social-scientific findings Palmberg and Fêo Rodrigues report a Cape Verdean tendency toward denial of the history of oppressive gender relations, such oppressive relations are suggested in the humanistic findings regarding double standards associated with virgin females. Additionally, whereas in the humanistic findings, postcolonial Cape Verdeanness is readily distinguishable from colonial-era Cape Verdeanness in a number of ways, including its ambivalence regarding the Cape 
Verdean future, inner conflicts regarding interpersonal romantic intimacy, a forwardness regarding matters of love and sexuality, and a significantly enlarged topical base which is both as small as Cape Verde and as great as the Universe, in the social-scientific findings such postcolonial rupture is not as readily visible.

It seems that what this research project has inadvertently determined is that the social sciences and the humanities, when examining the same general phenomenon, Cape Verdeanness, demonstrate the strengths and limits of their respective lenses, and that because of that one finds both complementary and confirming evidence through the use of such a multi-lens approach to this type of undertaking. It seems, then, that more lenses are better than fewer, or at least that two lenses are better than one. My prior research on Cape Verdean public health informed me about the distressingly severe situation on the Islands with regards to vision care and the extraordinary prevalence of diabetes. It seems that a public health lens on postcolonial Cape Verdeanness might also offer a unique and complementary perspective to that of the humanities and social- sciences.

In the end, postcolonial Cape Verdeanness may be seen to be like a quilt which includes the continuity of some aspects of Cape Verdeanness from its colonial era, several unique aspects of postcolonial Cape Verdeanness, distinctions of diasporic and non-diasporic status, postcolonial rupture and flux, and the identification of the various lenses through which postcolonial Cape Verdeanness has already been considered by various scholars besides me. Postcolonial Cape Verdeanness may be seen to encompass sodadi (especially for those born in the diaspora), morabeza (especially for those born in the Cape Verdean Islands), and everything else that is human. Some other lenses that 
might usefully inform further research on postcolonial Cape Verdeanness include examination of other cultural productions besides poetry, a study of prominent pedagogical styles in Cape Verde, an inquiry into the Cape Verdean criminal justice system, a study of the history of the establishment of Cape Verde's national parks, and a review of the changing nature of Cape Verde's manner of international diplomacy. That is to say, then, that any significant inquiry into Cape Verdean life might lead to a more fully developed understanding of postcolonial Cape Verdeanness. As holistic thinking informs us, the microcosm, in its essence, contains the macrocosm. 


\section{Bibliography and Works Cited}

Achebe, Chinua. Things Fall Apart. London: William Heinemann ltd, 1958. Print.

Anderson, Benedict. Imagined Communities. Extended ed. NY: Verso, 1995. (orig. pub. NY: New Left Books, 1991). Print.

Araújo, Norman. "New Directions in Cape Verdean Literature? The First Numbers of Raizes." In Critical Perspectives on Lusophone African Literature. Donald Burness, ed. Washington, D.C.: Three Continents Press, 1981. Print.

Batalha, Luís, and Carling, Jørgen, eds. Transnational Archipelago: Perspectives on Cape Verdean Migration and Diaspora. Amsterdam: Amsterdam UP, 2008. Print.

Brookshaw, David. "Cape Verde" (179-233). The Post-Colonial Literature of Lusophone Africa. Patrick Chabal, ed. Evanston: Northwestern UP, 1996. Print.

Burness, Donald, ed. Critical Perspectives on Lusophone Literature from Africa. Washington, DC: Three Continents P, 1981. Print.

---. "The Poetry of Adelina Da Silva: The Voice of a Capeverdean Expatriate" (229-44). Seasons of Harvest: Essays on the Literature of Lusophone Africa. Niyi Afolabi and Donald Burness, eds. Trenton: Africa World Press, Inc., 2003. Print.

Cabral, Amilcar. Unity and Struggle. trans. Michael Wolfers. NY: Monthly Review P, 1979. Print. (Speeches Selected by the PAIGC).

Campbell-Badger, Lindsey. "A Selective and Annotated Bibliography of English and French Language Sources on Cape Verdean Literature." Electronic Journal of African Bibliography, 12 (2009). Web. 31 Dec. 2009. 
Cape Verde Government. Cape Verdean Constitution (Second). Praia: Cape Verdean Government, 1999. Print.

Carter, Katherine E., and Aulette, Judy. "Creole in Cape Verde: Language, Identity and Power." Ethnography, 10 (2009): 213-36. Print.

Césaire, Aimé. Discourse on Colonialism. trans. Joan Pinkham. NY: Monthly Review P, 1972. Print.

---. Notebook of a Return to My Native Land. trans. Mireille Rosello with Annie Pritchard, introd. Mireille Rosello. Northumberland, UK: Bloodaxe Books, 1995, fr. Cahier d'un Retour au Pays Natal, 1956. Print.

Davis, Jarita Adia. As Minhas Mornas. Diss. U Louisiana-Lafayette, 2003. Ann Arbor: UMI, 2003. Print.

---. Telephone Interview. Fall, 2010.

deMedeiros, Paulo. “(Re-) Constructing, (Re-) Membering Postcolonial Selves” (37-49) Stories and Portraits of the Self. Helena Carvalhao Buescu and Joao Ferreira Duarte, eds. Amsterdam: Rodopi, 2007. Print. International Forschungen Zur Allgemeinen Und Vergleichenden Literaturwissenschaft 115.

Ellen, Maria M. Across the Atlantic: An Anthology of Cape Verdean Literature.

North Dartmouth, MA: Center for the Portuguese Speaking World, Southeastern MA U (U MA-Dartmouth), 1988. Print.

Fanon, Frantz. Black Skin, White Masks. Trans. Charles Lam Markmann. NY: Grove P, 1967. Print.

Fêo Rodrigues, Isabel P. "From Silence to Silence: the Hidden Story of a Beef Stew in 
Cape Verde.” Anthropological Quarterly, 81.2 (Spring, 2009): 343-76. Web. Project Muse. 1 May 2010.

---. "Our Ancestors Came from Many Bloods: Gendered Narrations of a Hybrid Nation." Revue Lusotopie, XII.1-2 (2005): 217-32. Print.

Fikes, Kesha. Managing African Portugal: The Citizen-Migrant Distinction. Durham: Duke UP, 2009. Print.

Glissant, Edouard. Caribbean Discourse: Selected Essays. trans. J. Michael Dash. Charlottesville: Virginia UP, 1989. Print. CARAF Books Series.

Góis, Pedro. "Cape Verdeanness as a Complex Social Construct: Analysis of Ethnicity through Complexity Theory" (257-78). Identity Processes and Dynamics in Multi-Ethnic Europe. Charles Westin, José Bastos, Janine Dahinden \& Pedro Góis, eds. Amsterdam: Amsterdam UP, 2010. Print. IMISCOE Research.

Gomes, Simone Caputo. "Echoes of Cape Verdean Identity: Literature and Music in the Archipelago" trans. Luis R. Mitras. rev. Mark Streeter. Cape Verde: Language, Literature \& Music. Spec. issue of Portuguese Literary and Cultural Studies, 8 (2003): 265-285. Print.

Hall, Stuart. "Cultural Identity and Diaspora" (222-237). Identity: Community, Culture, Difference. Jonathan Rutherford, ed. London: Lawrence and Wishart, 1990. Print. Previously pub. Framework 36.

Halter, Marilyn. Between Race and Ethnicity: Cape Verdean American Immigrants, 1860-1965. Chicago: U IL P, 1993. Print.

Hamilton, Russell. “'Chronicling' from the Center of the Periphery: Estorias Contadas 
(Tales Told) by Germano Almeida" Cape Verde: Language, Literature \& Music.

Spec. issue of Portuguese Literary and Cultural Studies, 8 (2003): 315-326. Print.

---. "Contemporary Cape Verdean Literature." Cabo Verde. Spec. issue of Transitions, 103 (2010): 26-35. Print.

---.Voices From an Empire: A History of Afro-Portuguese Literature. Minneapolis: $\mathrm{U}$ of MN P, 1975. Print. vol. 8, Minnesota Monographs in the Humanities.

Klima, Jan. "Origins of the Capeverdean National Identity.” KIA Papers Yearbook. Ian Haisman and Paulina Springerova, eds. Hradec Kralove, Czech Republic: The fac. of Arts, Centre of Ibero-American Studies, U Hradec Kralove, 2007. Print.

Lang, George. "Literary Crioulo since Independence in São Tomé, Guinea-Bissau and Cape Verde.” Luso-Brazilian Review, 33 (1996): 53-63. Print.

Lobban Jr., Richard A. Cape Verde: Crioulo Colony to Independent Nation. Boulder: Westview P, 1995. Print. Nations of the Modern World: Africa. Martin, Carla. "Cesária Évora: 'The Barefoot Diva' and Other Stories.” Cabo Verde. Spec. issue of Transitions, 103 (2010): 82-97. Print.

McNab, Gregory. "Reclaiming the Heritage: The Narratives of Manuel Veiga." Cape Verde: Language, Literature \& Music. Spec. issue of Portuguese Literary and Cultural Studies, 8 (2003): 111-23. Print.

Meintel, Deirdre. Race, Culture, and Portuguese Colonialism in Cabo Verde. Syracuse: Syracuse UP, 1984. Print.

Moser, Gerald M. "Changing Africa: The First Literary Generation of Independent Cape Verde" (1-102). Transactions of the American Philosophical Association Society, 
ns. 82.4 (1992) Web. JSTOR: 29 Sept. 2009.

Ngũgĩ, wa Thiong'o. Decolonising the Mind: The Politics of Language in African Literature. Portsmouth: Heinemann, 1989. Print.

Nunes, Maria Lisa. Becoming True to Ourselves. Westport: Greenwood P, 1987. Print. Contributions to the Study of World lit. 22.

Palmberg, Mai. “Expressing Cape Verde: Morna, Funana and National Identity.” (117-133). Playing with Identities in Contemporary Music in Africa. Mai Palmberg and Annemette Kirkegaard, eds. Uppsala, Sweden: Nordiska Afrikainstitutet, 2002. Print.

Rushdie, Salman. Imaginary Homelands: Essays and Criticism 1981-1991. London: Granta (in assn. with Penguin), 1991. Print.

Sánchez Gibau, Gina. "Contested Identities: Narratives of Race and Ethnicity in the Cape Verdean Diaspora." Identities: Global Studies in Culture and Power, 12.3 (2005): 405-38. Print.

---. "Diasporic Identity Formation among Capeverdeans in Boston." The Western Journal of Black Studies, 29.2 (2005): 532-9. Print.

---. “The Politics of Cape Verdean American Identity.” Transforming Anthropology, 6.1 (1997): 54-71. Print.

Sardinha, João. "Identity, Integration and Associations: Cape Verdeans in the Metropolitan Area of Lisbon." (233-55). Identity Processes and Dynamics in Multi-Ethnic Europe. Charles Westin, José Bastos, Janine Dahinden \& Pedro Góis, eds. Amsterdam: Amsterdam UP, 2010. Print. IMISCOE Research. 
Secco, Carmen Lucia Tindó. "Postcolonial Poetry in Cape Verde, Angola, and Mozambique: Some Contemporary Considerations.” trans. Russell G. Hamilton. Research in African Literatures, 38.1 (Spring, 2007): 119-33. Print.

Semedo, José Maria. "The Construction of Natural-Geographic Space in Cape Verdean Literature.” trans. Luis R. Mitras. rev. Mark Streeter. Cape Verde: Language, Literature \& Music. Spec. issue of Portuguese Literary and Cultural Studies, 8 (2003): 25-40. Print.

Sieber, Timothy. "Popular Music and Cultural Identity in the Cape Verdean Post-colonial Diaspora." Etnografica, IX.1, (2005): 123-48. Print.

Somé, Malidoma Patrice. The Healing Wisdom of Africa: Finding Life Purpose through Nature, Ritual, and Community. NY: Jeremy P. Tarcher/Putnam, 1998. Print.

Thomas, Dawna M. . "Culture and Disability: A Cape Verdean Perspective.” Journal of Cultural Diversity, 16.4 (Winter, 2009): 178-86. Print. 


\title{
Appendix A: Beyond Sodadi and Morabeza
}

A Poem by David J. Alpert

\section{Beyond Sodadi and Morabeza}

\author{
I am in Boston, \\ but I might as well be in Praia \\ while today's raindrops land on parched ground, \\ and caress my window screen. \\ The steadfast sun warms the visiting water. \\ It breezes in, giving steady, soft kisses \\ until the rainwater hides \\ in the mist in my room. \\ Every day I breathe deeply \\ Cabo Verde drizzles into my chest \\ and the vapors enter my blood. \\ I walk with muscles built \\ strong from Islands that reside \\ everywhere Cape Verdeans dwell. \\ Today, mornas by Cesária Évora perfume my room \\ with an infusion of the same sodadi she wore on her feet. \\ I no longer have to go to parties and parades \\ to meet the needs I have for the Islands' flavors. \\ I carry around a song of Cape Verde, \\ and it embraces me on my way. \\ The words I sing are both coarse and sweet, \\ they come from land and from sea. \\ All that's been happening forever on Cape Verde \\ paints a backdrop through which I perceive.
}




\section{Appendix B: Eleven Postcolonial Cape Verdean Poems}

\section{$\underline{\text { Indecision }}$}

By Alberto Ferreira Gomes (aka: Binga)

(Originally published in Aulil. Ilha do Sal, Municipio do Sal, 1987, p. 93-94. Written on Sal Island in Cape Verde in September, 1980.)

I don't know, I don't know

(For the Meteorologists, my colleagues)

If writing this poem is the right thing

While the rain is singing

Its songs on the rooftop and is stroking the ground

I don't know

If the hour is propitious

For plucking a poem

In the candle's dim light

While the current has failed

I don't know

Should I listen to the patter

Or write and follow its rhythm...

I awakened and thought I would write

On this rainy night in September...

\section{I don't know}

If by writing my unrhymed lines

I'll disrupt the dripping water...

The storm stopped the show in the movies

Its fury has cut the current

(That's what I saw through the window)

I don't know... what am I to do...

Screams and booms I hear

Thunder and shouts of youngsters

Youngsters cleansing themselves in the troublesome rain...

I don't know if by writing these verses

I shall break the fetters of raindrops

I don't know, I don't know 
If writing this poem is the right thing

While outside the water makes love to the earth

And the rain keeps composing its own lyric song

And here in the room while standing before me

The merciless candle

Is lapping my room's heavy air

I don't know if it's proper

For my pen on the bedstand

To be kissing the parchment

At such a solemn moment like this

When water from heaven so warmly

Is running off into earth's womb

And a body of beeswax

Is melting ever so slowly

Crowned by its merciless flame...

No, I don't know

I'll stop now, but wait...I don't know... 


\section{Eastwind From End to End}

\section{By Corsino Fortes}

(Originally published in Arvore \& tambor. Lisbon, Publicacoes Dom Quixote, 1986, p. 121-123.)

Part III of the poem has been omitted from Changing Africa by Gerald M. Moser.

I

From the muscles tensed from sea to sea

To the broad rock of the soul

We are

Ten faces of raw earth

And a homeland of few cereals

And there is no desert

no island nor well

unable to conquer

The eastwind from end to end

Through the goat's glassy eye

Which we returned yesterday

and return today

To the green bone heap of history

The flesh and the cross

$$
\begin{aligned}
& \text { of the "scourge" } \\
& \text { scourged as we were } \\
& \text { Here! Where }
\end{aligned}
$$

Drought is a weapon And Hunger! Defiance

The island is life And dryness is living

Love! May rain bring

The white flag

Of truce in our war between heaven \& earth

And

Even if heaven does not send us rain

And the Sun and the Moon

be

broken strings on the island guitar

Even thought the rain be the usury's bride

This navel

This corolla of absence

Between rock and face

Even

though the wind

be bending 
The axis of earth And the masts of the soul

The bones \& centuries of blood and dryness

Even then! No longer are we

The eastwind's scourged victims

II

Let them tell it

Those hills of plowing Which from afar stumble

upon limbs

of truant seedlings

Let them tell it

Those arms of the folk in the parish

And the drums of grains

Until they bleed

of pebbles \& pollen

In the wrists of women cursing

Such starvation! May hunger not die

And never die

On it scarecrow cross of the landlords

Amidst the bond of bread

And the ribcage of bakeshops

So then!

The knees And the elbows of the island

chiseled

In the human skull forever

The carnivorous flower of faraway visions

And the harbors drank

The worm

through the prows

Of the phantom ships

Of that tragic anchorless drama

And continuing to be! We are

"A folk that stands upright on the rock of the drama"

Here! Where

The plot is writing on the forethought

Shaping the rock And all else

Of this cape

Of this stage

Green with life 


\section{Permanence}

By José Luís Hopffer C. Almada (Zé di Sant'y Agu)

(Originally published in Voz di Letra (Praia), no. 4 (July, 1986), p.4.)

Stone remains inert

For Mito, in friendship

Night remains indefinite

Folly remains ephemeral

Dreaming remains eternal

Isabelle's face remains tender

projected into a future still

tunnel and lamp

Day in day out the water remains tepid

The tropic of Cancer staring at Santiago

remains hemispherical

In the Váreza stadium insults remain spherical

Sex served on the urban platter remains uninhibitedly seminal

Dawn beyond the urban maze remains chimerical

Tchibita's thumb remains cadaverous and withered

on the desert of his pate

The cadgers remain elegantly rickety

And seated compose the requiem of each day

Illusion remains verdant (like the verdant moon of serenades)

in this country

of stones on nights of folly

of stones that dream

facing the water

that carries cancer from the tropic

of insults to canceled saints

and to love in the thumb

of always erect illusion

as it greens

in the dawn of the cadgers... 


\section{The Time Had Come}

By Tomé Varela Da Silva

(Originally published in Kumunon d'Afrika. Onti osi manan. Praia, Instituto

Caboverdiano do Livro, 1986, p. 61-63.)

They made us wake up

They made us rise!

Cape Verde, you had slept aplenty:

Until our fifteenth century

you slept in the sea.

They discovered you

You did not wake up!

Beatings ferule slaps:

You did not wake up!

They violated your body

your soul as well:

you did not stop sleeping!

You were a virgin:

they made you bear their children:

you did not wake up!

You adopted your children

you gave them your affection!

all the time in prison.

All the time in sorrow

you sustained your children

without ever awakening!

You nursed them yourself

You brought them up by yourself

but you did not wake up!

You gave them your cornmeal

corn soup with meat

beans with salt pork.

Popcorn sweet potatoes

noodles with chicken

corncake with milk.

Porridge with butter

corncake with honey:

you did not wake up! 
Your children ate

drank slept.

Your children woke up.

They dressed they washed.

Your children played

worked got tired.

You did not wake up!

Guavas oranges bananas

mangoes jambos papayas.

Cassava with meat potatoes

with fish cassava with milk.

Sugarcane to chew cane juice

to drink rum to get warm.

Your children had fun they sang:

Your eyes did not open!

No shower opened

your dried-out body:

your children cried!

The oxen bellowed

the goats begged

the horses died!

Your children fell ill

died fled.

Nobody recognized you

all loved you dearly:

you had to wake up!

Lots of fish in the sea

fowls in the bush

monkeys on the rocks.

Salt to take from the sea

black soil going to waste

beaches to exploit.

Wine pozzolana

lime coffee cement:

Everything is waiting!

Your children and hope:

they have already waited aplenty: 
you have to wake up!

(..) 


\section{$\underline{\text { Distant Poem for a Creole Girl }}$}

By Tacalhe

(Originally published in Voz Di Povo, 1977)

Hot

Hot like the cold warmth of this absence

You throb Creole girl

In the red heart of Rotterdam at night

You throb Creole girl

In the veins of my long

Silence

Long as the sea that separates us

I will be profound

Like the sun

Like the sun

Profound with you, simple

Gathering the roses the pioneers breath

You make me remember

Always remember

You our my country

Country as a yellow green cab

Sure promise of a grand harvest

Like you, Creole girl

I always come with my arms full

Of the stars' brightness

That the sky of the new dawn

Also covers me far away

Far away to fill

My country of naked children running about

Even greater

Running about on the bank of the sea

Running about in far-off lands

Running about in foreign factories

My belly-button, my maize 
My bay, my tomb

My heart held strongly on the rocks

Oh, basalt roads,

Of serious curves and tree-less footpaths!

Oh, seedless fields

Without water

Without machines!

Few things, so few

Which made me feel foreign

In cities so great

So full of marvels...!

Only the hot body of my comrade Creole girl

Warms, in my steps,

the right direction to the goal

Only my islands without place on the map

Only my people without an echo in the world

Only my brothers-heroes a thousand times

Made succulent their steady steps

But one day I will return

To be with the calm breeze

In my sailboat of smiles

Hot

Hot like the cold warmth of this absence

You-Creole girl: my gusto and country

Will sing in my arms

The poem of our love 


\section{Who Said We Had Departed?}

By João Rodrigues

(Originally published in Perolas do Sertão: Pearls of the Desert, p. 17-18, Mindelo, 1986: Gráficado Mindelo)

Who said we had departed?

do not believe them

o small pearls

of our beloved desert

do not believe them

o tanned nymphs

of the rocky hills of our islands

nor you

tender nereids of our sea of tears.

Who said we had departed-

if in the dark hills

images of black faces still remain

if in the dry creeks

we left rivers of bitter sorrow

if in each street corner

a poem protests?

Who said we had departed

if in each of our beloved islands

the winds whistle our song-

the song of the departed

who did not wish to depart?

Who said we had departed-

if the sea that brought us here

will soon take us away

if each sunset is a prelude

to the dawn of our return?

Who said we had departed-

if soon we shall return

to join our hands

to your hands 
our voices

in a round dance

like children,

to sing the song of rain

our song of plenty:

\author{
corn in the pestle \\ cuscus on the night of São Silvestre \\ drums rolling in São João \\ colá na mim, colá na bô, ${ }^{*}$ \\ guitars crying for joy \\ a hymn of peace in each morna \\ and a golden dawn in the eyes of \\ each Creole woman?
}

\title{
WHO SAID WE HAD DEPARTED?
}

*An allusion to cola San Jon, a dance performed at the feast of São João. The line literally means "You come toward me, I go toward you." Translator's note. 


\section{Song for Cape Verde}

By David Hopffer Almada

(Originally published in Canto a Cabo Verde, Praia: INL, 1988, pp. 63-67. Poem translated by Francisco Cota Fagundes.)

I want

a different song

for Cape Verde.

I want

a different song

for these islands,

for this country,

for these people.

We are no longer

"Victims of the East Wind,"1

which we overpowered.

We are no longer contracted laborers

like beasts of burden heading South,

for we have conquered dignity.

And so

we need to sing

a different song

to Cape Verde.

And so

I sing,

differently,

a different song

to Cape Verde.

I'll forget and bury

the laments and sadness,

and the pain

of those who wish to remain

thwarting the fate of having to leave. 
I won't bemoan

poverty and weakness,

droughts,

and cruel nature.

I sing

the heroism of my people,

who challenge destiny,

disobey the gods,

tame nature,

conquer the seas,

calm the winds,

stubbornly cover with green

the parched and arid land,

extract fresh water

from the ocean's

salty waves,

make rocks fertile

and thorns bloom,

who create gardens

on volcanic ashes,

and plant orchards

on rocky soil,

and turn desert winds

into the sweetly delicious breezes

of beautiful tropical nights.

I sing

this triumphant Cape Verde

liberating itself

from yesteryear,

raising, on one hand,

the banner of peace and harmony

and, on the other,

the torch of brotherhood and liberty.

I sing

these African sandy pebbles

resting in the ocean between continents,

from the middle of the sea,

from the middle of the world,

signaling the course,

pointing the way, 
offering to all

the eternal gift

of warm morabeza

and the shelter

of our embrace.

I sing

these men and women

who plough the seas

to distant places,

or fly the skies

to unknown destinies -

wanderers who carry

progress and well-being to foreign lands.

I sing

This independent, sovereign and free

country:

this Cape Verde,

master of its fate,

architect of its path,

builder of its steps.

I sing

the country of blue seas,

open skies and lofty mountains.

I sing

the Fort of Santiago,

the carnival of Mindelo,

the First of May in São Filipe.

I sing

the joy of these people:

the funaná,

the drum dances,

the mornas,

the coladeira. 
I sing

for these people

a joyous song

of sabura,

of confidence, of certainty, of tomorrow-

breaking the bad fortune, the bad fate,

breaking the sadness

and the despair

of having to tread

roads leading to São Tomé,

breaking all the chains

of contracted,

exploited laborers.

Yes,

I want a new song

for Cape Verde,

a new song

for this country

that stone by stone

rebuilds itself,

that little by little, vigorously,

out of no past

builds its future.

1: This line is a translation of the title of a novel, Os Flagelados do Vento Leste (1960, by Manuel Lopes. Translator's note. 


\section{$\underline{\text { Atlantic Coasts }}$}

By Jarita Adia Davis (from As Minhas Mornas)

These boys could be in Praia, I think. Dried sea salt coarse across their shoulders. They dig their feet into the sand, chase

glimmers of polished glass and trail tracks along the shore leaving smudges like their grandfathers left on Cabo Verde at this age.

Across the ocean and decades before, two boys called each other in Crioulo. I picture the brown mountains watching from behind, and the sea washing up smooth rocks and jelly fish for them. But they're not in Praia, they're here, we're all here, in New Bedford where

they dig at the beach with sticks and face the Atlantic from the other side. "What are you taking pictures of?" The boys ask me.

"The beach," I say, and they scatter sand behind them to collect their stash. "Take a picture of this," the younger one suggests, holding

a twisted clump of seaweed and goo. The older boy is serious. He carries stones with important colors for me to photograph.

Our tie to each other and to the past is the water. They do not discover 
and uncover bits from shore,

their home, to remember lost family in Cabo Verde. This

is where they are. This is where we are. "Take a picture of this,"

the younger one offers, grinning at the snail peering from its shell. 


\title{
One Criolinha Speaks
}

(Title: One Dear Cape Verdean Female Speaks, my translation) By Jarita Adia Davis (from As Minhas Mornas)

\author{
I am not \\ the voice \\ of Cabo Verde \\ I am a voice \\ calling \\ for Cabo Verde \\ a lonely voice \\ naked \\ on the edge \\ of a stranger's bed \\ slipping \\ each poem \\ in turn \\ onto a thin \\ gold chain \\ like painted beads \\ from the necklace \\ broken \\ at my feet
}




\section{You Cannot Prepare For This Trip}

By Jarita Adia Davis (from As Minhas Mornas)

you can apply for a visa

memorize a few phrases

try not to hesitate over accents

buy insurance, film

and make this list to take with you:

go because your grandfather asked you

even though when he did, he was too old

to understand and called you

by your mother's name.

go to learn the value of water. to appreciate

the bowlful brought up a steep mountainside

upon the heads of women and girls

whose husbands and fathers and brothers left

them for work across the Atlantic.

go so the next time someone asks, Are you

Cape Verdean? you can say, Yes. instead of my grandfather was.

go with this picture of your grandfather in your pocket.

the name of his father and village written on the back. go because someone you have not yet met is waiting for you there.

go for a sense of direction. to feel the weight

of south and east and to walk in reference

to where the sun and ocean lie. 


\section{Return to the Homeland}

By Adelina C. Da Silva

(Originally published in Arquipélago, no. 9. Boston, May 1988, p. 36.)

I feel like a stranger

amidst these bare rocks

only yesterday walls

of a wretched cabin

that had been my home.

Step after step

along your beaches

a child's dim shape

continues walking

which at your breast

saw the light of day.

I'm hearing laughter,

a whisper

come, touch me,

feel me

we're one.

What I'm hearing is not

the voice of yore

the bond that bound me

is slipping I feel it

the sea's tender touches

the breeze bringing coolness

the warm shade of home!

How strange to feel like a prodigal son! 


\section{$\underline{\text { Acknowledgments }}$}

I would first like to thank the professors at Rhode Island College who have directly encouraged the development of my work on Cape Verdean Society and Culture. These professors include Dr. Peter Mendy, Dr. Maureen Reddy, Dr. Mark Anderson, Dr. Anita Duneer, and Dr. Daniel Scott. Another Rhode Island College professor whom I would also like to thank is Dr. Cathleen Calbert. It is primarily through Dr. Calbert's creative writing and contemporary poetry courses that I have developed my deepening capacity to carefully and critically read poetry.

I wish to thank the professors at Rhode Island College who have chosen to accept the invitation to join with my Master's Thesis Advisor, Dr. Daniel Scott, in serving on my Master's Thesis Committee: Dr. Mark Anderson, Dr. P. Khalil Saucier, and Dr. Richard Lobban (Emeritus). I also wish to also acknowledge the invaluable assistance which I received in undertaking research for this Master's Thesis from Professor Marlene Lopes, the Rhode Island College Special Collections Librarian. Professor Lopes' assistance was especially valuable because of both her forthrightness and her extensive knowledge of Cape Verdean scholarship.

Finally, I would like to thank my Master's Program/Master's Thesis Advisor, Dr. Daniel Scott. Dr. Scott's assistance throughout my Rhode Island College Master of Arts in Interdisciplinary Studies program has been extraordinarily valuable. But it has been during my year-long project on this Master's Thesis under Dr. Scott's guidance that I have come to truly appreciate Dr. Scott for his gentle and incredibly meticulous encouragement of my writing on Cape Verdean identity. Thank you so much, Dr. Scott. 


\section{David Joseph Alpert: A Brief Biography}

Since 1992, David Alpert has been a Licensed Mental Health Counselor in The Commonwealth of Massachusetts. Since 2004, David has been a Licensed Alcohol and Drug Counselor through The Department of Public Health of The Commonwealth of Massachusetts. David has been certified as an Elementary (1-6) Teacher by the Massachusetts Department of Elementary \& Secondary Education since 1984. Since 1993, David has been qualified through the Professional Child Care Qualifications Registry of The Department of Early Education and Care of The Commonwealth of Massachusetts as a Preschool Lead Teacher.

Born in New York, NY, David attended one year of private Nursery School followed by enrollment in the Yonkers Public Schools for thirteen years, Grades K-12, undertaking a rigorous academic program of study in High School, including four Advanced Placement courses. In his senior year of High School, David was awarded a four-year New York State Regents College Scholarship. While still in high school, and immediately after completing high school, David completed two summer sessions at Columbia University, in the City of New York.

David then completed two degrees at S.U.N.Y. Binghamton (Binghamton University, NY): a Bachelor of Arts (B.A.) from the University's Harpur College (with a Major in Philosophy) in 1982, and a Master of Science in Education (M.S. Ed.) from The University's Graduate School of Education in 1984. As a graduate student, at S.U.N.Y. Binghamton, David received a Graduate Assistantship to work with Professor Robert 
Carpenter. The assistantship work primarily involved research and writing in Professor Carpenter's primary subject of focus, juvenile delinquency. David followed his studies at S.U.N.Y. Binghamton by completing a counselor training program at The Carl Rogers Institute for Psychotherapy, Research, and Supervision, in La Jolla, California, in 1985. David Alpert has been a practicing psychotherapist since 1986. In 1995, David's article on his theory of psychotherapy, "We-Rhythm Therapy," was published in The Person-Centered Journal, a peer-reviewed journal in the field of mental health. David has presented his theory of therapy at a number of professional conferences, including, in 1994, at the Annual Conference of The Association for Humanistic Psychology, in Boston, MA. David has also developed an original theory of personality, which he has named "The Elemental Method." David has presented his theory of personality at numerous professional conferences of The Association for the Development of the Person-Centered Approach as well as at an annual conference of The International Primal Association.

Between 2007 and 2009, David Alpert completed two years of part-time undergraduate study in Cape Verdean studies by combining coursework at three Massachusetts public colleges and universities. In 2009, David Alpert's deepening interest in Cape Verdean Society and Culture led him to apply to, gain admission to, and commence an Interdisciplinary Master of Arts Program at Rhode Island College, in Providence, RI. In that program, David identified his interest in postcolonial Cape Verdeanness as his special interest within the field of Cape Verdean Studies. Given David's personal and academic interest in poetry, he decided to make Cape Verdeanness 
as expressed in postcolonial Cape Verdean poetry the focus of his Master's Thesis work in the Rhode Island College I.M.A. program. 